\title{
COLLECTION LATOMUS
}

VOLUME LXXXVI

Marie DELCOURT

\section{Hermaphroditea}

Recherches sur l'être double promoteur de la fertilité dans le monde classique
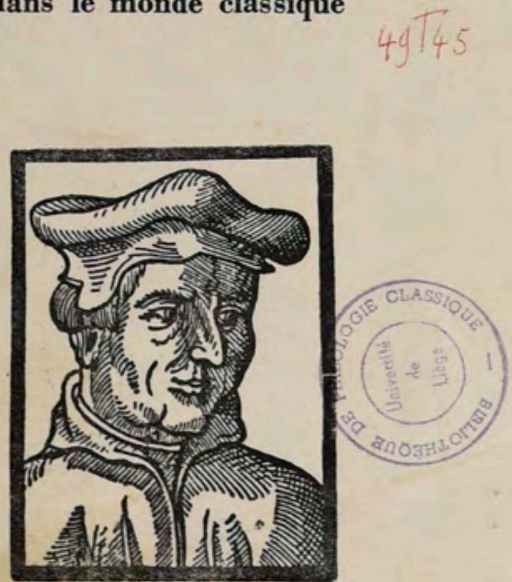

LATOMUS

REVUE D'ÉTUDES LATINES

60, Rue Colonel Chaltin

BRUXELLES 18

1966 


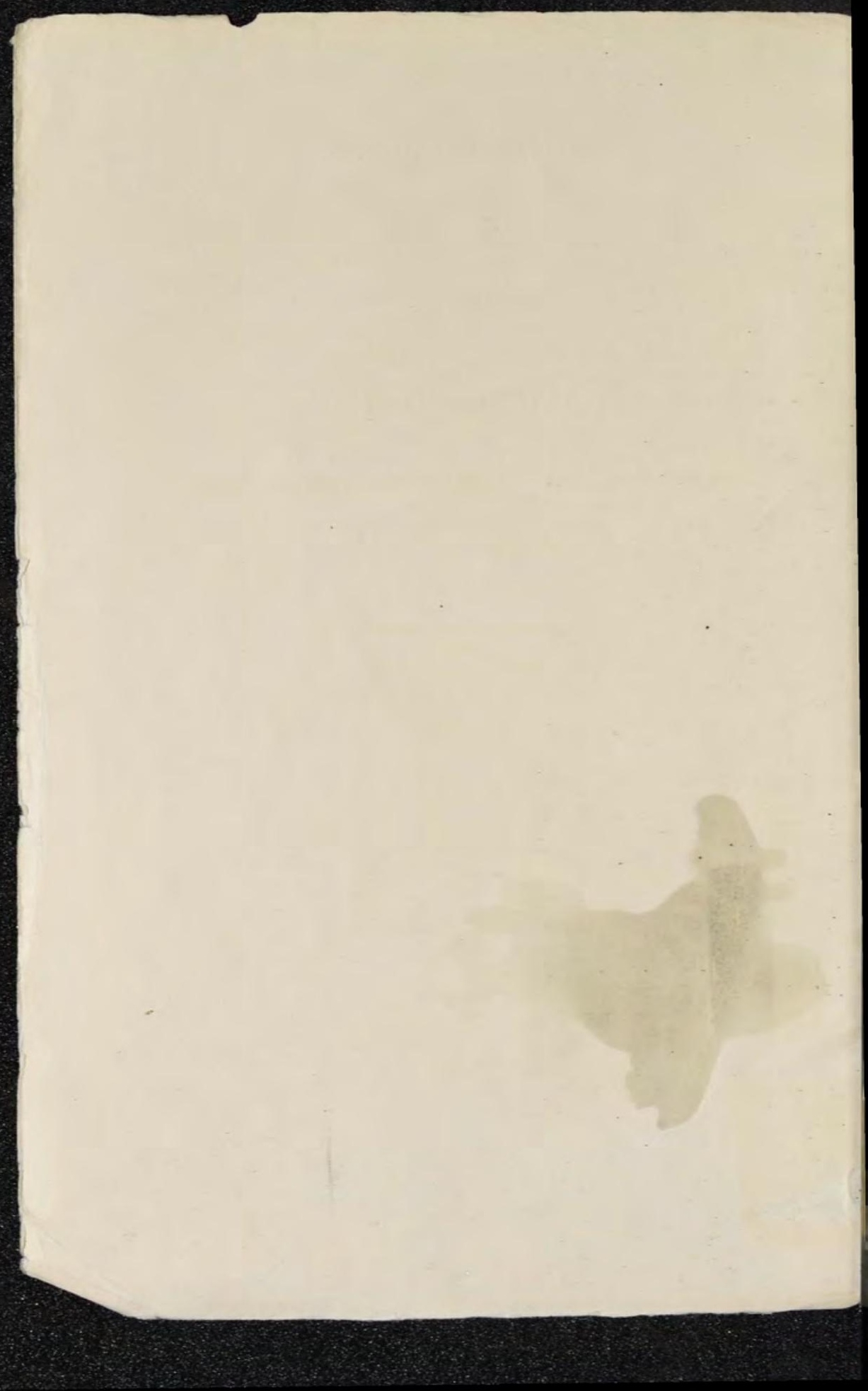


COLLECTION LATOMUS

volume LXXXVI

H E R M A P H R O D I T E A

RECHERCHES SUR L'ETRE DOUBLE PROMOTEUR DE LA FERTILITÉ DANS LE MONDE CLASSIQUE

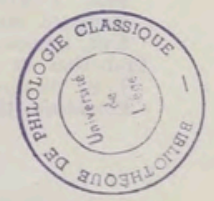




\section{A T OMUS REVUE D'ÉTUDES LATINES 60 , rue Colonel Chaltin, Bruxelles 18}

Fondée en 1937, la revue Latomus, que dirigent MM. Léon Herrmann et Marcel Renard, publie des articles, des variétés et discussions, des notes de lecture, des comptes rendus, des notices bibliographiques, des informations pédagogiques ayant trait à tous les domaines de la latinité : textes, littérature, histoire, institutions, archéologie, épigraphie, paléographie, humanisme, etc.

Les quelque 1000 pages qu'elle comporte annuellement contiennent une riche documentation, souvent inédite et abondamment illustrée.

\section{Montant de l'abonnement au tome XXVI (1967): \\ Abonnement ordinaire : \\ Abonnement de soutien : \\ Abonnement à vie : \\ Port et expédition : Belgique : $20 \mathrm{FB}-$ Etranger : $30 \mathrm{FB}$}

Prix des tomes publiés avant l'année en cours: 800 FB.

Les quatre fascicules d'un tome ne sont pas vendus séparément.

Compte de chèques postaux 7526.46 de la Société d'études latines de Bruxelles.

Pour l'achat des tomes I à XII, s'adresser à :

Johnson Reprint Corporation, 111, Fifth Avenue,

New York 3, New York.

Correspondants :

Argentine: M. le Prof. Fr. Nóvos, Caracas, 363, Buenos-Aires.

BrÉsIL : M. le Prof. Vandick Loxdres DA Nóbrega, Rua Araucaria, 32. Jardim Botanico, Rio-de-Janeiro.

Danemare: M. le Dr P. J. Jensen, Prof. à IUniv. de Copenhague, Rungsted Strandvej, 67, Rungsted Kyst, Danemark.

Etats-Unis et Canida: M. le Prof. J. R. Workmus, Brown University, Providence 12, Rhode Island.
Fraxce: M. J. Heurgon, Prof. à la Sorbonne, Le Verger, La-Celle-StCloud (S.et-O.), Compte ch. postal: Paris 7447.60 .

ITALIE: M ${ }^{11}$ M. L. PuLAdent, Via Bellotti, 13, Milano.

Pars-Bis: M. le Dr. K. H. E. Schut. TER, van Lenneplaan, 30, Driehuis. Compte ch. post. $n^{\circ} 424028$.

Suk̇de: M. le Prof. G. SAeflund, Luthagsesplanaden, $34 \mathrm{~A}$, Upsala.

Sutsse: M. A. Cartis, Grand-Rue, 14, Cormondrèche (Neuchatel), Suisse. 


\section{COLLECTION LATOMUS}

VOLUME LXXXVI

\section{Marie DELCOURT}

\section{Hermaphroditea}

Recherches sur l'être double promoteur de la fertilité dans le monde classique

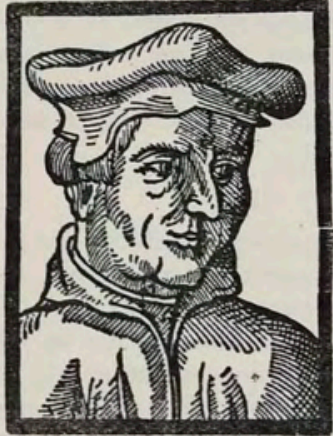

LATOMUS

REVUE D'ÉTUDES LATINES

60, Rue Colonel Chaltin

BRUXELLES 18

1966 


\section{$\mathrm{D} / 1966 / 0415 / 4$}

Droits de traduction, de reproduction et d'adaptation réservés pour tous pays. 
Cette étude doit s'ouvrir par un remerciement. Elle n'aurait pu être ni entreprise ni terminée sans l'aide et la constante collaboration d'un ami américain, M. Octavio J. Alvarez. Ce savant doit à sa formation de peintre une connaissance approfondie de l'anatomie humaine, indispensable pour distinguer, dans l'androgynie diffuse à laquelle se complaît l'art antique à partir du $\mathrm{III}^{\mathrm{e}}$ siècle, les traits révélateurs d'une intention délibérée en vue de représenter la réunion des deux puissances.' Il a bien voulu, parcourant les musées d'Europe, de Boston, de New-York, mettre son exceptionnelle perspicacité au service d'une question qui l'intéressa dès l'abord. Toute l'illustration du présent volume, presque entièrement inédite, est due à ses recherches. Beaucoup d'interprétations résultent de ses descriptions précises, de ses esquisses rapides et exactes, de ses ingénieuses suggestions. Je ne saurais dire ici toute la reconnaissance que je dois à sa science et à sa pénétration.

L'éditeur et l'auteur remercient la direction des Musei Capitolini, du Museum of Fine Arts de Boston et de celui de New-York, du Kunsthistorisches Museum de Vienne, des autorisations de reproduire qu'elles ont eu la courtoisie d'accorder gracieusement. Celle du Museo delle Terme avait autorisé préalablement M. Alvarez à photographier lui-même les monuments reproduits pl. III et VIII.

Peut-être verra-t-on une pétition de principe dans le fait de désigner, d'entrée de jeu, Hermaphrodite comme un dieu. Le nom de daimon, à vrai dire, n'aurait pas été beaucoup plus exact. Ce que nous atteignons en lui est une puissance, sentie comme mystérieuse et comme agissante, mais, en même temps, comme purement imaginaire. J'ai essayé de préciser sa fuyante figure et d'atteindre les racines psychologiques de la vénération qui semble s'être adressée à lui. Le mot culte est venu là, comme le mot dieu, pour une simple raison de commodité. Le présent essai tente de les éclairer l'un et l'autre par la description attentive et nuancée, pour un domaine limité, des affleurements d'un archétype, l'un des plus enracinés dans la psyché humaine, un de ceux aussi qui se présentent à nous le plus nûment, le moins transposé en légendes, demeuré, peut-on dire, un mythe pur. 


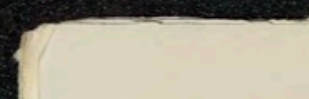




\section{INTRODUCTION}

L'être du dieu Hermaphrodite ne se laisse pas aisément approcher. - Son culte est attesté par des documents peu nombreux et peu explicites : une dédicace athénienne du début du rve siècle, un passage de Théophraste, un autre d'Alciphron, et des monuments qui offrent peu de prise à une interprétation. La seule légende qui le concerne est racontée au livre III des Métamorphoses (285-388): la nymphe du lac Salmacis près d'Halicarnasse s'éprend du fils d'Hermès et d'Aphrodite et s'unit à lui, au sein des eaux, si étroitement qu'ils ne composent plus qu'un seul être. Diodore de Sicile $(\mathrm{IV}, 6,5)$ et bien d'autres lui attribuent la même généalogie. Mais, pour eux tous, la nature double existe dès la naissance et elle résulte de la fusion des caractères des deux parents. Pour Ovide, elle vient d'une transformation, de la fusion d'un jeune garçon avec une nymphe. Ovide a rendu sensible le pouvoir attirant de l'eau. En revanche, il a totalement méconnu le sens archaique, nettement positif, de la bisexualité : l'être double qu'il appelle à l'existence est un neutrum et non un utrumque.

Rien d'étonnant si les historiens qui s'en sont tenus aux attestations explicites ont nié qu'il y ait eu en Grèce un culte d'Hermaphrodite. Son nom n'apparaît que dans une note de la Geschichte der griechischen Religion de Nilsson. A propos de l'étude d'Usener sur d'hypothétiques survivances chrétiennes de l'Aphroditos chypriote, il affirme (p. 491) : «Der Hermaphroditismus ist den ursprünglichen griechischen Vorstellungen so fremd dass es nicht nötig ist hier darauf einzugehen. Davon zu trennen sind die Bräuche des Kleidertausches " $\left.{ }^{1}\right)$. Les dieux aux attributs doubles ne résultent pour lui ni

(1) En vertu d'une analogue pétition de principe, Wilamowitz, qui nie également qu'il y ait jamais eu de culte grec d'Hermaphrodite, se refusait à voir un fait hellénique dans la claudication d'Héphaistos, l'intégrité physique, affirmait-il, étant le propre des dieux grecs. - Sur les «Feste mit Beziehung auf die Doppelgeschlechtigkeit» (rites d'Ariane à Chypre, d'Aphroditos, Ekdysia de Phaestos, Hybristika d'Argos), voir Nusssos, Griechische Feste, pp. 369-374. 
d'une influence orientale, ni davantage de la conception philosophique d'un Urwesen, d'une unité supérieure de la race divine ou de la race humaine dont la perfection aurait exigé la possession des deux pouvoirs. Ce sont, pense-t-il, les fêtes accompagnées d'échange des vêtements qui auraient donné naissance au personnage d'Hermaphrodite: des statues phalliques couvertes de vêtements féminins, du type de celle qui était honorée aux Ekdysia crétoises, auraient été modelées de façon à représenter un corps de femme. Cette explication ne fait évidemment que reculer la difficulté : si le dieu vient du travestissement, à quoi correspond le travestissement ? N'est-il pas plus satisfaisant pour l'esprit de voir dans l'être androgyne d'une part, et dans les rites d'autre part, deux affleurements d'un archétype unique, celui du double pouvoir, si fortement attesté parmi tant d'autres peuples qu'on n'a vraiment aucune raison de penser que le monde classique l'ait ignoré? C'est en étudiant conjointement des usages populaires et des spéculations philosophiques que Dïmmler, dès 1897 , a su donner une solidité au personnage d'Hermaphrodite, considéré jusque là comme une invention de sculpteurs dont le maniérisme cherchait des renouvellements dans des fantaisies orientales $\left({ }^{1}\right)$.

Dans un petit livre écrit il y a dix ans, $\mathrm{j}$ 'ai rapidement indiqué les traces que le rêve de la bisexualité a laissées dans les traditions religieuses du monde classique $\left({ }^{2}\right)$. Les premières puissances de la cosmogonie hésiodique, Chaos et Érèbe, sont désignées par des mots neutres. La Terre commence par engendrer, seule, le Ciel auquel

(1) Dans ses Sittengeschichtliche Parallelen, article posthume (Philologus, t. LVI, 1897, repris dans les Kleine Schrifien). Indépendamment de lui, le Dr. von Rö̀nž, d'Amsterdam, publia en 1903 dans le Jahrbuch für sexuelle Zuischenslufen, V, 2, p. 711-941), une savante et pénétrante étude, inspirće au départ par Creuzer et les mystiques juifs et chrétiens; il y suit l'image androgyne dans le Proche-Orient, l'Égypte et la Grèce et en reconnait le caractère cosmique à une époque où les historiens des religions n'y voyaient qu'immoralité d'un monde en décadence: voir le consternant article de P. Hrrrarasx dans Roscher (1900). Celui de Jessen, dans P.-W. (1912), très supérieur, car il avait été guidé par Dümmler, aurait été moins timide si l'auteur avait lu l'ouvrage de Rōmer. Celui-ci a été utilisé, et cité le moins possible, par J. Ch. L. Halley des Fontaines, dans sa très superficielle Contribution à l'étude de l'androgynie, Paris, 1938, thèse de médecine. Je n'ai malheureusement connu l'étude de Römer que par Hermann Butusanss (infra, page 10) qui en a vu la valeur.

(2) Hermaphrodite, ch. II, les dieux doubles, et V, le symbole androgyne dans les mythes philosophiques. 
elle s'unira plus tard. Héra, déesse nuptiale, procrée toủtefois Héphaistos et Typhée "sans l'aide du tendre amour». Ce ne sont là que des indications abstraites. Des représentations symboliques apparaissent autour du Zeus mamelu de Labranda en Carie, de l'Aphrodite barbue de Chypre et de Pamphylie ; une Vénus chauve, protectrice des naissances, existe en Italie, ainsi qu'une Vénus nourricière que le poète Lavinius déclare honorer « qu'il soit femelle ou qu'il soit mâle», ce qui rappelle la formule des invocations romaines : sive mas sive femina. Vers 100 avant J.-C., Valerius Soranus parle d'un Jupiter genitor genitrixque. Quant à Dionysos, dont il existe de nombreuses représentations ambiguës, il est dit arrhénothêlus dans une tradition littéraire ancienne et indépendante de toute influence étrangère.

Une imagerie beaucoup plus précise se dégage des cosmogonies non hésiodiques, où des figures bisexuées sont concrètement décrites. Le thème de l'androgynie prend une importance croissante dans les spéculations philosophiques à la fin de l'antiquité. Mais il suffit de se reporter aux anthropogonies d'Empédocle, de Platon, de Lucrèce, pour se convaincre qu'il ne s'agit là ni d'innovations, ni d'importations orientales, explication à laquelle Eusèbe de Césarée avait recouru bien avant les philologues modernes. Lisant le discours d'Aristophane dans le Banquet - de tous les mythes de Platon, c'est à coup sûr le plus authentiquement enraciné dans l'inconscient - il ne put admettre que Platon l'eût inventé. Il pensa que le philosophe avait lu le second chapitre de la Genèse, mais avait mal compris la section qui sépara Ève d'Adam (Prép. évang., XII, 12). En fait, l'image platonicienne des êtres doubles et la créature à la fois mâle et femelle du rédacteur élohiste s'expliquent en dehors de tout emprunt: elles sont pareillement nées de la psyché.

Unissant deux pouvoirs en un seul corps, l'être double exprime l'aspiration majeure de toute espèce vivante qui veut se perpétuer. L'échange rituel des vêtements apparaît en Grèce et à Rome dans des usages nuptiaux, dans les initiations par lesquelles les jeunes gens sont admis dans la classe nuptiale, dans des fêtes de la fertilité végétale et dans des réjouissances débridées dont le dénouement est mal connu. Le peu que nous savons du culte d'Hermaphrodite est qu'une veuve qui désire trouver un mari ou un amant apporte à son image, en un lieu public, une eiresioné; que le Superstitieux de Théophraste couronne les hermaphrodites qui sont dans sa maison le quatrième jour du mois : or on plantait l'eiresionê dans/les fêtes

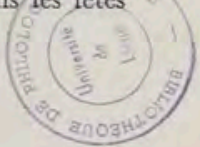


de mariage et de naissance, et Hésiode déclare le quatrième jour propice aux unions.

J'ai vu en Hermaphrodite un daimon de l'union sexuelle, définition que je voudrais ici creuser et élargir. Capable de promouvoir les forces génératrices de la terre aussi bien que celles des humains, le dieu double a une signification plus étendue qu'il ne semble au premier abord. Elle se révèle dès qu'on étudie plus attentivement, d'une part les différents types sous lesquels on l'a représenté et, d'autre part, ceux de l'Éros androgyne, dont on ne saurait le séparer. Cette double étude est l'objet de ce livre.

Le petit volume de 1958, dont l'éditeur avait limité le nombre de pages, était en épreuves quand je connus le grand ouvrage où Hermann Baumann, synthétisant des observations très nombreuses et très attentives, défend la même thèse. Les rites symbolisant la bisexualité, dont le plus simple et le plus répandu est l'échange des vêtements, visent, dit-il, à renforcer par superposition les forces vitales de l'un et l'autre sexe. Des formes plus compliquées peuvent simuler et partiellement réaliser un changement de sexe, comme c'est le cas dans le chamanisme ${ }^{(1)}$. Au niveau magique, ces rites apparaissent comme un phénomène si général qu'il intéresse, peut-on dire, toute l'humanité. Chez les Naturoölker toutefois, ils aboutissent rarement à une élaboration mythologique. Certains , peuples seulement ont imaginé des dieux androgynes.

Les Grecs l'ont fait. Mais leur rêve de l'être double ne s'est que timidement développé en figures concrètes. En effet, il rencontrait en eux une résistance majeure : une profonde angoisse devant tout ce qui impliquait une altération du type héréditaire. L'apparition d'un nouveau-né porteur de caractères anormaux annonçait une mystérieuse colère divine, qui se manifesterait par une stérilité de la terre et des êtres vivants si la communauté ne se désolidarisait aussitôt de l'enfant maléfique, chargé tacitement des fautes dont il était le signe, et ne le mettait dans des conditions telles qu'il dût immanquablement périr. Une des malformations les plus redoutées concernait les organes sexuels. L'hermaphrodisme vrai est rarissime, mais non l'hypospadias, où seuls sont anormaux les organes externes.

(1) Das doppelte Geschlecht, notamment ch. 1, Der kultische Geschlechtsuandel. Jai interprété de mon côté la légende de Tirésias comme une stylisation de la bisexualité chamanique. 
Le sexe véritable, dans ce cas, mal interprété à la naissance, se révèle après la puberté. L'ambiguitté apparente et le passage d'une dominante à l'autre parurent également inquiétants. Un siècle avant notre ère, on brûla encore un «hermaphrodite» adulte à Rome et un à Athènes.

L'androgynie occupe donc les deux póles du sacré. Pure vision de l'esprit, elle apparaît chargée de la promesse la plus précieuse. Mais il ne faut pas qu'elle s'actualise en un être né d'un homme et d'une femme. Une note de Diodore de Sicile essaie de concilier les deux points de vue, sans comprendre leur foncière hétérogénéité : « Semblable par son origine à Priape (fils de Dionysos et d'Aphrodite) est celui qu'on nomme Hermaphrodite, fils d'Hermès et d'Aphrodite, désigné des noms associés de ses deux parents. Les uns disent qu'il est un dieu, qu'il se produit de temps en temps parmi les hommes et qu'il naît avec un corps marqué de la double nature masculine et féminine, avec la vigueur de l'un, la douceur de l'autre. D'autres disent que ceux qui révèlent des natures de cette sorte sont des monstres qui apparaissent rarement et qui annoncent tantôt des malheurs, tantôt des bonheurs " (IV, 6, 5). La formule les uns... les autres peut induire en erreur, car elle marque une alternative qui n'exista jamais. Les deux attitudes d'esprit pouvaient être celles d'une seule et même personne, qui accordait valeur de talisman à une figure androgyne et qui tenait inévitable l'élimination d'un nouveau-né marqué des deux sexes. A Éphèse même, la naissance d'une fillette polymaste aurait sans doute été considérée comme un danger public.

C'est peut-être en vertu de cette réluctance que la cosmogonie hésiodique n'attribue les deux puissances à certains êtres créateurs que d'une façon purement allusive, en les désignant par des neutres, ou presque abstraite, en les faisant engendrer sans conjoint. De même que la polymastie d'Artémis, la bisexualité d'Aphroditos, du Zeus mamelu, est figurée symboliquement. Aphrodite porte une barbe, les seins de Zeus sont figurés sur le vêtement, comme le cœur de Jésus dans l'art sulpicien. Les plus modestes Hermaphrodites du culte - un fût portant une tête féminine et un emblème viril - ont un caractère analogue. Les indications romaines marquant l'indétermination sexuelle de la divinité excluent toute imagerie concrète.

Les exigences psychologiques auxquelles répondait la notion de bisexualité durent être puissantes pour être arrivées à vaincre ces 
résistances jusqu'à développer une figure vivante, attestée par des types très différents dont la variété même est significative. Les débuts nous en échappent. Un hiatus subsiste entre les valeurs, heureusement convergentes, qui se dégagent des travestissements rituels et les monuments qui attestent un culte privé et peut-être public, peu important, mais dont l'existence ne saurait être mise en doute. Pour le combler dans la mesure du possible, il faut interroger solidairement les images d'Hermaphrodite et celles d'Éros androgyne. Et, tout d'abord, les grouper. 


\section{ESSAI DE TYPOLOGIE}

Un examen attentif les révèle aussitôt plus nombreuses et plus expressives que les inventaires publiés ne le donnent à croire. Presque tous les archéologues ont abordé le problème avec le sentiment qui reste celui de Nilsson - que l'androgynie est une conception indigne du génie grec. Les fouilles de Myrina révélèrent des dizaines d'Hermaphrodites et d'Éros androgynes, beaucoup d'un style excellent. Une exceptionnelle liberté d'esprit n'empêcha pas Salomon Reinach d'écrire ces lignes étonnantes:

«Pas plus que Phèdre ou Charmide, l'Éros de Praxitèle n'est hermaphrodite. Il est beau de la double beauté de l'homme et de la femme. C'est le chef d'œuvre, ce n'est pas une erreur de la nature». Mais " une pente rapide conduit des jeunes dieux de Praxitèle aux représentations sensuelles de l'Hermaphrodite. L'influence des religions orientales à la fois mystiques et grossières et surtout la décadence des mœurs dénaturèrent l'idéal que la civilisation athénienne avait conçu. L'hermaphrodisme ne fut plus la synthèse de deux beautés, mais celle de deux sexes.» (1)

Comment un historien des religions ne s'est-il pas avisé que la synthèse figurée des deux sexes - alors que la même synthèse, dans la réalité, inspirait la terreur - est un symbole qui doit avoir une signification? que cette signification est totalement indépendante de tout idéal, de toute norme esthétique? que des coroplastes ne représentent pas, en grand nombre, des Éros androgynes à mettre dans les maisons et les tombes sans avoir dans l'esprit une intention que leur clientèle comprend sans autre explication, même si, à nous, elle pose plus d'un problème?

L'Éros de Praxitèle se trouvait à Parion sur l'Hellespont, ville fondée, disait-on, par un fils de Jasion, ce qui indique peut-être une association avec Déméter. La statue y était encore au temps de 
Cicéron, dernière attraction pour les touristes. Le dieu, dit Pline (XXXVI, 23) était nu, ailé, l'arc à la main. Religieusement parlant, l'œuvre est insignifiante. Les monnaies de la ville en disent davantage ${ }^{(1)}$. La statue y apparaît à gauche d'un petit monument bas, malaisément discernable, probablement un hermès, l'ancienne statue de culte.

Dans une pénétrante étude parue en 1848 dans les Abhandlungen de l'Université de Berlin, Gerhard attira l'attention sur les représentations androgynes d'Éros, sur l'étroite parenté d'Éros et Hermaphrodite. Il publia des pièces qui attestent l'existence d'un culte de ce dernier: documents modestes, sans grande importance artistique, mais où se distinguent des attributs, des accessoires, des contiguités susceptibles d'être interprétés. A regarder attentivement ce qu'il a réuni, on se rend compte que, si les artistes archaiqques ont été avant tout soucieux de signifier, cette préoccupation i subsiste dans bien des productions mineures et tardives. L'étude de Gerhard ne reçut pas l'attention qu'elle méritait. Quarante ans après, dans son article Éros de l'encyclopédie de Roscher, c'est à peine si Furtwängler mentionne l'existence de figures androgynes. On aurait lu Gerhard plus soigneusement, on n'aurait pas mis si longtemps à reconnaître que l'être double est tout autre chose qu'une création d'un art en décadence.

En dehors d'un préjugé influencé par des considérations morales, l'erreur s'explique par la primauté qu'on accorda longtemps aux œuvres d'une grande beauté artistique. Et je m'accuse d'avoir versé dans cette erreur en choisissant l'illustration du petit volume de 1958. Comme l'Éros de Praxitèle, les plus beaux Hermaphrodites sont à peu près dépourvus de signification. De la fameuse statue de Polyclès, que Pline appelle nobilis, on ne sait rien, pas même si elle est de Polyclès l'Ancien (début du rve s.) ou, comme le soutiennent ceux qui se refusent à reconnaitre l'existence d'un dieu double à l'époque classique, d'un des artistes du même nom qui travaillèrent au $\mathrm{II}^{\mathrm{e}}$ siècle. Parmi les nombreuses représentations conservées, il est impossible de dire avec certitude laquelle remonte à l'original de Polyclès. On a proposé, assez vraisemblablement, la statue de Berlin (infra, p. 29).

(1) Un spécimen dans Roscher, s.v. Eros, t. I, col. 1358. Voir P. Woltres, Arch. Zeitung, t. 43, 1885, p. 90 . 
Pour saisir ce qu'a pu être le rôle du dieu double dans les conceptions des anciens, il faut refuser tout privilège à l'esthétique et tenter un classement d'après les types, les accessoires, les attitudes et les personnages associés. Un classement tout à fait rigoureux est au surplus impossible, car les catégories s'entrecroisent : on trouvera le même geste dans des types différents, des attributs différents à l'intérieur d'un type unique. Le groupement ci-dessous, qui n'est nullement un catalogue, pourra cependant aider celui qui tentera un jour d'établir un répertoire complet.

\section{Monuments du culte}

Un culte domestique est attesté en Grèce pour la seconde moitié du rve s. par ce que dit Théophraste du Superstitieux (Caractères, 16) qui, « le quatrième jour du mois, prescrit à ses gens de faire cuire du vin, puis s'en va au marché acheter du myrte, de l'encens, des galettes et, rentré chez lui, couronne les Hermaphrodites tout le reste de la journée». Remarquons ce pluriel. Il faudra revenir sur ce témoignage et le situer dans son contexte.

Un culte en dehors de la maison est mentionné dans une lettre d'Alciphron (III, 37 ; II, 35, Schepers), qui écrit sous les premiers Antonins, mais qui prend pour décor l'Athènes de l'époque classique. La veuve Épiphyllis a tressé une eiresionê pour l'offrir à l'Hermaphrodite d'Alopèce. La vraisemblance de ce renseignement a été confirmée par la découverte d'une dédicace à Hermaphrodite, à Vari, non loin de la grotte, près d'un des éperons sud de l'Hymette (ancien dème d'Anagyros). C'est une petite base rectangulaire en marbre pentélique, présentant au milieu une excavation quadrangulaire où était logée une figure votive, laquelle était de dimensions modestes, car le creux n'a que $4 \mathrm{~cm}$ sur 5 et 3 de profondeur. La base porte l'inscription:

$$
\begin{aligned}
& {[\Phi] \alpha v \dot{\omega}^{\prime} E \varrho \mu \alpha \varphi \varrho \omega[\delta i] \text { (sic) }}
\end{aligned}
$$

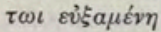

que les éditeurs datent approximativement de 385 avant J.-C. - Il s'agit donc d'une consécration à la suite d'un vœu. Le monument lui-même, qui a disparu, devait être un petit hermès et constituait une sorte de chapelle semblable à celles qui figurent au bord de 
nos routes. Aucune dédicace ne paraît jamais avoir été faite à l'intérieur d'une maison. ( $\left.{ }^{1}\right)$

Or, de tels hermès sont connus, soit par des statuettes conservées, soit par des représentations qui les révèlent comme objets de culte. Gerhard en a fait dessiner plusieurs pour illustrer son étude sur Éros. Il semble n'avoir connu qu'un seul monument en place:

1. Un terme romain en marbre avec les emblèmes des deux sexes sur le fût, surmonté du buste d'un jeune homme et portant une dédicace de M. Valerius Antonius à Jupiter Terminalis (pl. III, 3).

2. Il signale ensuite des figurations: Un terme quadrangulaire portant le symbole viril et surmonté d'une tête féminine coiffée du calathos $\left(^{2}\right)$ (statuette en bronze alors au Musée Royal de Berlin, Gebhard, pl. III, 7). - Un autre, semblable, est figuré sur le vase Bellérophon du musée de Carlsruhe; une adorante s'appuie au pilier (pl. III, 5) $\left(^{3}\right)$. - Un troisième, peint sur un oxybaphon de Naples (pl. III, 6) porte sur le fût l'emblème viril devant et le caducée sur le côté ; devant se trouve un autel dont s'approchent d'un côté une bacchante, de l'autre un silène portant un thyrse et une corne à boire.

3. Sur un groupe de marbre du musée de Berlin, un petit Hermaphrodite ithyphallique dans une grotte relève sa robe à deux mains. Sur le rocher subsistent les petits pieds d'un Éros qui a disparu. A côté de la grotte est un personnage féminin, de taille très élevée, une Aphrodite ou une adorante, vêtue, l'épaule droite nue (pl. IV, 2 ; Reinach, Stat., II, p. 378, 8; reproduit dans Roscher, I, p. 2340).

4. Ces documents étaient seuls connus quand fut décousert dans le Sarno, intact, adossé à un autre fût quadrangulaire, un hermès en marbre supportant une tête féminine; le vêtement voile strictement la poitrine et retombe jusqu'en bas, révélant seulement le sexe érigé.

(1) Sur le site et la grotte, voir M. Ed. Duxrus, A.J.A., t. 7, 1903, The cave at Vari, p. 263; l'inscription a été publiée par J. Krrchner et St. Dow, Inschriften pom att. Lande, Ath. Mitt., t. 62,1937 , p. 7.

(2) Le calathos n'apparait sur une tête masculine que chez un Atlante nu, oú il n'a pas valeur de coiffure, mais de support, comme c'est aussi souvent le cas chez des cariatides (Rernach, Stat., I, 215, 4).

(3) Mon. dell Instituto, t. 2, pl. L. La tête est analogue à celle du triple hermès Chablais (infra, p. 55) et Briux, Annali, t. 9, 1837, p. 249 y voit un Êros. 
On dirait un pieu habillé. Le tout a $71 \mathrm{~cm}$. de hauteur. Carl Robert, qui a publié le monument, attire l'attention sur la tête aux grosses lèvres, quelque peu satiresca $\left(^{(1)}\right.$. - Un exemplaire tout semblable a été retrouvé à Pompéi (Reinach, Stat., IV, 331, 6).

5. Un petit buste féminin en bronze, avec symbole viril sur le fût, de $8 \mathrm{~cm}$. de haut, a été retrouvé Sofia et publié par Seure (Reo. Arch., 1913, 1, p. 57); un autre, semblable, à Pompéi ; un autre encore, en marbre, le buste nu et les pieds figurés à la base du pilier (Reinach, Stat., V, 262, 11 et IV, 331, 5).

Ces monuments nous donnent une idée du style et de la dimension de celui que dédia Phano. Ils offrent presque tous des symboles schématiques supportés par des piliers exposés en plein air ou dans l'enceinte d'un sanctuaire. Le $n^{\circ} 3$ suggère un culte dans une grotte ; le dieu double y est associé avec Éros. La veuve dont Alciphron raconte l'histoire vénère un Hermaphrodite à Alopèce, où nous savons qu'existait un sanctuaire d'Aphrodite. La Mère des Dieux était honorée dans le dème d'Anagyros où fut trouvée la dédicace de Phano; et, non loin, la grotte de Vari révéla des représentations d'Hermès et d'Aphrodite. Ces contiguités sont intéressantes.

6. Un hermès en marbre, de Londres, doit se placer en marge de cette catégorie. Le sujet a été traité par l'artiste avec trop de liberté pour qu'on puisse y voir la reproduction d'un monument de culte. C'est une interprétation. Une figure féminine au visage grave, nue, dont les hanches se fondent dans le support quadrangulaire marqué du symbole viril, soutient un oiseau du bras gauche et lui présente de la droite une grappe de raisins. On a, à tort, considéré longtemps les emblèmes végétaux comme un « Genremotiv das mit der Natur des Hermaphrodit nichts zu tun hat $\left({ }^{2}\right)$. Nous retrouverons ailleurs la même association, avec une signification très précise. On imagine le terme de Londres dans un jardin, chargé de stimuler la nature végétale.

(1) Annoli, t. 56,1884 , p. 88-9; le terme est à présent dans la collection Barracco (Rervach, II, 525, 10). Couve l'a utilisé dans son article Hermaphrodite du Dict. Ant., fig. 3821 , sans en tirer la conclusion qui s'imposait, à savoir qu'un culte véritable avait existé.

(2) Sic P. Herrmann, Roscher, I, p. 2320. Le terme (Rennach, I, 367, 5) est reproduit p. 21, fig. 5 d'Herm. éd. angl. 
C'est en partant des Hermaphrodites du culte et notamment du terme Barracco retrouvé dans le Sarno (supra, $\mathrm{n}^{\circ} 4$ ), que nous classerons les types connus, sans tenir aucun compte de leur valeur artistique. Non sans surprise, nous nous verrons aussitôt conduits vers des figures bisexuées qui n'ont aucune parenté ni avec Aphrodite, ni avec un Apollon ou un Dionysos juvénile, mais avec Déméter. La virilité apparaît sur des figures graves, chastement voilées, maternelles.

\section{TYPE DÉMÉTRIEN}

Plusieurs statues de marbre semblent une variante du petit hermès Barracco ( $n^{\circ} 4$, p. 16). Le corps tout entier est strictement vêtu; la tunique relevée ne révèle que le sexe et les jambes: geste identique à celui du petit personnage ithyphallique du relief de Berlin ( $n^{\circ} 3$, p. 16) qui se comporte comme un Priape. On s'étonne d'autant plus de trouver cet audacieux anasyrma dans des monuments du caractère le plus grave et visiblement le plus religieux. Il est caractéristique de toutes les représentations démétriennes, mais il ne leur est point propre : il apparait exceptionnellement dans des figures de type aphroditéen et chez une Aphrodite non androgyne (infra, p. 23) ainsi que chez des Éros funéraires (p. 64).

1. Le corps lourd de l'Hermaphrodite de Stockholm se termine en un terme que le vêtement recouvre par derrière et qui aboutit à deux pieds stylisés, joints et nus (Reinach, Stat., I, 371, 7; bonne reproduction dans mon Herm, éd. anglaise, p. 36, fig. 6).

2. Celui de Paris (Reinach, I, p. 372, 4) a la poitrine et le bassin couverts; les jambes nues, d'un très beau modelé, sont d'une matrone et non d'une jeune fille.

3. L'Hermaphrodite Torlonia, de la collection Giustiniani (Reinach, I, 371, 2), est couvert d'un ample manteau bordé de franges qui, par derrière, tombe jusqu'aux talons; les pieds sont chaussés de cothurnes.

4. Terme de marbre surmonté d'un buste de femme vêtue; les bras manquent ; la draperie révèle le sexe érigé (Reinach, II, 526, 1) exemplaire analogue à Pergame (IV, 331, 4).

5. Statuette de marbre, vêtue, la tête manque, les jambes sont nues; ithyphallique, comme la précédente (Reinach, II, 791, 8 et II, 73, 8, provenant toutes deux d'Asie Mineure). 
Les $\mathrm{n}^{\circ} 4$ et 5 sont des œuvres vulgaires et grossières, où un trait priapique altère le caractère démétrien. Les trois autres, si le haut seul en avait été conservé, on n'aurait pas hésité à reconnaître une Déméter. Celle de Stockholm porte le calathos rempli de fruits. Elles ne ressemblent en rien aux Hermaphrodites-éphèbes où se retrouve, précisé, l'androgynisme diffus de l'art grec tardif. Le contraste entre ces figures graves et maternelles d'une part, et, d'autre part, le mouvement de l'anasyrma, produit sur nous une impression choquante. Le sentiment des anciens était certes très différent. La déesse nue babylonienne écarte son manteau de la même façon et, sur des cylindres syro-hittites, elle ouvre par devant sa robe à franges $\left({ }^{1}\right)$. En Grèce même, le travestissement rituel, attesté dans des cérémonies des plus sérieuses, apparaît également dans des réjouissances débridées comme les hybristika d'Argos. Toutes les réactions qui concernent la vie sexuelle peuvent se porter d'un extrême à l'autre. Source de la fécondité, elle est - surtout chez les peuples pour qui ce souci est primordial - l'objet d'une crainte révérentielle qui se manifeste par de sévères tabous. Mais dans les moments où ce respect cesse d'être sous-tendu par un puissant instinct vital, il se dissipe dans le rire, sans laisser de place à un état intermédiaire. Le phallos, révéré des anciens, l'est encore en Italie, où ses symboles ont gardé leur double valeur : de promouvoir les forces et d'écarter les mauvais sorts. Tout cela était senti, et l'est toujours, avec une gravité qui étonne les hommes du nord $\left({ }^{2}\right)$. Et cependant les emblèmes sexuels d'usage apotropaique s'appelaient des geloia, ridicula, le rire étant du reste capable, en soi, de rompre un enchantement.

Les statues démétriennes suggèrent une polarité analogue. A-t-il jamais existé une Déméter apparentée à la «pure et sainte Misé, mâle et femelle» du XLHe hymne orphique? Nous n'en savons rien. Elle est toutefois nommée Chalcocrotos par Pindare (Isthm., VIII, 3) et grande Mère par Euripide (Hél., 1355), épithètes de Cybèle qui avait des aspects doubles. Les Cabires de Samothrace

(1) G. Contenuu, La diesse nue babylonienne, 1914, p. 88 , fig. 89 et 93 .

(2) M. Alvarez vit à Amalfi une bicyclette d'ouvrier au guidon curieusement décoré : en haut, le portrait d'un frère mort, entouré de fleurs artificielles; au dessous, celui de la mère morte, entouré d'un chapelet; puis celui d'une « girl-friend», le tout flanqué de deux emblèmes phalliques en plastique rouge et de deux drapeaux italiens. Des queues de renard ornent souvent les bicyclettes des garşons, non celles des filles. 
étaient Axieros, Axiokersa et Axiokersos, c'est-à-dire Déméter, Perséphone et Hadès, un quatrième, Casmilos, étant Hermès ( $\left.{ }^{1}\right)$. Des hypothèses sur une Déméter virile seraient imprudentes. Les trois noms ne sont que des épiclèses et le premier était senti comme un féminin. Et les dieux de Samothrace posent pour leur compte trop de problèmes pour qu'on doive leur demander d'en résoudre d'autres. On peut toutefois se souvenir de ce que dit Hemberg (p. 277) de leur foncière indétermination; rappeler qu'à l'entrée du temple se trouvaient des statues ithyphalliques et que les fouilles ont révélé quantité d'emblèmes des deux sexes $\left({ }^{2}\right)$.

La statue de Stockholm attribue l'anasyrma à un être double qui, pour tout le reste, a l'exacte apparence d'une Déméter. La légende veut que Baubo, en se dévoilant devant elle, ait fait rire la déesse affligée $\left({ }^{3}\right)$. Baubo signifie ventre; baubôn ne désigne nullement, comme le conte le donnerait à penser, l'organe féminin, mais bien, ainsi que le prouve un passage d'Hérondas (VI, 9), le phallos. G'est-à-dire que le geste canaille de Baubo correspond exactement à celui de nos statues, comme si Baubo n'était qu'un dédoublement de la déesse, son aspect bouffon face à son aspect vénérable.

Ces ouvrages énigmatiques peuvent être considérés, au sens large, comme des statues de culte. Non qu'ils aient jamais été, tels quels, offerts à la vénération. Mais les artistes qui les ont conçus se sont inspirés de monuments authentiques qu'ils ont stylisés conformément à une image religieuse où la force virile se trouve unie à une généreuse puissance maternelle. Ils n'ont rien accordé à la gracilité qui était à la mode de leur temps et, sacrifiant toute élégance facile, il ont concentré l'attention sur le double symbole.

(1) Sources et théories apud Bempt Heamerg, Die Kabiren, Upsala, 1950, notamment, p. 87 et 306 .

(2) Lemann, A.j.A., t. 43,1939 , p. 140 et t. 44,1940 , p. 335.

(3) Le motif se retrouve curieusement dans un conte égyptien oủ $\mathrm{Ra}$, offensé par Baba, se renferme dans un sombre silence jusqu'au moment où sa fille Hathor le fait rire en se dévoilant devant lui (Myth. of the ancient World, ed. by S. N. Kruser, p. 80 : Ancient Egypt by R. Avthes. - RenvaCh, (Rire rituel, dans C.M.R. t. 4, p. 116), signale un parallèle japonais où la « femme terrible du Ciel» relève son vêtement jusqu'au-dessus de la ceinture, sur quoi « les huit cents myriades de dieux se mettent tous en même temps à rire». 


\section{L'Hermaphrodite Chablais}

Une curieuse statue du musée du Capitole a gardé, en dépit d'un traitement assez libre, une parenté avec les statues démétriennes. Elle est, je crois, unique de son espèce.

C'est un ouvrage en marbre grec, de $75 \mathrm{~cm}$, de hauteur, provenant de la collection Chablais (Reinach, Stat. I, 372, 6). H. Stuart Jones le décrit dans son catalogue, tel qu'il l'a vu en 1912. "La figure repose sur la jambe droite; la gauche fléchie ne touche le sol que des orteils. Un manteau retombe sur le dos, dans les plis duquel elle tient à deux mains un Éros ailé. Les formes sont longues et sveltes, la poitrine est féminine. "Poor late work, much damaged».

La statue, probablement une copie romaine d'une œuvre plus ancienne, a été depuis débarrassée d'une partie de ses restaurations, non toutefois de la tête, qui est déplorable. On peut juger de l'état actuel par la belle photo $\mathrm{n}^{\circ} \mathrm{I}$. Je la dois à M. O. J. Alvarez, qui fut frappé par la singularité de l'œuvre. Elle avait échappé à Jones qui vit, restaurée en Éros, la figurine supportée par la draperie. Le restaurateur s'était laissé influencer par les nombreux monuments qui associent Hermaphrodite et Éros. Ce que tient la statue Chablais n'est pas un Amour, mais un sorte d'enfant symbolique, beaucoup plus petit que nature.

Celui-ci donne à l'être double un caractère maternel, moins accusé toutefois que dans les statues démétriennes. La poitrine est moins ample que la leur. Le corps est celui d'un être jeune, élancé, aux épaules et aux hanches étroites. Le membre viril est attaché à un pubis féminin. La draperie est libérée pour faire valoir la grâce du corps nu. Elle est relevée de bas en haut, dévoilant le sein gauche et le ventre au-dessous du nombril, comme dans certaines statues aphroditéennes (infra, p. 23). L'ensemble donne l'impression de remonter à l'interprétation, par un excellent sculpteur, d'une statue de type démétrien. Le traitement des pieds accuse la différence; ils esquissent un mouvement de marche, alors qu'à Stockholm le fût quadrangulaire rappelle les termes du culte et qu'au Louvre les pieds sont lourdement d'aplomb sur le sol. Dans d'autres cruvres d'une même qualité artistique, le vêtement n'est pas retroussé, il retombe sur la jambe (infra, p. 24-7). Le sculpteur a gardé ici le mouvement de l'anasyrma. Mais, alors que celui-ci, dans les statues démétriennes, a quelque chose de mécanique, de

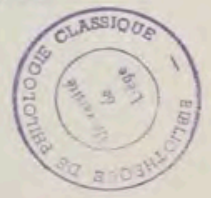


purement rituel, il se fait ici presque oublier. Le tissu semble n'être relevé que pour soutenir l'enfant, sur lequel le regard se porte. L'enfant est du reste traité avec si peu de réalisme que l'artiste, on n'en peut douter, a voulu le réduire à une sorte d'allusion.

Aucune réplique n'est connue de cette ceuvre $\left(^{1}\right)$ qui est singulière dans tous ses détails. Les artistes anciens en effet n'ont apporté aucun intérêt au thème de la mère portant son enfant. On s'attendrait à le voir traité dans la sculpture funéraire; il n'en est rien. Al. Conze (Die att. Grabreliefs, 1893) a publié plusieurs stèles qui associent une femme et un enfant; une seule ( ${ }^{\circ}{ }^{59}$ ) place le bébé sur les genoux de la mère; un autre enfant ( $n^{\circ} 58$ ) est debout près de la sienne; un autre ( $\left.n^{\circ} 462\right)$ à ses pieds; un autre lui est présenté par une servante ( $n^{\circ} 280$ ). Les Attic grave-reliefs of the class. period de H. Friis Johansen (1951) offrent une seule stèle ( $n^{\circ} 4$ ) où une femme tient l'enfant mort de sa fille. La peinture de vases ignore à peu près le sujet de l'allaitement. Il y a quelques exceptions. Une hydrie de Berlin montre Ériphyle allaitant le petit Alcméon (voir mon Oreste et Alcméon, 1959, fig. 5, p. 45); sur un lécythe apulien à figures rouges, du début du rve siècle avant J.-C., Aphrodite allaite un Éros ailé debout sur ses genoux, plusieurs autres voletant autour d'elle (Musée de Tarente, voir J. Boardman, Greek Art, p. 199). L'une et l'autre, entièrement vêtues, sont assises, comme le ferait toute mère humaine. La statuaire représente plus souvent un enfant dans les bras d'un homme que dans ceux d'une femme. Hermès ou Silène portent Dionysos; mais quand Éros apparaît avec Aphrodite, il est généralement à côté d'elle ou à ses pieds. Il existe des quantités d'Isis romaines; rares et douteuses sont celles qui portent l'enfant Horus, comme elle le fait dans l'art égyptien. Elles sont debout, comme le personnage Chablais.

Les rares monuments qui placent un enfant dans les bras d'une femme n'illustrent pas la maternité physique, mais un symbole, celui de l'adoption. Des figurines de pierre ou de bronze, assez grossières, représentent une femme toujours vêtue, rarement debout (Reinach, II, 255, 5 et 7), presque toujours assise ou couchée (II, 259,$8 ; 260,1$ à $7 ; 423,5$ ), tenant ou allaitant un ou plusieurs enfants. Ces courotrophes étaient probablement des figures talis-

(1) Sauf peut-être Rervach, Stat,, III, 243, 5, de Pompéi, qui semble tenir quelque chose sur le bras gauche. Je n'ai pu avoir de renseignement sur la statue. 
maniques. Celles qui ont abouti à une élaboration artistique n'ont pu recevoir que des désignations conjecturales: Dea Rumina (II, 260, 1) ; Héra allaitant Héraclès (I, 204, 2) ; Eiréné et Ploutos (II, 254, 7 et 8) ; Ino et Dionysos (I, 374, 1, 3, 4; II, 798, 1). Elles semblent figurer un pur symbole, celui de la courotrophie.

C'est à ce symbole que l'on pense devant l'Hermaphrodite Chablais, à demi-vêtu, alors que les courotrophes masculins sont nus et que les féminines sont drapées. Aucune autre image de l'être double ne suggère une telle valeur.

Il a ici la dignité d'une apparition divine. Il y a une étonnante spiritualité dans le mouvement qui élève l'enfant jusque près du sein, sans toutefois qu'il le touche. On songe à des représentations d'Isis maternelle et, comme nous le verrons (infra, p. 35), la coiffure des hermaphrodites est souvent celle d'Isis. D'autres œuvres peuvent avoir, esthétiquement, plus de valeur ; aucune n'exprime plus gravement ce qu'a pu être la symbolique incluse dans le dieu ambigu et le caractère religieux de la vénération qu'il a inspirée.

\section{TYPE APHRODITÉEN}

Nous réunissons ici des figures dont l'anatomie accuse une dominante féminine et dont les gestes et les accessoires apparaissent ailleurs comme ceux d'Aphrodite.

1. Certaines semblent dérivées du type démétrien. Telle est une statuette en bronze du Louvre (Reinach, II, 177, 5; voir aussi V, 79,4 et 5). Le corps est moins lourd, sans avoir cependant la sveltesse de la plupart des petites figurations de la déesse; les hanches et les cuisses sont larges, le membre viril fixé à un pubis et à une aîne féminins; le vêtement, relevé à deux mains jusqu'au-dessus du nombril, dévoile le sein gauche comme dans la statue Chablais. Ni la tête, un peu inclinée à droite, ni les jambes n'ont la raideur des modèles démétriens. Les pieds sont chaussés de cothurnes, comme l'exemplaire Giustiniani (supra, p. 18). Un autre exemplaire aux pieds nus a été rapporté par Mariette du Sérapéion de Memphis. Sans l'indication de la double nature, on croirait voir une Aphrodite. Du reste, une Aphrodite purement féminine, en bronze, au surplus toute semblable, a été retrouvée à Bordeaux ( $\left.{ }^{1}\right)$.

(1) Retwach, Stat., II, 337, 4; comparer aux bronzes dessinés V, 79, 3, 4, et 5; voir C.M.R., II, p. 325 où l'Aphrodite et l'Hermaphrodite sont représentés face à face. 
2. La ressemblance est plus accentuée quand le personnage est ou bien vêtu d'une draperie non relevée, mais retombante, ou bien nu et paré de colliers comme Aphrodite pséliouméné. Comme elle, il porte souvent le grand collier double, qui dessine deux diagonales sur la poitrine. Les figures égéennes à colliers sont connues; des figures nues élamites portent des colliers en sautoir ${ }^{1}$ ). Déonna a sans doute raison de voir là moins des ornements que des accessoires cultuels $\left({ }^{2}\right)$. Comme sur les statues d'Aphrodite, ces colliers n'apparaissent que sur le dieu nu : un collier simple, à pendeloques, sur le petit bronze Caylus (Reinach, II, 177, 6), un collier double sur le marbre de Londres (I, 370,6). Une curieuse peinture de Pompéi, donc l'interprétation reste énigmatique, présente un grand Hermaphrodite nu, debout sur un socle de deux marches, portant le grand collier double, un autre enserrant le cou, des bracelets, et une grande étoile sur la tête; en face de lui est une femme assise, les jambes seules couvertes. Entre eux est un Éros ailé tenant un miroir que la femme touche du doigt. Dans le fond est une grande colonne de temple $\left(^{3}\right)$. Ces colliers étaient volontiers associés avec Hermaphrodite. Une petite terre cuite du musée de Naples (salle LXXXVII, vitr. 12, inv. CS 76), destinée à être suspendue, le représente nu avec, peintes, les traces du double baudrier. De même un lourd Éros de Myrina (n61, p. xvi), coiffé de pampres et de baies, aux épaules étroites, aux hanches larges, porte la double chaînette croisée sur la poitrine avec un médaillon central.

3. Nombreuses sont les Aphrodites nouant le strophium (Reinach, Stat. II, 345,1 à 8 ). On a retrouvé au début de ce siècle sur le forum de Castel Ruscino un curieux petit bronze où le dieu double, $\mathrm{nu}$, coiffé du tutulus, fixe une étroite bandelette, attirant ainsi l'attention à la fois sur ses seins et sur une coiffure, souvent portée par la Vénus latine, et qui est un symbole phallique $\left(^{(}\right)$.

(1) G. Contenav, La deesse nue babjlonienne, p. 62 et 75.

(2) W. DÉosxa, Gestes d'Aphrodite et d'Apollon, R.H.R., t. 80, 1919, pp. 30 sqq.

(3) Fresque de la Casa del Diadumeno, publiće par Rosssuch, Vier pomp. Wandbilder, Arch. Jahrb., 1893, p. 56, qui semble n'avoir pas remarqué l'ambiguité du personnage principal, qu'il identifie, à cause de l'étoile et de la colonne, avec Phaéthon, fils d'Eos et de Céphale, enlevé par Aphrodite pour etre le gardien de ses temples (Hés., Théog., 986). - Rervich, Peint., 67, 1. - Heusic, 967, pl. XI ; scènes analogues, 964, 5, 7 et 8.

(4) Publié par Reivach, $R$. Arch., t. 22, 1913; Stat., V, 79, 1 et 2 ; voir aussi DÉonsa. R. Arch., t. 8, 1918 , p. 138. 
4. Aphrodite porte souvent la main à sa chevelure, geste prêté également à Apollon ( ${ }^{1}$, , et qui s'explique par la force magique incluse dans les cheveux, source de vigueur et de fécondité. L'Hermaphrodite Albani (Reinach, Stat. I, 368, 1; dessiné dans Herm., p. 94) pose le dos de la main gauche à plat sur le haut de la tête. Celui de Londres (I, 371, 5) arrange ses cheveux, mais la statue, visiblement, a été fortement restaurée. Portent également la main à leur chevelure les figures de bronze signalées par Reinach (Stat., II, 176, 1, 3, 4 et 6 ) et Babelon et Blanchet ( $\left.{ }^{\circ} 307\right)$. Tel était probablement aussi, avant une restauration maladroite, le geste de la statue désignée comme Faune hermaphrodite (Reinach, I, 373, 1) et qui est une Vénus virile provenant de Pompéi, actuellement à Naples (salle XXXVII, inv. 6352). Je ne vois toutefois aucun exemple d'Hermaphrodite tordant ses cheveux, ce qui aurait été concevable si la légende racontée par Ovide était devenue populaire.

5. La Callipyge de Naples, qui se retourne comme pour regarder la face dorsale de son corps (Reinach, I, 328, 1-3) semble n'avoir pas de réplique. Nombreux au contraire sont les Hermaphrodites qui font ou qui esquissent le même mouvement. Ils ne se copient pas les uns les autres et appartiennent à des types différents. Contrairement à la Callipyge, tous sont nus. Le plus beau est un bronze découvert à Épinal, de type éphébique (Reinach, II, 176, 2, dessiné Herm. fig. 3, p. 93). Il en existe un autre assez semblable au British Museum et le grand bronze Payne-Knight a la même torsion en arrière (Reinach, III, 54, 4). Aucun accessoire ne les accompagne. L'Hermaphrodite Alcochète et celui de la Tamise (Reinach, II, 176,3 et 1), qui portent la main gauche à leur chevelure, tiennent de la droite un miroir, le premier rond, le second ovale, et semblent regarder le reflet de leur dos. La torsion du cou est souvent faiblement indiquée, par exemple dans le petit bronze 307 de la Bibliothèque Nationale et dans un joli petit bronze de $8 \mathrm{~cm}$. du musée de Vienne (Reinach, II, 176, 4 et 5), représentant un Hermaphrodite féminin et ithyphallique, nu; la main gauche, brisée, se portait probablement vers les cheveux; la droite abaissée, semble avoir tenu un miroir pour réfléchir le dos $\left(^{2}\right)$.

(1) Comment n'être pas frappé du caractère féminoỉde d'Apollon dans presque toutes les statues où il touche ses cheveux?

(2) Décrit dans les nouvelles acquisitions de l'Arch. Anzeiger de 1892 (t. 7 des Arch. 
Le regard tourné en arrière apparaît dans trois reliefs presque identiques, d'Athènes, de Pise, de Rome, où le geste peut s'expliquer dans un cadre dionysiaque (infra, p. 29). Mais le monument le plus caractéristique est un curieux bas-relief découvert à Sens, grossièrement sculpté sur une pierre funéraire : un androgyne nu émerge d'un culot de feuillage; il tourne la tête en arrière en portant la main droite à sa chevelure et la gauche, tenant un miroir, vers le bas des reins $\left(^{1}\right)$. Il n'y a pas ici de recherche d'artiste; le mouvement doit avoir une signification qui nous échappe, ainsi que l'a supposé Déonna, lequel n'a pas vu cependant à quel point il est fréquent dans les représentations de l'être double.

6. Au musée de Naples (salle LXXX, vitr. 11) est une Aphrodite, semblable au bronze Balanée (Reinach, II, 349, 2) ; nue, un collier, trois bracelets, un strophium et la grande chaine double peints et dorés sur le marbre. Sa main droite se porte à la lourde sandale du pied gauche - elle la dénoue, suppose Déonna, pour accomplir un sacrifice qui requiert les pieds nus - ; le pied droit touche, comme s'il allait l'écraser, une miniature d'enfant aussi réduit que celui de l'Hermaphrodite Chablais. La main gauche, brisée, reposait sur la tête d'un petit Priape. Un bronze de Paris (Reinach, II, 178, 6, dessin dans Herm., p. 69, fig. 5 ; photo dans l'éd. angl., p. 20, fig. 4), présente, dans un contexte analogue, un Hermaphrodite féminin qui s'appuie d'une main à un hermès phallique et caresse de l'autre les cheveux d'un petit garçon qui joue de la flute de Pan. Soutenu par le coude gauche, le vêtement retombe obliquement sur le genou droit; l'anasyrma, en effet, signalé ci-dessus ( ${ }^{\circ} 1$ ) chez une Aphrodite et quelques Hermaphrodites tout semblables à elle, n'apparaît pas dans les autres variantes du type aphroditéen. Dans

Jahro., p. $51, n^{\circ} 79$ ); des trous indiquent que la figurine, d'exécution soignée, était fixée à quelque chose. L'article la rapproche des ouvrages signalés ci-dessus et d'un relief en bronze, de Naples, désigné à l'époque comme n॰ 5342 et 7657 dans la salle II des bronzes. Ces pièces ne nous apprennent pas grand chose, sinon la diffusion du type. - Wivter, II, p. 359,5 , fait connaitre une terre cuite de $48 \mathrm{~cm}$., la tête fortement inclinée à droite ; sa singularité dans ce groupe est d'être vétue; la tunique relevée sur l'épaule gauche recouvre le dos et la jambe droite, en découvrant le sexe. Si le mouvement respiciens a eu une valeur symbolique, conjointement, comme il semble, avec la nudité, ce coroplaste l'a méconnue.

(1) Espérandiev, IV, 28 ; Renvach, Reliefs, II, 306 ; W. Déonsa, R.H.R., t. 30, 1919 , 2, p. 34 ; J. A. Blanchet, Rev. Arch., t. 28 , 1896 , pp. 160-2. 
une statuette en marbre du musée d'Athènes, malheureusement mutilée (dessinée Herm., p. 100), le péplum glisse également de l'épaule droite, retenu par la main gauche. Une charmante Vénus virile, peinte à Pompéi (Reinach, Peint., 98, 2), d'un geste plein d'afféterie, élève légèrement de la droite un voile qui lui couvre la tête et passe sur l'avant-bras gauche; la main tient une large feuille. Mouvement un peu différent dans les Hermaphrodites Pamphili et, beaucoup plus librement traité, dans le Cavaceppi (Reinach, I, $371,3$ et $4 ; 372,1)$, où toute la draperie est massée autour de la ceinture. Les artistes ont drapé le personnage comme ils auraient fait d'une Aphrodite ou d'un Apollon. Ces ouvres paraissent dépourvues de toute valeur religieuse.

7. Aphrodite figure dans des ensembles avec Hermaphrodite. Gebhard (Eros, pl. II, 5) reproduit un groupe attique en terre cuite où une Aphrodite assise, vêtue d'un péplum qui laisse le haut du corps à découvert, embrasse un petit Hermaphrodite nu. On a retrouvé à Pompéi, ensemble, des statues de la déesse et du dieu double.

8. L'emblème d'Aphrodite est le coquillage lequel, dans l'ordre des légendes, rappelle la naissance dans la mer et, dans celui des symboles, l'organe féminin, le mot ktéis ayant les deux sens. De nombreuses nymphes sont représentées tenant à deux bras, à la hauteur des hanches, une large coquille (1). Cette attitude, qui semble propre à des divinités féminines, est parfois prêtée au dieu double. Reinach signale aussi (Stat., II, 437, 8), dans la même attitude, un Éros androgyne en marbre, ailé et nu, trouvé en 1771 dans le lac de Némi et conservé au château de Pavlovsk en Russie.

Trois petits bronzes, de valeur inégale, ont représenté Hermaphrodite tenant une coquille, laquelle a disparu, peut-être parce qu'elle était d'une autre matière, plus fragile. La position des bras ne peut guère s'expliquer autrement.

a) Une statuette gallo-romaine, assez lourde et maladroite, de $60 \mathrm{~cm}$., hauteur exceptionnelle pour les bronzes trouvés en Gaule, a été découvert à Pont-S.-Maxence dans l'Oise. Le personnage est nu; les seins sont féminins mais les bouts ne sont pas marqués; le phallus est très faible; une petite cavité triangulaire s'arrête à la

(1) Par exemple Rensach, Slat., I, 438, 4, 5, 7; II, 405, 3, 4, 5; le bassin que tiennent parfois les Danaides est plus étroit et placé plus bas : I, 441, 5 et 6 ; II, 405, 1 . 
base des testicules comme pour indiquer le sexe féminin ${ }^{(1)}$. Le socle, qui reposait sur des pattes de lion, figure deux marches, semblables à l'entrée d'une piscine; à droite et à gauche sont des rosaces à 8 pétales. Les exemplaires $b$ et $c$ ont un socle identique. La figure devait supporter un objet à la hauteur des hanches, vraisemblablement une coquille de petites dimensions, à en juger par l'écartement des bras; le gauche est brisé.

b) M. Alvarez a remarqué à Rome dans la salle des bronzes du musée des Conservateurs (vitrine 9), un bronze à patine verte de $48 \mathrm{~cm}$, inédit, semble-t-il, du même type que le précédent, mais d'une exécution très supérieure (fig. II). Les seins sont délicatement modelés; les plis du cou sont d'une jeune fille; le torse et le ventre sont harmonieusement composés de traits masculins et féminins. Les bras, largement ouverts, devaient tenir une grande coquille. Entre l'acromion et le cou, le muscle trapèze est renflé, indiquant que les bras supportaient un poids considérable. La statue, qui n'était pas une fontaine, est ithyphallique, ce qui, rapproché du symbolisme de la coquille, souligne la double nature. L'oxydation peu profonde semble indiquer que la statue n'était pas exposée en plein air; peut-être cependant près d'une source d'eau, car les jambes sont plus corrodées que le reste du corps.

c) Un bronze de $1 \mathrm{~m} .20$ de hauteur totale, trouvé au Viminal, actuellement au même musée, représente un personnage semblable à celui de Pont-S.-Maxence. Du dos, partant d'un appendice en ( forme de carquois, s'élève un motif floral presque aussi élevé que la figure elle-même : une tige bizarrement tordue sort de deux volutes en forme de lyre et se termine par une fleur. Les deux bras, intacts, sont largement ouverts. Le membre viril, érigé, est percé d'un trou. La statuette était une fontaine. Elle semble être une copie de la précédente, gâtée par des accessoires de mauvais goût.

(1) Rernscr, qui a signale l'Éros de Pavlovsk et publié cette statuette ainsi que le n० b) (Rev. Arch., 1898, I et II = C.M.R., II, pp 319-37; Stat., II, 176, 7 et III, 54, 3), dit n'avoir jamais constaté ce détail ailleurs; on lui a signalé une statuette en marbre penthée conservice dans les jardins de l'ambassade russe à Thérapeia sur le Bosphore qui aurait la meme particularité. L'emblème des deux sexes figure sur le terme romain signalé rupra, p. 16. 


\section{Type Dionysien}

Presque toutes les statues tardives d'Apollon sont féminoìdes, à tel point que devant plus d'un exemplaire les archéologues se sont demandé s'ils n'avaient pas affaire à un Hermaphrodite $\left({ }^{1}\right)$. Ils auraient souvent répondu affirmativement sans la lyre ou l'arc posés à côté du dieu ; mais ces accessoires ont parfois été ajoutés par des restaurateurs.

Dionysos prêtait encore davantage à l'ambiguité. Il en existe des représentations intentionnellement androgynes. Un marbre de Naples le représente vêtu, élevant le thyrse; la double nature s'accuse sous le vêtement; assez semblable est un petit marbre de Florence, aux pieds croisés (Reinach, I, 373, 3 et II, 791, 7).

Nous rangerons dans ce groupe : $1^{\circ}$ les Hermaphrodites éphèbes, $2^{\circ}$ ceux qui apparaissent dans un contexte bacchique, $3^{\circ}$ ceux que des attributs désignent comme des promoteurs de la fertilité végétale.

1. Ephèbes, - La plus bel exemplaire de ce type, auquel appartient la statuette d'Épinal (supra, p. 25) est l'Hermaphrodite de Berlin (Reinach, I, 372, 2 et 3 ; dessiné dans Herm., p. 88, fig. 1 ; éd. angl., p. 4, fig. 1), réplique hellénistique ou romaine, en marbre, d'un original de style excellent qui pourrait remonter au début du rV $^{e}$ s., c'est-à-dire à un bronze de Polyclète l'Ancien. Le Dr Paul Richer, au t. V (p. 291-306) de son livre Le nu dans l'art, l'a décrit en anatomiste, admirant l'harmonieuse fusion des caractères féminins et des caractères virils. La figure est nue, la tête couverte d'un linge plié. On peut en dire autant d'une statue de Florence (Reinach, I, 367, 6). Celle de Berlin a tenu un thyrse; celle de Florence aussi, probablement, avant une restauration hasardeuse.

2. Contexte bacchique, - Une représentation nous est parvenue en trois états différents, attestant la diffusion du type. C'est chaque fois un personnage androgyne tenant un thyrse, portant une sorte d'écharpe qui flotte entre l'épaule droite et l'avant-bras gauche.

(1) Voir l'Apollon du Vieil-Évreux, publié par Lenormand (Gaz. Arch., t. 1, 1875, p. 34, pl. XI = Rervach, II, 103, 9). Ce qu'il appelle l'Apolline de Florence est probablement Reinach I, 367, 6. Reinach hésite parfois entre Apollon et Hermaphrodite (II, 104, 7). Plus d'une désignation devrait etre corrigée, mais on ne saurait le faire sans avoir vu la statue et mesuré l'importance des restaurations. 
Il se retourne comme pour regarder celui qui le suit, attitude qui est souvent celle de Dionysos lui-même ou des satyres de son escorte.

a) Hermaphrodite d'Athènes $\left({ }^{1}\right)$, plaque de marbre pentélique de $44 \mathrm{~cm}$. sur 33 , la figure a $34 \mathrm{~cm}, 5$ de hauteur. Les cheveux semblent noués sur le haut de la tête, mais il y a peut-être une coiffure malaisée à discerner. Les hanches, les cuisses, le bas-ventre sont h. féminins; le relief des seins a été particulièrement maltraité par le temps; il reste à peine trace de celui de gauche. L'ouvrage, qui est de style ancien, peut être du $\operatorname{III}^{\mathrm{e}}$ s. avant J.-C.

b) Relief Barracco (Reinach, Reliefs, III, 161, 1 ; dessiné dans Herm, p. 88 , fig. 1 ; édit. angl., p. 4, fig. 1), découvert probablement sur l'Esquilin, fragment de $58 \mathrm{~cm}$. sur $45-$ la figure a $53 \mathrm{~cm}$. de haut - d'une grande amphore de marbre. C'est une sorte de copie lagrandie du relief athénien, mieux conservée (le modelé des seins est intact) mais d'un moins bon style, datant peut-être de l'époque d'Auguste.

c) Un grand cratère de Pise (Reinach, Reliefs, III, 108, 2) présente, dans un cortège dionysiaque, une figure identique aux deux précédentes, tournant le dos à une autre qui la reproduit à peu près en miroir.

Sur le relief Barracco un petit Éros ailé précède l'androgyne, tenant une torche inclinée; ce motif manque dans les deux autres.

3. Le dieu double tient des fruits dans sa tunique relevée à la manière d'un tablier.

Sur un petit bronze du Louvre (Reinach, II, 178, 4) une gracieuse figure féminine émerge d'une touffe florale; la draperie relevée découvre le bas du corps et le sein gauche; elle ressemble à une Panesse nue, cornue, posée de même, qui tient un enfant sur le bras gauche (Reinach, II, 72, 6). Un petit bronze de la Bibliothèque Nationale (Babelon et Blanchet, n 310 ; Reinach, II, 177, 7) représente de même, mais très grossièrement, une figure féminine phallique retroussant une tunique pleine de fruits.

Des images de ce genre étaient certainement conçues pour être mises dans des jardins (voir supra p. 28). M. Alvarez a découvert en 1964, dans un corridor de l'administration du musée des Thermes

(1) ReiNuch, Reliefs, II, 352, 4 ; décrit par KIEsERrTZKY dans son article sur l'Hermaphrodite Costanzi (infra, p. 26) dans Annali del Inst., 1882, p. 261, pl. V. 
à Rome (inventaire $n^{\circ}$ 104477) une fontaine de fertilité qui semble | être inédite (fig. III).

La tête a été brisée ainsi que les jambes au-dessous des genoux et les bras au-dessus des coudes. Une étroite ceinture retient la tunique sous les seins qui sont nettement féminins, de même que les cuisses ; relevée à deux mains, remplie de fruits, elle révèle le sexe. Le dos offre un trou au niveau de la cinquième vertèbre lombaire; la pierre a été forée d'arrière en avant à un angle d'environ 30 ; le canal, d'environ $3 \mathrm{~cm}$. de diamètre, a pu contenir un tube de métal qui débouchait sous le tablier; une dépression carrée indique l'endroit où se trouvait le phallus, qui a disparu ; il a pu être redressé à l'horizontale afin que l'eau se répande sous le tablier de pierre et ruisselle à petites gouttes, effet souvent réalisé par ce moyen dans des fontaines et des grottes; il pouvait continuer aussi dans l'axe du canal. En tout cas, la masse du tablier est telle qu'il n'a pu avoir aucun caractère priapique.

Les fontaines anthropomorphiques ont été étudiées récemment par Waldemar Déonna ${ }^{(1)}$. Il a montré tout ce que les inventions baroques des sculpteurs et dessinateurs de la Renaissance doivent à l'antiquité. L'art romain a conçu plus d'une fontaine où l'eau łaillit, soit des seins d'une nymphe, soit du pénis d'un jeune garçon, semblable à celui dont Duquesnoy devait doter Bruxelles. Des enfants rinant figurent avec des Éros ailés sur des sarcophages d'enfani:. Déonna n'a connu, dans la catégorie des fontaines, qu'un seul androgyne, la figure de bronze décrite p. 28 (Reinach, III, $54,3)$, de laquelle les symboles végétaux, à supposer qu'ils aient existé, ont disparu. La fontaine de marbre des Thermes est beaucoup plus significative. Des monuments de ce genre sont restés courants en Italie: on connaît, devant la cathédrale d'Amalfi, surmontée de la statue du patron de la ville, la Fontana Sant' Andrea, où l'eau jaillit des seins de deux nymphes. On met couramment dans les jardins des statuettes représentant un jeune garçon qui retrousse un tablier, son seul vêtement, rempli de fruits. Au cours du voyage à Rome où il découvrit, dans la poussière d'un corridor, la fontaine des Thermes, M. Alvarez vit en plein air deux audacieux petits jardiniers de cette espèce, l'un, qu'il estime pouvoir remonter

(1) La femme aux seins jaillissants et lenfant « mingens» dans Genava, nouv. suite, t. 6, 1958 , p. 239-296; voir p. 263. 
au $\mathrm{XVII}^{\mathrm{e}}$ ou au $\mathrm{xVIII}^{\mathrm{e}}$ siècle, dans le jardin de l'ambassade des tatsUnis, un autre près de la Trinité des Monts: ouvrages modernes, mais inspirés par des modèles antiques; ils ne portent toutefois aucun indice de bisexualité.

Remarquons ceci: Dans toutes des statues d'Hermaphrodite, si un seul sein est nu, c'est toujours le gauche. Il en est ainsi, on l'a vu, dans les trois reliefs «bachiques» décrits p. 30 . Le personnage de la fontaine des Thermes porte une sorte de chemise qui dégage l'épaule gauche et qui est retenue par le relief du sein. Les visiteurs du musée de Naples peuvent y voir exposées des statuettes androgynes, modernes certainement, mais peut-être copiées d'un modèle antique ( $\left.{ }^{1}\right)$, dont le sein gauche est également dévoilé. Mentionnant, du côté de la Scythie, le peuple des Androgynes, Pline ajoute: "Aristote dit que chez tous le sein droit est celui de l'homme, le gauche celui de la femme» (VII, 15-16). Sculpteurs et peintres ont toujours représenté l'être double avec des seins identiques, nus ou voilés, mais, lorsqu'ils n'en dévoilent qu'un, c'est invariablement le gauche, convention qui n'existe pas dans les statues d'Aphrodite. Ils n'avaient pas besoin d'avoir lu Aristote pour savoir que le côté gauche est celui de la femme $\left.{ }^{2}\right)$. Hermaphrodite, dieu de la génération, n'engendre pas. Empédocle, Platon, Lucrèce, ont insisté sur l'impuissance d'un être double à se reproduire. Du même fond peut-être, Héra, déesse nuptiale, enfante sans époux et Artémis, invoquée des femmes en gésine, est vierge. Il fallait néanmoins que la mamelle découverte fût la plus féminine des deux.

\section{Type Priapique}

Il n'est pas rare de voir le dieu double associé, non seulement avec Pan et Silène, mais aussi avec Priape. Ce sont surtout des

(1) Toutes les vitrines de la salle LXXX du musće de Naples reposent sur des statuettes d'environ $50 \mathrm{~cm}$ représentant un hermaphrodite ailé, vêtu seulement d'une nébride retroussée remplie de fruits; il émerge d'un culot de feuillage issu d'une patte de lion. On aimerait connaître le modèle, probablement ancien, de cette étrange synthèse, dont la présence, dans un endroit ouvert à tous, montre à quel point une certaine imagerie antique est restće vivante dans le monde méditerranéen (cf. supra, p. 19).

(2) Baumans, Doppelie Geschlecht, p. 124 a montré ce qui reste d'imagerie dualiste dans les idées des anciens relativement à la conception, au rôle de la droite et de la gauche dans leurs rapports avec de l'être humain. 
peintures. Dans une région montagneuse, un Hermaphrodite retient un petit Pan qui le regarde avec effroi et qui veut fuir; à côté est un petit temple avec un terme de Priape. Ailleurs, un Hermaphrodite est paré par deux jeunes filles aidées par un Éros; un Priape lui tend le miroir $\left({ }^{1}\right)$. On pourrait multiplier ces exemples qui, le plus souvent, attestent surtout l'ingéniosité de l'artiste. Cette * contiguité permet d'expliquer un petit bronze de la Nationale (Babelon et Blanchet, p. 137, n³08), représentant un Hermaphrodite nu, agenouillé. On n'en possède, je crois, aucun autre de ce type, mais on connait des Silènes, des satyres, des Priapes dans cette attitude qui fait communiquer avec la terre la force incluse dans les genoux $\left({ }^{2}\right)$. Le petit personnage, au surplus, n'est nullement ithyphallique ; nous avons signalé quelques androgynes qui le sont, (pp. 16, 18, 28) ; ils constituent une exception; l'indication est généralement sommaire, presque schématique.

\section{Hermaphrodite couché}

Il est probablement inutile de chercher une signification religieuse aux nombreux ouvrages hellénistiques et romains qui donnent à un Hermaphrodite féminoīde, attaqué par Pan, repoussant un Faune, une place souvent occupée par une Nymphe ou une bacchante; ils ne révèlent guère que l'ingéniosité des artistes.

Il n'en est pas de même de l'Hermaphrodite couché. Il est parfois étendu sur le dos, le buste plus ou moins redressé, comme les personnages symboliques représentant un Fleuve ou une nymphe. Promoteur de la fertilité, il pouvait alterner avec une divinité des caux. On ne s'étonnera pas de le voir dans ce rôle : certaines figurations de Hapi dieu du Nil conjoignent la barbe, des seins féminins et une indication de grossesse. Tel est un Hapi égyptien du Musée de Boston (bas-relief, vers 1350 avant J.-C.). Reinach signale deux hermaphrodites allongés (Stat., I, 338, 6 et 436, 3), tous deux en Angleterre, qui ont été mutilés intentionnellement pour figurer des

(1) Voir Hans Herter, De Priapo, Giessen, R.V.V., 1932, p. 138, n॰ 38 ; p. 130, n॰ 9 ; p. 16 , n० 199 ; Renvach, Peintures, 99, 2 ; 98, 1.

(2) Sur les Priapes à genoux, voir Herter, p. 98. Il y aurait une recherche à faire sur le symbolisme phallique des genoux et du menton, en grec, en latin et ailleurs. - Quelques petits bronzes romains de la Nationale (BAarLon et BLANCHET, 499 à 502) montrent des Priapes ithyphalliques tenant des fruits dans leur giron. 
nymphes des fontaines. Une recherche systématique en ferait certes découvrir d'autres.

Beaucoup plus énigmatique est le type le plus célèbre, où la figure à demi vêtue est couchée sur le côté, le ventre nu tourné vers la terre. A l'époque où une typologie n'était qu'un chapitre d'histoire de l'art, Reinach proposa de voir là une variante de la ménade - endormie, épuisée par une longue course. Mais les personnages endormis (Endymion, Ariane, Silènes, Faunes) sont couchés sur le dos. Une autre explication a été proposée en 1903 par le Dr. von Römer, rappelant le vieux thème légendaire d'un être naissant de la terre où est tombée la semence d'un dieu: c'est ainsi que Posidon fait naître le cheval ; qu'Héphaistos fait naître Érichthonios ; que de Zeus endormi (ou épris de Rhéa), naît Agdistis, qui a les deux natures. Le pouvoir générateur d'Hermaphrodite ne saurait être que purement symbolique, car pour lui également vaut la définition que Dümmler a donnée d'Éros: «Ein doppelgeschlechtiges Wesen ohne Zeugungskraft ». Elle résume la pensée des philosophes. Les anthropogonies d'Empédocle, de Platon, de Lucrèce, comportent, à l'origine, des êtres doubles qui, doués des deux puissances, sont incapables d'en exercer aucune: erreur de la création qui, chaque fois, a dû être corrigée. L'idée même de cette retouche accuse l'hiatus qu'il y avait, dans la pensée grecque, entre un archétype de la pérennité humaine et la répulsion devant toute déviation du type normal.

Si l'Hermaphrodite agenouillé était moins mal représenté nous ne le connaissons que par le petit bronze qui vient d'être signalé -, il nous donnerait peut-être une transition entre tant de figures debout et cette seule figure étendue face au sol. Le Dr. von Römer a étudié en médecin les exemplaires conservés qu'il divise en deux groupes (p. 878 sqq.). Les uns expriment un paroxysme qui se détend: telle est la statue Costanzi, aux Thermes (Reinach, II, 177, 9) et celle du Louvre (I, 153). Dans les statues de Florence (I, 371, 6) et de la galerie Borghèse (II, 178, 1), ce moment est passé, le sommeil est proche $\left({ }^{1}\right)$. Römer a très bien vu que ce sont

(1) Kresertraky (voir n. 29) en 1882 avait exactement décrit et distingué les deux types, sans en voir la valeur symbolique. - Un critique italien, Al. Parroschi, Sul probabile tipo del Cupido dormiente di Michalangelo dans Arle antica e modema, t. 27, 1964, p. 281-94, estime que pour cette cuvre perdue et aussi pour le Christ de la Pietà de S. Pierre, « un mort qui doit se réveiller», l'artiste a été influencé par l'Hermaphrodite 
les œuvres du premier type, dans leur impudeur apparente, qui ont saisi une signification véritable: " Das höchste körperlich-ekstatische Moment der All-Natur darzustellen verrät tiefen religiösen Sinn; das Moment der Erschlaffung zu reproduzieren, aber, eine oberflächliche Auffassung jener originellen Darstellung, als gebe sie nur die sexuelle Erregung wieder» (p. 883).

Cette signification, pour être évidente, requerrait le contact de l'être avec la terre. Les ouvrages que nous connaissons l'étendent sur son vêtement. De fâcheuses restaurations le font parfois reposer sur un matelas capitonné d'assez mauvais goût, qui pourrait bien remonter au Bernin (Louvre, Florence, et Reinach, II, 178, 5).

On aimerait savoir ce que les anciens ont éprouvé devant ces œuvres étranges, tout à fait différentes des types précédents, puisqu'clles sont seules à attribuer un acte à ce qui n'est ailleurs qu'une puissance. L'explication de Römer permet de saisir une intention de l'artiste qui travaillait peut-être d'après une légende perdue. Mais cette intention, encore qu'elle aille dans la direction générale du symbole, y introduit une disparate capable d'en altérer la signification.

\section{ATTRIBUTS}

Quelques objets d'interprétation assez claire apparaissent à côté du dieu double. Le calathos, représenté uniquement sur la statue de Stockholm (supra, p. 19) accuse une parenté avec Déméter; les colliers et le miroir, avec Aphrodite; le thyrse, avec Dionysos. Restent deux accessoires qui méritent quelque attention.

Plusieurs figures ont sur la tête un morceau d'étoffe rectangulaire, plié, assez semblable au mouchoir dont les femmes italiennes se couvrent symboliquement les cheveux pour entrer dans une église. On le distingue nettement sur les statues de Berlin (Reinach, I, $372,2$ et 3$)$, de Florence (I, 367, 6) ; celles de Londres (I, 370, 6),

de Florence. L'hypothèse donne à réfléchir. Elle prouve en tout cas à quel point les Italiens, artistes et critiques, ont abordé l'antiquité de plain-pied, sans être encombrés par nos préjugés. Cf. Suz. Collon-Gevaerr, Le Christ mert de Jean Del Cour, dans Chron. arch. du pays de Lilge, 57• année, 1966, p. 16. 
de la collection Hirth à Munich (III, 54,6) ont, posé sur le sommet de la tête, un bandeau dont les pans retombent sur les épaules, ainsi qu'on le voit à certaines statues d'Isis (I, 155, 5). L'Hermaphrodite de la Tamise se le noue sur la tête (II, 276, 1). Même coiffure sur un bronze de Carlsruhe (II, 176, 8), qualifié Apollon par une inscription étrusque gravée sur la figure, mais évidemment androgyne. Aucun autre Apollon n'a semblable coiffure. Elle est d'autant plus frappante que le personnage, chaque fois, est nu. H. St. Jones la signale sur un double hermès aux têtes identiques, "de sexe indécis», de la salle de la Colombe au Capitole, pour lequel il suggère prudemment « a derivation from a Hermaphrodite-type of the later Greek period ». Étudiant ce que les Romains ont appelé calvatica, calantica ou calautica, mot d'origine inconnue désignant une coiffure portée surtout par les femmes, E. Wuescher-Becchi $\left(^{1}\right)$ en a remarqué la présence sur plusieurs Hermaphrodite. Elle y voit une adaptation du kleft, la coiffure de Hathor, d'Isis, qui passa en Grèce propre, en Grande-Grèce et à Rome, avec plusieurs formes comportant toutes un moyen de l'attacher au front ou au cou de façon à faire une sorte de coiffe aux pans tombant sur les épaules. Celle de nos statues, qui n'est fixée à rien et qui tomberait au moindre mouvement, n'en est qu'une stylisation. Celle de Berlin en est la forme la plus schématique; celles de Londres et de Munich accusent la ressemblance avec Isis; les autres sont plus proches de la réalité.

Isis avait des aspects androgynes (Plut., Isis., 43). La tête de l'Hermaphrodite Chablais, qui pour l'attitude fait penser à la déesse égyptienne, est malheureusement une restauration moderne et nous ne pouvons juger de ce qu'était la coiffure. Il ne semble pas que c'était une calautica; celle-ci au surplus, portée surtout par des femmes, apparait sur des statues qui toutes, sauf celle de Londres, sont de type éphébique: était-elle destinée à compenser par un élément féminin la dominante masculine?

Un autre accessoire est le linge qui pend sur une borne - ou une cruche? - à côté du personnage, sur la statue Chablais (supra, p. 21), sur un marbre de Naples (I, 373, 1), sur celui de Berlin et sur celui de Munich, ces deux derniers coiffés de la calautica. Est-ce

(1) H. St. Jones, A Catalogue of the Museo Capitolino, p. 148; E. Wuescher-Becchl, Il palliolume e la caloatica, dans Bull. della Commissione arch. comm. di Roma, 1901, p. 109-123. 
une allusion au bain nuptial? Il ne faut pas attacher trop d'importance aux supports dont les sculpteurs étaient obligés de soutenir un personnage debout lorsqu'ils copiaient en marbre un original en bronze.

Nous pouvons, ici, faire le point.

1. Les monuments du culte semblent avoir été de simples termes portant le double symbole sous une forme plus ou moins concrète.

2. La représentation qui s'en rapproche le plus donne à l'être double les traits de Déméter. Aucune contiguité légendaire n'explique cette ressemblance. Les relations qui la supportent n'ont abouti, à notre connaissance, à aucune formulation explicite. Elles sont du reste sous-jacentes aux fêtes de Déméter, où se pratiquaient les mêmes aischrologiai qu'aux Hybristika d'Argos et où figuraient les emblèmes des deux sexes, non toutefois toujours réunis ${ }^{(2)}$.

3. Alors que les rites nuptiaux du travestissement supposent une puissance accrue par superposition, l'Hermaphrodite Chablais est le seul monument connu qui présente explicitement l'être double, avec une simplicité pleine de noblesse, comme promoteur de la fécondité humaine. Le bronze du Louvre (supra, p. 26) en donne une image symbolique. Le rôle humain du dieu n'apparaît nulle part ailleurs dans l'art. Son rôle végétal en revanche a de nombreuses illustrations.

4. De nombreuses pièces le rapprochent d'Aphrodite, qui d'après la légende était sa mère. On s'attendrait à lui trouver aussi des traits d'Hermès, son père. Il n'en est rien. Nous devrons toutefois revenir sur le triple terme Chablais (Reinach, I, 329, 2) où figure, entre Aphrodite et Hermès, un Hermaphrodite identifié à Éros. Il est isolé. En revanche, le dieu double est souvent entouré d'un symbolisme végétal qui rappelle le décor de Dionysos, ou de personnages qui composent le train du dieu.

5. Alors que plusieurs témoignages anciens le rapprochent de Priape, il n'offre qu'exceptionnellement une ressemblance concrète, et toujours atténuée, avec lui.

(1) Nrusson, Griechische Feste, p. 322. 
Points de contact avec Priape dieu des jardins, avec Aphrodite,

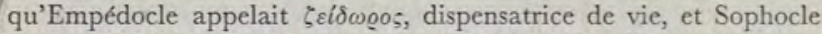

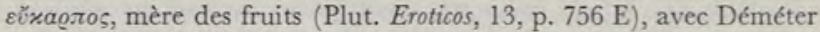
et Dionysos, qui représentent les deux formes essentielles de la vie végétale (on se souvient du couplet de Tirésias à Penthée dans les Bacchantes): alors que les travestissements doivent promouvoir la I fécondité humaine, les représentations du dieu double suggèrent bien davantage une action sur la fertilité de la terre. Mannhardt dans ses Wald- und Feldkulte fut le premier, en 1875, à insister sur l'importance et la signification des travestissements rituels dans les fêtes de la moisson à travers toute l'Allemagne. Après avoir réuni, dans le monde entier, des coutumes où une juxtaposition purement allusive des deux sexes doit fortifier les êtres humains et leur assurer une descendance, $\mathrm{H}$. Baumann constate que seuls les peuples agriculteurs ont des croyances et des rites impliquant la vertu de la bisexualité. Les civilisations reposant sur la chasse et la cueillette n'ont aucune conception sexuelle du monde (Doppelte Geschlecht, p. 40 ; voir aussi 163).

Les Grecs au contraire ont senti une parenté profonde entre la plante et l'animal. Ils désignent par le même nom les parties des plantes et celles des animaux, les muscles étant homonymes des fibres, le sperme de la semence, les veines appartenant aux deux règnes. Aussi ont-ils attribué un sexe aux plantes. Ainsi pensent, dit Théophraste (Recherches sur les plantes, III, 9, 6; III, 12, 2), les Macédoniens, les gens de l'Ida. Les bûcherons (III, 9, 3) affirment que la distinction entre mâles et femelles existe chez tous les arbres. Cette sexualité ne correspond pas à ce que nous nommons ainsi, mais à des caractères extérieurs de proportions et de robustesse : on désignait comme mâle ou femelle des variétés légèrement différentes d'une même espèce. Bien avant Théophraste, on l'avait dit du palmier-dattier, du sapin, du hêtre, du cornouillier. Pline dira plus tard: «Les meilleurs connaisseurs de la nature affirment que les deux sexes existent, non seulement dans les arbres, mais dans toutes les plantes que produit la terre» (XIII, 7). Ces "connaisseurs» répétaient simplement ce que tout le monde pensait, la notion de sexualité chez les plantes ne résultant nullement d'un examen de la réalité, (mais d'une vue de l'imagination. Toute vie est venue de la terre, omniparens :

X genuit tellus eadem quae nunc alit ex se (Lucr. II, 1156). 
Elle continue de nourrir les hommes et les animaux dont elle a émis la première souche. Les végétaux sont donc la preuve par excellence de sa force génératrice et la meilleure illustration de l'idée de fertilité (1).

Comme Priape, Hermaphrodite est pour elle une puissance tutélaire. Ils ne se confondent pas. Le second n'est jamais « viril au-delà de la mesure", comme dit joliment Lucien à propos du premier. Il est vrai qu'à la fin de l'antiquité, quand le Priape barbu et un peu grotesque reçut quelque grâce et quelque beauté, on peut parfois, devant certaines peintures, hésiter entre l'un et l'autre. Mais les croyances les distinguent. Démon de la vie rurale, Priape fait abonder les fruits de la terre et les naissances parmi les troupeaux. Un seul texte fait de lui un promoteur de la fécondité humaine et il est suspect : saint Augustin ne lui attribue ce rôle que pour ravaler l'ancien paganisme en prêtant à Junon un auxiliaire dont elle ait à rougir (De consensu Evang., I, 25).

Priape, de plus, est apotropaique, ce qu'Hermaphrodite ne semble pas avoir jamais été : on le représente bifrons afin qu'il puisse surveiller les deux côtés de l'enclos. On le vénère dans les jardins, les vignes, les forêts ; on place ses images sur les clôtures; on les pend aux arbres, on les met en contact avec les pierres et avec le sol. A l'époque ancienne, elles ne sont jamais sous toit. Plus tard, quand le sens primitif du dieu agreste se fut altéré, elles apparurent dans des lupanars $\left({ }^{2}\right)$. On a retrouvé au contraire quantité de figurines d'Hermaphrodite destinées à être suspendues dans les maisons. Et son image devenait un thème de réflexion pour les philosophes tandis que Priape était honoré par les paysans.

(1) L'image de la végétation informe l'animisme généralisé qui, jusqu'au début du siècle dernier, domina les conceptions relatives à la nature, minérale aussi bien qu'animale. « Il semble que la végétation soit un objet vénéré par l'inconscient. Elle illustre le thème d'un devenir tranquille et fatal » dit G. BAcheLARD, Formation de lesprit scientifique, 1938, p. 153 ; sur son rôle dans la médecine antique, cf. R. Joty, Le niveau de la science hippocratique, 1966, p. 97.

(2) Hans Herter, De Priapo, Giessen, pp. 78, 187, 225, 245. 


\section{LE CULTE D'HERMAPHRODITE}

Nous pouvons essayer à présent de préciser ce que fut le culte d'Hermaphrodite à partir du rv ${ }^{e}$ siècle jusqu'à la fin de l'antiquité. Nous n'avons pu ici qu'esquisser le cadre d'une iconographie. Plus complète, elle apprendrait plus à l'historien de l'art qu'à celui qui cherche à saisir un être mythique et les croyances qui l'entourèrent. De modestes figurines en terre cuite sont sur ce point révélatrices, ne serait-ce que par leur grand nombre et leur diffusion sur toute l'étendue de l'ancien monde.

Pendant trop longtemps, on n'a voulu voir dans les productions des arts mineurs à l'époque tardive que des œuvres de genre dont les détails résultent uniquement de la fantaisie d'un artiste. Avec sa perspicacité habituelle, Déonna fit remarquer que les créations du paganisme finissant sont souvent plus près du symbolisme primitif que celles de la Grèce parvenue à sa maturité. Il proposait une explication: des influences orientales auraient « en quelque sorte ramené à leurs origines les vieux thèmes dont le sens s'était peu à peu obscurci dans l'art classique» (R.H.R., t. 80, 1919 p. 22). Je verrais plutôt, dans cette fidélité, une caractéristique de la dévotion populaire. Des catholiques de culture moyenne mettent sur leur cheminée, plutôt qu'une reproduction de Michel-Ange ou de Fra Angelico, une statuette sulpicienne où les significations se marquent par des emblèmes très simples, qui sautent aux yeux et se comprennent sans hésitation possible. Un rigoriste pourra admirer au point de vue esthétique un crucifix archaique ou une interprétation d'artiste, sans estimer pour autant que, suspendu dans la salle commune, un tel objet marque suffisamment l'attachement à une croyance. Un crucifix banal en dira davantage, justement parce que toute sa valeur est dans ce qu'il veut dire.

Il existe certes quantité de représentations petites et sommaires des grands dieux. Le type de l'admirable statue en bronze de Zeus lanşant la foudre, retrouvée au large de l'Eubée et placée à présent au musée d'Athènes, était connu depuis longtemps par de grossières reproductions découvertes à Dodone et à Oympie. Beaucoup plus nombreux toutefois sont les Éros, les Éros androgynes, les androgynes non ailés qui furent révélés par les fouilles. Ces objets ont peuplé les maisons, posés ou suspendus, parfois associés à un support; ils ont orné les jardins; ils ont été par dizaines déposés dan? 
des tombeaux. Nous n'avons aucune raison de douter du témoignage de Théophraste lorsqu'il décrit le Superstitieux honorant les Hermaphrodites (au pluriel) qui sont dans sa demeure.

Précisément, a-t-on dit, il n'y a là ni religion, ni culte, mais seulement superstition. Cette distinction n'est plus recevable. Elle pourrait se concevoir, au moins théoriquement, face à une doctrine capable d'établir des critères et, d'après eux, une frontière, ce qui ne fut jamais le cas dans l'antiquité. Cicéron, il est vrai, oppose la superstitio, timor inanis deorum, à la religio, cultus pius deorum.

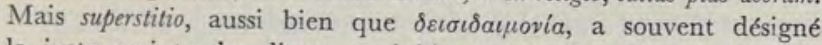
la juste crainte des dieux, aussi bien que celle qui est excessive. Théophraste décrit son Superstitieux comme un homme obsédé de scrupules: en profondeur, quelle différence y a-t-il entre eux et ceux qui sous-tendaient les rites pratiqués par l' tat athénien ou le cultus pius de Rome? "Praktisch genommen lassen sich Glaube und Aberglaube nicht unterscheiden", dit Goethe en une formule dont Wilamowitz et Nilsson ont méconnu la force. «Beim Glaube kommt alles darauf an, dass man glaube; was man glaube ist völlig gleichg ltig». Il ajoute : "Mit dem Wissen ist es gerade das Gegenteil; es kommt nicht darauf an dass man wisse, sondern was man wisse, wie gut und wieviel man wisse». Devant une effigie, comment savoir si elle a figuré un être vénéré (auquel cas nous parlerions de religion), ou si le culte s'est adressé à elle-même (il s'agirait alors d'idolâtrie) ou si l'objet est doué en soi d'une efficacité immédiate? Que ceux qui croient à ces distinctions autrement que comme catégories de la pensée essaient d'en faire usage, dans S.-Pierre de Rome, devant la statue du premier apôtre dont le soulier de métal est remplacé périodiquement après avoir été usé par les baisers des fidèles. La statue est à la fois représentation, idole et talisman, non pas en elle-même, mais d'après le sentiment de celui qui l'aborde. Étudiant la Déesse nue babylonienne, qui désigne ses seins comme Aphrodite, qui écarte ses voiles comme Hermaphrodite, Contenau dit (p. 10) que l'image dut n'être d'abord que talismanique, que plus tard elle figura sur un petit socle comme une idole. Disons plutôt qu'elle fut talisman pour les uns, idole pour d'autres.

Situons la vénération des Hermaphrodites parmi les autres pratiques du personnage de Théophraste. Il redoute les belettes, les serpents, les chouettes; après s'être inondé d'eau sainte au temple, il garde toute la journée une feuille de laurier dans la bouche; il 
inonde d'huile les pierres des carrefours et s'y agenouille; il n'est jamais sûr d'avoir assez purifié sa maison, tant il craint de la voir hantée par Hécate; il refuse de s'approcher d'un mort ou d'une accouchée; il crache sur sa poitrine quand il rencontre un fou ou un épileptique ; il fréquente les exégètes, les devins, les augures pour savoir à quel dieu ou déesse il doit sacrifier après un songe; avant de se faire initier, il consulte les Orphéotélestes. Ce Superstitieux est un traditionnaliste, car tout cela relève des plus anciens tabous. Le seul dieu étranger mentionné ici est Sabazios, Thrace comme Dionysos et assez semblable à lui, qui s'introduisit à Athènes pendant la guerre du Péloponèse. Il n'est pas même dit que l'homme participe à ses mystères, mais simplement qu'il l'invoque - de même qu'il invoque Athéna lorsqu'il voit une chouette - quand apparait dans sa maison un de ces serpents qu'on appelait des joufflus, et que manipulaient les fidèles du dieu, ainsi que Démosthène raille Eschine de l'avoir fait (Couronne, 259). Toutes les autres observances font partie de ce que Murray appelait «the inherited conglomerate». E. R. Dodds a montré comment celui-ci s'accrut dans Athènes - seule partie de la Grèce où nous puissions inscrire les phénomènes religieux dans une perspective historique lorsque les malheurs de la guerre y provoquèrent une forte réaction contre le rationalisme des poètes et des philosophes et un recours massif à ce que ceux-ci eussent considéré comme des superstitions : introduction du culte d'Asclépios en 420, des rites de Sabazios, probablement vers la même époque ( $\left.{ }^{1}\right)$.

C'est alors aussi, semble-t-il, que des croyances relatives à l'efficacité des deux puissances superposées, attestées depuis longtemps par les rites de l'échange des vêtements, se fixèrent sur un daimon personnalisé. Il devint le centre de pratiques anciennes, puisque le Superstitieux l'honore le quatrième jour du mois qui, dit Hésiode, convient, à condition que les présages soient propices, pour amener une épouse dans la maison; et Proclus, dans sa note au vers 800 des Travaux, déclare ce jour consacré à Aphrodite et à Hermès et, à cause de cela, propice aux unions $\left({ }^{2}\right)$. Croyances et pratiques

(1) E. R. DODDs, The Greeks and the irrational, 1956, ch. VI et R. CraHAY, La religion des Grecs (1965). p. 140-142.

(2) Le 7* jour, dit encore Hésiode, convient pour jeter sur l'aire le blé sacré de Déméter; selon Proclus, c'est un bon jour pour un nouveau-né. Mais le texte de Théophraste, taí Éodouáat, semble altéré et il semble imprudent d'en rien conclure. 
trouvèrent dans l'Athènes de 400 de bonnes conditions pour cristalliser autour d'un symbole sans légende qui avait valeur de talisman. La peste et la guerre en effet avaient réduit la population de l'Attique, au surplus fort appauvrie. Tout poussait à honorer un daimon de la fertilité. C'est en Attique que l'on trouve deux des seuls témoignages explicites attestant un culte et ils sont contemporains : entre 400 et 385 . Nous ignorons totalement comment il se fit que le dieu double reçut un nom, mais ce nom, qui est grec, le rattache à une mythologie toute hellénique.

Nilsson, dans son puritanisme, a reculé devant l'idée de lui faire place dans sa Geschichte der griechischen Religion. Comment n'a-t-il pas vu qu'il devait du moins l'introduire dans sa Religion populaire de la Grèce antique (1954) ? Accueilli avec une faveur qu'il doit principalement au nom de son auteur, cet ouvrage traite les croyances du peuple comme des entités distinctes, alors qu'il suffit de les examiner avec quelque attention pour voir s'effacer les frontières qui sont censées les séparer des conceptions attestées dans les cultes officiels. Toutes résultent des mêmes images enracinées dans l'inłconscient. Cette homogénéité est évidente en ce qui concerne Hermaphrodite. Ceux qui ont mis son effigie dans leurs demeures, dans leurs jardins, dans les tombeaux de leurs proches, étaient peutetre de petites gens, ainsi que la modestie des figurines le donne à penser. Mais l'archétype qui a donné naissance au dieu double est un de ceux qui ont le plus occupé l'esprit humain.

On le trouve en Grèce à tous les niveaux de la pensée. Le rêve d'un androgyne primitif, tel qu'il apparaît dans le Banquet, est un mythe authentique dont il existe des variantes dans plus d'une mythologie, avec, le plus souvent, une valeur anthropogonique sous laquelle une valeur cosmogonique se laisse parfois deviner. On a pu se demander si la castration d'Ouranos ne correspondait pas à une version plus ancienne (dont on trouve des variantes ailleurs) où un seul être primitif est coupé en deux pour former le Ciel et la Terre. A un autre pôle figurent des dévotions familières, dans les maisons et les jardins, sur les chemins, probablement aussi en marge de certains sanctuaires, trop petitement pour que Pausanias ait jugé nécessaire de les mentionner, à cause précisément de leur banalité. On pourra en dire à peu près autant d'rÉos, à la fois puissance cosmique et objet de vénération domestique: Éros qui est souvent représenté avec les deux natures.

Un inventaire des terres cuites atteste leur étroite parenté. Celui 
de Franz Winter a fait connaître quantité d'Hermaphrodites, ailés ou non. Presque tous les types qu'il a groupés existent en plusieurs exemplaires, non identiques mais semblables, des provenances les plus diverses. L'être double est généralement figuré sans accessoires. Il n'est jamais priapique, rarement ithyphallique. Les deux natures sont, le plus souvent, indiquées avec une telle discrétion qu'on peut hésiter à les reconnaître ${ }^{1}{ }^{1}$. Nulle part ne se révèle rien de cet " intérêt malsain" où les archéologues du xix ${ }^{e}$ siècle ont voulu voir l'origine de cette représentation. La signification de ces figurines est celle d'une image de saint Calogero à Syracuse ou de sainte Thérèse en Normandie, mais avec un rayonnement beaucoup plus étendu, car on en a trouvé depuis le proche Orient jusqu'en Gaule. Quant à savoir si elles étaient objets de vénération ou si elles avaient valeur de talisman, il faudrait, pour en décider, avoir pu pénétrer dans l'âme des usagers, lesquels auraient probablement eu quelque peine à comprendre la distinction.

Laissant de côté de nombreuses statuettes assez insignifiantes et à peu près identiques, ainsi que celles qui tiennent un coq, sur lesquelles je reviendrai (p. 65) signalons quelques pièces énigmatiques : ঠun quadrupède ithyphallique, provenant probablement de Tanagra, terminé en buste de femme tenant un enfant; une autre représenotant une figure androgyne assise en amazone sur un bélier; un petit marbre mutilé découvert par M. Alvarez dans un corridor du musée des Conservateurs (invent. 1822), représentant un androgyne nu - chevauchant un animal qui est peut-être un bouc. Il existe plus d'un Dionysos sur un bouc (Reinach, Stat., I, 389, 3 ; II, 133, 1 et 2, marbres). Ils sont nus, comme celui-ci, avec une sorte d'écharpe qui retombe sur le dos de la monture, et ils ont la même cambrure en arrière. Mais ce sont des putti, tandis que le marbre romain montre un corps nettement féminin qui n'est nullement celui d'un enfant; le ventre est gras et même proéminent, la taille mince; il s'agit d'une jeune femme bien développée; l'organe viril a été sculpté avec une grande précision. Ces œuvres bizarres peuvent être de pures fantaisies; elles peuvent aussi correspondre à des représentations dont la clef nous manque encore.

(1) Wreter, Terrakotten, Hermaphrodites non ailés, II, 352, 8, 9; 355, $8 ; 356,3$; 358,4 ; douteux, non indiqués comme tels : 286,$4 ; 357,4 ; 359,8 ; 362,4$; tenant un coq, t. I, 181, 5; 182, 3 ; chevauchant un animal, I, 36, 2 et 163,7 , duquel il existe au moins deux exemplaires, l'un à Berlin, l'autre à Athènes; le $\mathrm{n}^{\circ} 165,5$ semble aussi un androgyne; quadrupère androgyne p. 36, 2. 


\section{SON PROPRE JUMEAU}

Dans son étude de 1851 sur le Liebesgott, Jacob Grimm chercha dans la mythologie germanique des correspondances à l'Éros androgyne sur lequel Gerhard avait attiré l'attention. Il y écrit : «Das Mannweibliche bricht vor in dem Doppelnamen Freyr und Freyja », ajoutant que la légende ne leur a jamais prêté aucune descendance. Admirable divination, à une époque où aucune recherche ethnographique, en révélant des faits surprenants, n'avait encore éclairé latéralement l'archétype de la bisexualité de façon à en faire saisir les significations cachées. Il voit Freyr et Freyja comme nous voyons Faunus et Fauna, Tellurus et Tellus, Liber et Libera, Ruminus et Rumina, paires composées par l'esprit pour épuiser les aspects d'une puissance unique, conçue plus ou moins consciemment comme douée des deux natures. Comme Freyr et Freyja, les couples latins, toujours stériles, sont des divinités paysannes, promoteurs de la fécondité sous toutes ses formes. Un Cerus, peut-être la plus ancienne dénomination latine pour un être divin de cette sorte, fut tôt oublié au profit de Cérès. Liber, dieu de la vigne, dit saint Augustin (Cité de Dieu, IV, 11), l'est aussi de la fécondité des hommes (virorum seminibus) et Libera de celle des femmes. Et il s'étonne (VII, 11) que pour allaiter les animaux il ait fallu donner à Jupiter Ruminus une obscure parèdre, Rumina, au lieu de le désigner tout d'un coup comme Ruminus et Rumina, puisque Soranus l'appelle progenitor genitrixque.

On rapprochera de cette idée de Grimm ce que Baumann rapporte (pp. 82-128), d'après les recherches de Marcel Griaule et de Germaine Dieterlen, sur les conceptions des Dogons du Niger relativement à la dualité de l'âme au moment de la naissance. Le nouveau-né en reçoit deux ; plus tard se dessine le sexe qui sera le sien. Mais toujours subsiste en lui quelque chose de l'androgynie primitive: curieuse entrevision de la théorie de Jung sur l'animus et l'anima. Dans cette conception, celui qui garde les deux sexes est donc son propre jumeau.

Rien dans la mythologie grecque et latine ne rappelle exactement les paires germaniques et latines. Mais un curieux petit monument donne à réfléchir. C'est un groupe en marbre de la collection Dattari, trouvé en 1905 sur l'emplacement de l'antique Memphis 
et publié par Déonna. Une Aphrodite Anadyomène est accostée à sa gauche par deux enfants nus, un garçon à droite, une fille à gauche, qui s'étreignent si étroitement qu'ils semblent collés l'un à l'autre. Déonna signale une terre cuite romaine qui traite le même sujet. Les deux enfants ne s'embrassent pas; chacun touche le sexe de l'autre. On pourrait y ajouter un petit bronze de la Nationale où un homme et une femme nus, de même taille, et, sauf le sexe, identiques, sont debout, les bras enlacés, l'autre main posée sur la hanche $\left(^{1}\right)$.

On peut se demander si les groupes décrits par Déonna, et peutf être le troisième, ne représentent pas une sorte de dédoublement du dieu double, celui-ci étant ramené aux deux jumeaux dont il est la synthèse. Il y a quelque chose de semblable dans une peinture de Pompéi $\left({ }^{2}\right)$. Le personnage androgyne et ailé décrit ci-dessus (p. 32, n. 1) est transformé en un couple volant. Un jeune garçon relève de la main droite un tablier plein de fruits et regarde gravement une jeune femme dont le vêtement flottant ne couvre que les jambes et, derrière elle, gonflé par le vent, forme comme une aile. Elle tient une hampe de la main gauche et pose la droite sur l'épaule du garçon qui, de la gauche, lui prend la taille.

On objectera qu'il s'agit là d'une œuvre banale et que Pompéi a donné plus d'un échantillon du couple dansant. Aucun autre, toutefois, ne porte le tablier plein de fruits. Il faut remarquer aussi que ces peintures ne s'inspirent nullement de la danse telle qu'elle était pratiquée dans l'antiquité. Le pas de deux était connu, mais l'homme et la femme dansaient séparés; c'est très rarement et seulement sur des monuments tardifs qu'ils se touchent ou se tiennent par la main. Leur gesticulation semble toujours avoir une valeur mimétique. Je ne pense pas qu'il faille voir dans les couples volants fde Pompéi une imagerie bacchique ou amoureuse inspirée d'une

(1) Déonsa, Rev. Arch., t. 8, 1918, p. $130=$ Renvach, Stat., IV, 230, 4. Déonna suggère de voir dans le groupe Dattari un "cadeau de noces» pour jeunes époux. - BAbeLon et BLANChet, n॰ 805 = RenNaCh, II, 519, 3 ; voir aussi IV, 324, 1 et, un peu différents, IV, 321, 3 et 4 . Un motif analogue a été utilisé comme poignće sur des cistes de Préneste (II, 520, 1) ; voir Mon. dell Inst., t. 10, p. 29 et t. 8, 54. Méme thème avec des personnages ailés: ReIvach, Stat., II, 461, 4.

(2) Découverte dans la maison des Dioscures, à présent au musée de Naples, salle LXXIV, inv. 1935; bonne photographie dans Bianca Maturi, Le musie de Naples, p. 104, et dans Arturo Stentco, Roman and Etrusean Painting, fig. 84. - Reinach, Peint., p. 140,4 . 
hypothétique orchestique italiote. Sur un vase à figures jaunâtres de la fin du ve s. avant J.-C., un Pan et une jeune fille se tiennent par la main haut levée; cette attitude ne doit rien à la réalité; elle traduit une idée que nous ne sommes pas en état de préciser. On peut en dire autant de deux bacchants qui, sur un vase à figures rouges de la fin du ive, s'avancent du même pas en se tenant par le cou, à la suite d'un satyre qui joue de la double flute; la femme porte une torche ; derrière le couple voltige un Éros androgyne qui agite des cymbales $\left({ }^{1}\right)$. La représentation inclut évidemment un symbole. Est-il téméraire de supposer une intention analogue à propos du couple volant de la maison des Dioscures?

Un androgyne franchement figuré n'avait assurément rien qui pût effaroucher les gens de Pompéi lesquels, plus d'une fois, l'ont fait peindre dans leurs demeures $\left({ }^{2}\right)$. C'est chez eux que fut retrouvé, dans ce qu'on nomme le jardin du temple de Vénus, une statue d'Hermaphrodite en face de celle de la déesse, avec un autel devant chacun d'eux. Mais la fantaisie des artistes a cherché des renouvellements, tout en respectant la signification essentielle du dieu - double. Le peintre du couple volant a mis en valeur l'abondance des fruits et placé dans la main de la jeune femme un accessoire qui évoque le dieu de la force végétale, plus d'une fois déclaré arrhéno. thêlus par les poètes et représenté comme tel par les artistes.

Peut-être quelque heureuse trouvaille permettra-t-elle de combler l'hiatus qui subsiste entre le dédoublement schématique du groupe Dattari et la libre interprétation du peintre pompéien. L'Éros androgyne qui accompagne le couple du vase bacchique nous donne une indication qui sera peut-être précisée par quelque autre document.

(1) PAnofra, Muste Blancas XXIII, et Mon. dell Inst., t. 3, pl. XXXI ; voir Maurice Emmanues, La dane grecque antique, 1896, fig. 501 et 499 , p. 238-41, et, sur le pas de deux, L. SÉchuN, La danse grecque antique, 1930, p. 47-65. - Couples volants à Pompéi : Rernach, Peint., pp. 141 à 143.

(2) Plus souvent encore que ne le donnerait à penser l'index du répertoire de Reinach ; ses dessins permettent de compléter : pp. 67,$1 ; 68,2,3,5,6,7 ; 98,1,2,4,6,7 ; 99,1$, 2, 3, provenant de Pompéi, Herculanum et Stabies. 


\section{ÉROS ET HERMAPHRODITE}

Capable de stimuler toute les forces vitales, Hermaphrodite est apparenté à Aphrodite, à Dionysos et, encore davantage, à Éros.

Très nombreux sont les monuments où ils apparaissent ensemble. Un temple, un arbre, un cratère sur une colonne composent le paysage du relief Colonna (Reinach, Reliefs, III, 220, 2) ; au premier plan, à gauche, une figurine de déesse est supportée par une autre colonne; au centre est un grand Hermaphrodite chaussé dont le vêtement tombant découvre les seins et le sexe. Il tient sur le bras gauche un petit Éros ailé qui se détourne pour poser la main sur la tête d'un terme dont le fût est marqué du symbole viril. On pourrait en décrire plus d'un autre.

Les contiguités entre Éros et le dieu double vont souvent jusqu'à la synonymie, ainsi que le prouve, parmi d'autres figurations, le triple hermès Chablais (infra, p. 55). Elles rappellent une revendication que Plutarque met dans la bouche de son père au début de son Eroticos (13, p. 756 C) :

«Ce n'est pas aujourd'hui pour la première fois qu'Éros réclame un autel et des sacrifices. Il n'est pas un dieu venu de l'étranger,

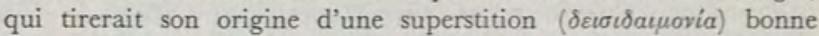
pour des barbares et qui, grâce à des androgynes et à des femmes, se serait introduit ici, comme certains autres qu'on nomme des Attis ou des Adonis, pour recevoir à la dérobée des honneurs auxquels il n'a pas droit. »

Les « androgynes» sont peut-être les prêtres de la Grande Mère qui se faisaient parfois châtrer. Plutarque, plus probablement, prend le mot avec le sens général qu'il avait de son temps, non d'un utrumque mais d'un neutrum. De même Philostrate décrivant Favorinus d'Arles (Sophistes, 1,8), un eunuque imberbe à la voix aiguẽ, le déclare androthellus, la juxtaposition des deux natures étant conçue comme une sorte d'asexualité. Le nom d'androgyne, d'autre part, s'était rapidement dégradé jusqu'à équivaloir à gynandre et à désigner tout efféminé. "Ce n'est plus à présent qu'un nom chargé d'opprobre", disait déjà Aristophane dans le Banquet (189E). Le contexte, l'allusion aux dévotes d'Attis et d'Adonis, donne à penser que le mot a ici cette valeur toute générale. 
La revendication elle-même repose sur un fait exact. Le culte public d'Éros en Grèce était fort peu de chose, sans proportion avec le rôle que tenaient, et dans la philosophie et dans la vie courante, les conceptions fort divergentes dont son nom était le centre. Plutarque, Béotien, avait de bonnes raisons de s'en offusquer, puisque le seul endroit où Éros était grandement honoré - en dehors de Parion sur l'Hellespont, de Samos et de Leuctres en Laconie était près de chez lui, à Thespies, dont il évoque la grande fête quadriennale au début du dialogue.

Si la revendication oppose les titres d'Éros à ceux de divinités nouvelles-venues, c'est qu'ils devaient être du même ordre, mais meilleurs, Éros gardant la supériorité d'être un dieu indigène. C'est-à-dire que Plutarque pensait à un Éros doué, comme Attis, des deux puissances, mais conçues positivement, en termes d'accroissement et non plus de privation, le dieu auquel on consacrait des gymnases, le dieu honoré par des luttes et des jeux, comme c'était le cas à Thespies et aussi à Samos, où la fête se nommait Eleutheria, parce que, disait-on, ce fut l'amour d'Aristogiton pour Harmodius qui valut la liberté à Athènes. Les concours athlétiques de Thespies reflétaient une conception d'Éros maître des vertueuses émulations, telle que Pausanias l'expose dans son discours du Banquet; elle se traduit dans les usages des Lacédémoniens, des Thébains, des Samiens, dans les traditions athéniennes relatives aux tyrannicides ${ }^{(1)}$. Elle réduit Éros à n'être plus que le sentiment Iqui est son homonyme. Pour savoir si, en plus, il était encore senti dans ces fêtes comme une hypostase de la force vitale en soi, il faudrait pouvoir débarrasser nos témoignages de la littérature édifiante qui les alourdit et probablement les défigure.

Avant Plutarque, Euripide et Platon se sont étonnés qu'un dieu qui joue un si grand rôle dans le monde reçoive si peu d'honneurs. Parlant ainsi dans un drame où l'amour apparaît comme une malédiction (Hippolyte, 536), le premier pensait surtout à l'instinct qui promet aux hommes tant de joies et qui leur apporte tant de souffrances. Dans un dialogue qui attache au nom d'Éros à peu près toutes les valeurs imaginables, Platon en marque également, en passant, le sens cosmique, le seul qui intéresse Lucrèce. Celui-ci ne nomme que deux divinités, Vénus et la Grande Mère, qui représentent pour

(1) Nilsson, Griechische Feste, p. 424, - Paus., IX, 31, 3 ; Athénée, XIII, 12, p. 561 E. 
lui ce que Bergson appelait l'élan vital. Éros, leur agent, est bien pour lui la puissance primordiale qu'Hésiode mentionne au début de son poème pour ne plus lui donner ensuite qu'une fonction purement psychologique. Éros à Thespies était honoré «de toute antiquité", dit Pausanias, sous la forme d'une pierre brute. Il y avait encore en Grèce, au début de l'ère chrétienne, quelques pierres sacrées, dont on expliquait la présence par des raisons surajoutées $\left.{ }^{1}\right)$. Dans les usages quotidiens, les pierres levées étaient associées au culte d'Apollon, les tas de pierres à celui d'Hermès. Le culte public d'Hermaphrodite semble bien s'être adressé à des termes portant de sommaires emblèmes sexuels. Ses premières représentations anthropomorphisées ressemblent à des pieux habillés. La vieille idole d'Éros à Parion parait avoir été du même ordre. Le culte de Thespies, comme tant d'autres, fut justifié après coup par une légende sentimentale : un amant de Narcisse, méprisé par lui, s'y serait tué (Conon 24).

Quelques traditions éparses mettent Éros en rapport avec la fertilité végétale. Honoré à Thespies en même temps que les Muses dans les Érotidia quadriennales, où des concours musicaux accompagnaient les joutes athlétiques, il l'était à Élis conjointement aux Charites, lesquelles sont d'anciennes déesses de la végétation. Et ces mêmes Charites à Orchomène, comme lui à Thespies, semblent avoir été anciennement vénérées sous forme de pierres brutes. Sur un vase de Munich, un Éros vole autour d'une grande Coré sortant de terre, comme pour lui être favorable $\left({ }^{2}\right)$.

A Thespies même existait une dévotion curieuse. Arnobe, dans un passage où il raille les idolâtries des paiens, - les Perses qui adorent les fleuves, les Arabes qui adorent une pierre informe -, dit que "les Thespiens ont honoré une branche pour Cinxia", c'est-à-dire Junon protectrice du mariage, qui noue et dénoue la ceinture $\left(^{3}\right)$. Au sanctuaire d'Éros à Leuctres, sur la côte ouest de la Laconie, « il y a, dit Pausanias (III, 26, 5), un bois sacré qu'un

(1) Paus. IX, 27, 1 et 2 ; III, 22, 1 ; Plut. Quest gr., 13. - Cf. Genèse, XXVIII, 18, Jacob fonde Béthel par la consécration d'une pierre.

(2) Paus. VI, 24, 6; le sens du passage n'est pas sûr. - Coupe de Luynes, Munich, 558, Mon, dell Inst. t. 4, 1847, pl. XXXIX. Furtwänglez (Arch. Jaharb., t.6, 1891) extime que c'est Gé qui fait s'envoler un Éros de son sein.

(3) Adversus nationes, VI, 11 : Colvisse namam pro Cinria Thespios. Sur Cinxia, voir Festus (Muller) p. 63: Cinriae Junonis nomen sanctum habebatur in nuptiis. 
ruisseau traverse en hiver; les feuilles qui tombent des arbres au printemps ne sont pas emportées hors du bois par les eaux, même en période de crue». Ce qui tombe des arbres au printemps et que les Grecs prenaient pour des feuilles, ce sont des fleurs. Faut-il comprendre qu'elles ne doivent pas souiller le ruisseau ou, au contraire, qu'elles ne doivent pas quitter le bois sacré?

A travers toutes ces variations se maintenait la tradition de l'Éros primordial, "le plus ancien des dieux", "le père des temps Ogygiens ", dit Lucien (Erotes, 37). Ibycus comme Hésiode le fait naître du Chaos, du Vide; Sapho, de Gê et d'Ouranos; Simonide, d'une Aphrodite sans époux, ce qu'on banalisa bientôt en lui donnant pour père Héphaistos ou Arès. Ce plat anthropomorphisme ne parvint pas à détruire une image que les cosmogonies orphiques gardèrent présente, celle de Nuit et de Chaos faisant naître un œuf brillant comme l'argent d'où sortait Éros, la force créatrice. Elle resta présente à la pensée philosophique, à Épiménide, à Phérécyde. Si elle n'avait pas été familière à son public, Aristophane n'aurait pu l'interpréter avec fantaisie, mais en respectant les grandes lignes de la tradition:

«Dans le sein sans limites de l'Érèbe, la Nuit aux ailes noires produisit d'abord un ouf clair d'où, l'heure venue, naquit Éros le désiré au dos étincelant d'ailes d'or, léger comme les tourbillons du vent " (Oiseaux, 693, sqq.).

Éros sort d'un œuf clair, c'est-à-dire non fécondé : Aristophane entend probablement par là que la Nuit n'a pas eu d'époux ( $\left.{ }^{1}\right)$.

\section{L' EUF PRIMORDIAL}

L'image d'Éros sortant d'un œuf, à notre connaissance, n'a guère été valorisée par les poètes. Les artistes eux-mêmes en ont tiré peu de parti. Un vase de Berlin (n*2430) présente, sur un autel, un ouf contenant un petit garçon; Éros sort d'une coquille brisée sur une gemme publié par Furtwängler. Sa parenté avec Aphrodite a amené une altération du symbole : l'œuf est devenu un coquillage. Celui-ci rappelle, dans l'ordre de la légende, la naissance marine

(1) Voir Dario SABвatucct, Saggio sul misticismo greco, 1965, pp. 105 sqq. 
de la déesse et, plus secrètement, le double sens du mot $x \tau \varepsilon i \zeta$ qui désigne la coquille et l'organe féminin. L'inerte coquillage, qui inclut un être vivant, réserve en s'ouvrant la même surprise que l'œuf, moins vive toutefois et moins frappante que celle que provoque la naissance du serpent et, surtout, de l'oiseau. Dans la 'même ligne se situe l'image d'Éros naissant d'une plante, attestée par des gemmes italiques où le dieu adulte - ailleurs c'est un Hermaphrodite - jaillit d'une fleur ou d'une grenade $\left(^{(1)}\right.$. Si les anciens se faisaient du sexe des plantes une idée inexacte, influencée par le dimorphisme humain, ils savaient au contraire que la graine, le sperma, le semen, est homologue d'une part à la semence des mammifères et, d'autre part, à l'œuf.

A travers toute l'histoire d'Éros, on peut suivre le sillage des trois imaginations apparentées, quoique différentes, de l'œuf, de la graine et de la coquille, associées toujours à un être naissant. De cet être résulta la figure enfantine d'Éros, qui a fini par venir au premier plan. D'autre part, un être qui sort d'un œuf est généralement ailé, ce qu'Aristophane exprime à sa manière en faisant de lui la souche des oiseaux. Il faut remarquer toutefois que les gemmes de style archaique ne le représentent nullement comme le putto espiègle de l'époque hellénistique : celles où il sort de la coquille lui donnent des formes dures et maigres qui sont celles d'un adulte.

Des trois symboles, l'œuf est assurément le mieux enraciné dans l'inconscient, celui qui devait avoir la prolifération mythique la plus riche. L'objet en soi a quelque chose de mystérieux, d'énigmatique. Une forme parfaite, invariable chez une même espèce, géométrie incompréhensiblement élaborée dans le corps d'un animal, apparaissant au printemps avec la régularité apaisante d'un phénomène tellurique (Lucrèce, $\mathrm{V}, 802$ ); une enveloppe qui, lorsqu'on la brise, contient deux matières dont l'homme peut se nourrir, l'une claire, l'autre opaque et sphérique; mis dans des conditions requises pendant une durée donnée, toujours la même, l'œuf s'ouvre pour livrer passage à un être vivant qui rapidement grandit et se développe : forme de génération qui rappelle à la fois celle des mammifères et celle des plantes. A quoi il faut ajouter que,

(1) Antike Gemmen, III, pl. L, n॰ 37 ; coquillage, p. 141, pl. XIV, 6 et LXI, 29 ; fleur ou grenade, p. 290, pl. XXIV, 37, 48, 49, 50, 51 ; pl. XXV, 8, 10. Agathe rayće de la collection Demidoff, Gerhard, Eros., pl. I, 15. 
si le sexe est discernable dès la naissance chez l'homme et la plupart des mammifères, il ne l'est que plus tard chez les ovipares qui semblent ainsi rester quelque temps en état d'indétermination. L'œuf des philosophes, diront les alchimistes, contient les quatre éléments, et aussi le Filius Hermaphroditus. Enfin, l'œuf non fécondé, l'œuf clair d'Aristophane, est, en apparence, identique à un autre, si bien que tout œuf semble venir d'un être unique sorti luimême d'un autre œuf et ainsi, en remontant toujours, d'un œuf archétype. Ce n'est pas un hasard si, pour exprimer la difficulté de saisir un point de départ dans une série continue, on parle du problème de la poule et de l'œuf. Tous les Grecs ont considéré l'Artémis d'Ephèse comme polymaste ; sur plusieurs statues toutefois, les seins qui entourent sa gaîne n'ont pas de tétons et ressemblent plus à des œufs qu'à des mamelles. L'indication des tétons semble avoir été tardive. Une curieuse peinture de Naples montre près d'une montagne, à côté d'un serpent géant et d'un oiseau, un Bacchus tenant un long thyrse $\left(^{1}\right)$. Il est englobé dans une énorme grappe de raisins dont chaque grain semble un œuf. Tout un folklore atteste l'importance de l'œuf comme symbole de la fécondité. Un autre folklore, d'interprétation plus malaisée, parle du caractère - inquiétant de la coquille, réceptacle capable de loger des êtres malfaisants, provisoirement invisibles, qui pourront, à l'abri dans cette sorte de matrice, se développer et surgir à l'improviste $\left(^{2}\right)$.

Rien d'étonnant si tant de mythologies ont élevé ces images au niveau cosmique. Le ciel créé par Ohrmazd est un œuf en métal brillant et la terre est au milieu comme le jaune de l'œuf. La division de l'œuf cosmique est parfois l'œuvre d'un être qui s'y trouve inclus. Le P'an-ku chinois est engendré à l'intérieur d'une masse confuse où Ciel et Terre sont inextricablement mêlés. Il grandit avec elle qui se partage en un élément léger et brillant, et un autre lourd et obscur, qui s'éloignent progressivement l'un de l'autre. L'ouf du monde, à travers ses variantes, correspond à la représentation de l'être sphérique divisé en homme et femme, même

(1) Voir Arturo Stenico, Roman and Etruscan Painting, fig. 123.

(2) Elisce Legros, Trois reccits de lutins, Enquêtes du Musće de la Vie mallonne, VI, $29^{\circ}$ année, p. 129-227: légendes du changeling (Wechselbalg) du type Grimm, 39, 3 où apparaissent des coquilles d'cuf servant uniquement à faire reconnaitre l'enfant de la fée, après quoi il disparait pour toujours. La coquille doit avoir eu un rôle plus important, qui échappe. Il y aurait là une recherche à faire. 
si la représentation du couple, le Ciel-Père fécondant la Terre-Mère, apparait plus souvent que celle de la séparation. Le mythe du Banquet, qui les combine à l'intérieur d'une anthropogonie, en faisant de la séparation une condition de la fécondation, est tout autre chose qu'une allégorie inventée par un philosophe.

Les cosmogonies orphiques ont été à peu près seules en Grèce à conserver explicitement ces conceptions. Un uf, dit l'une d'elles, est à l'origine du monde; les deux morceaux de sa coquille brisée sont devenus le ciel et la terre. On bien un Chaos, qui n'est pas le Vide, mais qui contient toutes choses en soi et qui ressemble à l'apeiron d'Anaximandre, fait sortir, à la manière d'un œuf gigantesque, une forme double, androgyne, composée par adjonction des contraires (1).

\section{ÉROS ANDROGYNE}

Cet être porte, dans les traditions orphiques, différents noms, Phanès, Protogonos, Erikepaios, Éros enfin que l'Hymne LVII déclare diphùs. Cette représentation n'est nullement propre à une secte, ni même à certaines spéculations philosophiques. Je ne ferai pas grand état du fragment d'Alexis (cité par Athénée, XIII, 13, p. 562 B) qui, pour décrire la complexité et les contradictions d'Êros, dit de lui : "Il n'est ni homme ni femme, ni dieu ni humain, ni étourdi ni réfléchi, mais formé d'éléments venus de toutes part, portant en une seule forme une multiplicité de caractères...". Les monuments figurés en disent davantage. On y trouve un Éros semblable en tout à Hermaphrodite, sinon qu'il est ailé. Une de ses (généalogies accuse la parenté, en faisant de lui également un fils d'Hermès et d'Aphrodite. Les monuments de culte d'Hermaphrodite associent une figure féminine et un emblème viril plus ou moins schématisé. Une symbolique analogue représente souvent Éros

(1) Mythologies of the ancient world, ed. by Samuel Noah Krusezr, p. 339 (Ancient Iran, by M. J. Dresdev) et 382 (Ancient China, by Derk Bodde). - O. Kers, Orph. Gr. Fragm., 1922 , fr. 28, 55, 56 et 60 . - Mircea ElAADE, Traite d'histoire des religions, ch. XII ; les $\$ \S$ $157,159,160$ traitent successivement de l'ceuf cosmogonique, de la coincidentia oppositorum et du mythe de l'androgynie divine et humaine. - Voir aussi Dario SabBatuocr, Saggio sul misticismo greco, 1965 , p. 88 et 92 sqq. 
comme un jeune garçon tenant un coquillage, indication aussi claire qu'une représentation du sexe féminin, plus frappante et plus facile à utiliser plastiquement ou graphiquement. Un groupe en marbre de Naples (Reinach, Stat., I, 325, 1) met à côté d'une Aphrodite debout un petit Éros ailé tenant une large coquille qui lui cache la région de la ceinture.

Le monument qui illustre le mieux l'équivalence d'Éros et d'Hermaphrodite est le triple terme Chablais, actuellement au Vatican. Une des faces représente une Aphrodite vêtue; à ses pieds, une petite Aphrodite nue désignant son sein gauche et son sexe. A sa droite, le terme marqué du symbole viril supporte un buste d'Hermès barbu; à la base, un jeune Hermès jouant de la lyre. Entre eux deux, un buste féminin avec emblème viril sur le terme et, à la base, un Éros ailé. On voit là, entre ses deux parents, un Hermaphrodite deux fois représenté, en haut comme sur les monuments de culte, en bas par son synonyme, Éros. Les témoignages qui associent Hermaphrodite et Hermès ne sont pas nombreux. La triade ici est complète $\left.{ }^{(}\right)$. Ce qui est curieux, c'est que les-deux étages correspondent à des niveaux qui nous paraissent religieusement différents : en haut, une déesse strictement vêtue, un Hermès barbu, viril, très peu semblable au Mercure adolescent de l'art tardif, un Hermaphrodite schématisé ; en bas, une réduction de la Vénus de Médicis, un Hermès enfant qui vient d'inventer la cithare, et le petit Éros dont les sculpteurs hellénistiques et romains ont multiplié les effigies. Les figurations d'un Éros androgyne sont extrêmement nombreuses. Les peintres de vases, toutefois, l'ont rarement représenté. Des vases apuliens et lucaniens ont cependant traité le sujet. Gerhard a fait dessiner (Éros, pl. III) un vase italique où un Hermaphrodite conduit debout, précédé par un Éros également androgyne, un char attelé de la panthère bacchique et du griffon, animal essentiellement apollinien, entré aussi dans le cycle de Dionysos $\left({ }^{2}\right)$.

(1) Rennach, Stat., I, 329, 1; Baumasw, Doppelte Geschlecht, p. 191 et 149, marque la correspondance avec un monument hindou (étudié par W. Krrfet, Die dreikóp fige Gottheit, Bonn, 1948) représentant Shiva androgyne entre un visage féminin et un visage barbu. Kirfel, p. 120, voit dans Hermès un dieu qui aurait eu une forme tricéphale.

(2) Voir Marcel Rexarn, Griffons de Buzenol et d'ailleurs dans Pays Gaumais, années XXIV et XXV, 1963-4, p. 117-157. Griffon apollinien, p. 119, 149, 150, accessoirement dionysiaque, 119, 151, 153; accompagné d'attributs dionysiaques, 137; à éléments de panthère, 120; Éros dompteur de griffons, p. 141, fig. 25, monument d'Igel ; chevauchant un griffon, p. 142, fig. 26, relief d'Andelot. 
Tous les deux ont en baudrier le double collier d'Aphrodite. Un vase " gnathia » de Vienne, du rve ou du $\mathrm{III}^{\mathrm{e}} \mathrm{s}$. (fig. IV), vaut par sa singularité. Une grasse créature ailée, phallique, tient d'une main une feuille stylisée et de l'autre un disque (peut-être le miroir des statues aphroditéennes?) ; elle survole une oie parmi des feuillages. Cette figure tranche sur toutes les autres par le style; mais les attributs sont ceux des autres hermaphrodites.

Alors que les figurines à pendre ou à poser sont des plus nombreuses, les deux êtres doubles ont été rarement figurés sur des vases. Cela s'explique. Les statuettes sont des emblèmes capables de porter bonheur, comme un rameau de buis bénit dans la chambre d'un catholique. Un vase est un ustensile, et il le reste, même si le peintre y a retracé un acte rituel, comme c'est le cas dans quelques exemplaires décrits ci-dessus ; même s'il porte quelque figure d'une efficacité magique immédiate, comme c'est le cas pour les yeux apotropaĩques; même si sa forme a une valeur en soi, comme c'est le cas, je crois, pour le rhyton, substitut de la corne et des puissances qu'elle inclut. Un talisman se présente indépendamment de toute utilisation. En face d'une statuette, nous ne saurions préciser ce qu'a pu être sa signification talismanique, laquelle a deux composantes, l'objet lui-même et le sentiment qu'il inspire à son possesseur, et la seconde restera toujours hypothétique. Quelques accessoires, quelques attributs, permettent du moins de l'approcher.

On constatera aussitôt une foncière équivalence entre Éros et Hermaphrodite. En présence d'un spécimen peu expressif, il n'est pas toujours facile de les distinguer. L'un et l'autre stimulent la croissance végétale. Un groupe en marbre montre un Éros melléphèbe, non ailé, adossé à un arbre et cueillant des grappes audessus de sa tête; un autre, ailé, en dispose dans une corbeille que tient un Pan; les branches révèlent encore un Éros et un petit satyre barbu $\left({ }^{1}\right)$. On trouve rarement Éros entouré d'une symbolique végétale aussi riche. Mais les nombreux Éros androgynes en terre cuite, nus, portent presque tous, pour emblèmes, des feuilles et des fruits le plus souvent discrètement indiqués, par une couronne parfois schématisée en un simple bourrelet.

(1) Publié par A. Mıcriẫuts, Eros in der Weirlaube, Arch. Zeit., t. 37, 1879, p. 170-177, pl. 13-14 = Rervich, Stat., II, p. 71, 2 et 3. La question d'Éros attaché à l'arbre devrait être reprise. 
Un classement des différents types d'Éros reste à faire. Nous n'avons à considérer ici que les androgynes, représentés surtout par des terres cuites, et très abondamment. Les fouilles de Myrina ont révélé l'extrême popularité du type. Parmi les figurines retrouvées, où il n'y a pas un seul Zeus, à peine quelques Olympiens, il y a 53 Aphrodites, 7 Dionysos et une quinzaine de sujets bacchiques, 5 Déméter, 4 Attis, 14 Niké et 70 Éros pour la plupart ambigus. Le musée de Boston en possède sans doute la plus belle collection; elle a permis à M. Alvarez, qui l'a étudiée sur place, d'établir une distinction nette entre les putti, petits garçons aux grosses têtes, aux courtes jambes enfantines, et les figures androgynes aux têtes anormalement petites, comme si l'artiste avait voulu indiquer clairement qu'il s'agit d'adultes, d'êtres divins. M. Alvarez les groupe en trois types anatomiques:

1. Féminoide, coiffure féminine, seins développés, cuisses larges, pli pubien secondaire contrastant avec le signe viril.

2. Équilibre des deux éléments; formations masculines entourées de détails féminins, épaules larges et seins arrondis, ou cuisses larges autour du signe viril.

3. Viril avec modulation féminine, épaules plus larges, hanches plus étroites, poitrine plus large avec seins moins développés, parfois petits et coniques, parfois réduits au grand pectoral, oblique externe bien marqué, muscles abdominaux allant jusqu'à l'os pubien. L'androgynie de ces exemplaires est parfois douteuse.

Des critères artistiques donneraient un classement tout différent, accusant un type dépouillé, qu'on dirait volontiers "classique», un style "renaissance», avec plus de recherche d'élégance, un type "baroque», caractérisé par un mouvement exubérant. Les deux classements, bien entendu, ne concordent pas et peuvent, en se combinant, donner un grand nombre de variétés.

Ces statuettes offrent peu d'attributs intéressants. Voici ceux qui permettent d'entrevoir une signification particulière $\left.{ }^{1}\right)$ :

(1) Je renvoie ci-dessous à l'ouvrage de Potrier et ReINach lorsqu'il donne un commentaire et une reproduction. - Eros sans particularités, les uns ailés, les autres non, ce qui rend impossible une distinction rigoureuse entre eux et Hermaphrodite : W INTER, I, 188,7 ; II, 290, 7 ; 336, 1, 3, 4, 5, 6; 338, 1 ; 341, 3, 4; 346, 7, 8; 354, 6; 357, 4 (le $\mathrm{n}^{\circ} 3$ est semblable, mais sans ailes); 354,8 . 
Éros androgyne, ailé, les bras pleins de fruits (Winter, II, 288, 8)

- ayant à ses pieds un oiseau (Winter, II, 286, 5)

- nu, portant une corne d'abondance (Myrina, n ${ }^{\circ} 104$, p. 341, pl. XVII, 9 et n०209, p. 400, pl. XXIX, 8).

- dansant ou jouant, lourdes couronnes de fleurs et de fruits traitées en bourrelets; tous ne sont pas ailés; statuettes en général d'un très bon style (Myrina, n० 54, 55, 56, 57, 58, 66, 67, pp. 324-330, pl. XI, 2 ; XII, 2 ; XIII, 1, 3 et 5 ; XIV, 1 et 2 ). Le n ${ }^{\circ} 58$ joue de la double flûte; le 54 (XI, 2) nu, rieur, danse en déployant ses larges ailes, le bras droit levé, le corps arqué; le no 55 (XII, 2) a une expression plus sérieuse et un caractère féminin plus marqué.

- figure ailée, androgyne, debout, tenant de la gauche une lyre appuyée à une colonne, de la droite un plectre, coiffure courte ornée de pampres avec couronne en bourrelet (Myrina, n 178, p. 304, pl. VII, 4). Est-ce Éros avec la lyre d'Apollon tel qu'on l'honorait à Épidaure (Paus., II, 27, 3) ou le Dionysos Psilax d'Amyclées (III, 19, 6) dont on interprétait le nom en rappelant que $\psi i \lambda_{. o v}$ signifie aile en dorien?

Le symbole de l'arc est exceptionnellement associé à l'Éros androgyne, ce qui n'a rien d'étonnant: il a surtout été traité dans la statuaire d'apparat et, d'après elle, sur des réductions, monnaies ou gemmes. Gerhard (Eros, pl. I, 9) signale une gemme, de style archaĩque, où une figure ailée, féminine de corps et de coiffure, tend l'arc.

On n'a pas accordé aux petites terres cuites l'attention qu'elles méritent, ni au point de vue de leur signification ni au point de vue de leur valeur artistique. Le Dr. Paul Richer a décrit avec admiration, à propos de l'Hermaphrodite de Berlin, la science du sculpteur qui, de caractéristiques masculines et féminines exactement observées, a fait un tout harmonieux. On peut en dire autant de plus d'un coroplaste. Voici, d'après M. Alvarez, qui l'a fait photographier pour la première fois, la description d'un Éros de Vienne (fig. V).

" La tête, très petite en proportion du corps, empêche que l'on pense à un enfant. Le visage aux joues rondes et pleines est féminin. Quoique l'ossature des hanches soit celle d'un garçon, le symbole masculin est entouré de formations féminines. Le ventre plein, doux et gras, ne révèle aucune musculature; la ligne oblique de l'aîne conduit d'un trait au pli subpubien, ce qui est féminin, de 
même que le renflement du pubis et le grand pli semi-circulaire de l'abdomen. L'obliquus externus, au sommet de la hanche, très accusé chez l'homme, peu visible chez la femme, n'apparaît pas ici. Les cuisses sont grasses; on n'y voit pas le dessin sinueux du vaste interne, de l'adducteur de la cuisse et du vaste externe. La poitrine ne révèle pas la musculature masculine, carrée, du grand pectoral, mais seulement la rondeur des seins féminins». Une photo prise de profil fait mieux ressortir les traits féminins.

Les mêmes termes pourraient décrire un bel Éros de Boston, qui porte le double collier aphroditéen, retenu entre les seins par un médaillon. Un bras levé, il esquisse un mouvement de danse (fig. VI).

- Les caractères féminins sont plus accusés dans un charmant Éros nu, dansant, de Boston (fig. VII). Tous viennent probablement de Myrina.

\section{L'ARCHÉTYPE DE L'ENFANT}

Les coroplastes se sont peu souciés de marquer une distinction entre un Hermaphrodite et un Éros androgyne. De nettes différences s'acctrent en revanche dès qu'on suit l'histoire des deux figures.

Celle d'Hermaphrodite a peu de variantes. Un symbole schématique s'est actualisé en types influencés parfois par celui de Déméter ; plus souvent par ceux d'Aphrodite et de Dionysos; rarement et accidentellement, par un caractère priapique atténué. Il est toujours juvénile, sans jamais être représenté comme un enfant, ni engagé dans une activité enfantine, pas plus que dans aucune autre. Il garde presque partout la gravité d'une apparition religieuse. L'absence de toute légende autour de lui explique en partie la stabilité du type.

Êros, puissance cosmique, apparait accompagné des symboles de la naissance : l'œuf, la fleur, la coquille, sans toutefois que l'art archaiqque l'ait marqué d'aucune puérilité. Dans cette ligne se situent les terres cuites, en accentuant parfois une grâce rieuse qui manque à Hermaphrodite. Tout différent est le putto gras, le bébé masculin de l'époque tardive.

Ce que Jung et Kerényi ont appelé l'archétype de l'enfant, avec l'espèce d'androgynie qu'il comporte, que Baumann a retrouvée, 
sous différentes formes, dans bien des croyances d'autres peuples ${ }^{(1)}$, a donc abouti à deux images d'Éros: d'une part la double potentialité associée à une figure jeune, mais non puérile; d'autre part, les traits caractéristiques de la petite enfance, saisis dans leur réalisme.

De l'évolution du type d'Éros, rapprochons celui de l'Ange. Pour la pensée religieuse, l'ange est toujours le messager du Seigneur. Dans l'imagination des artistes et du peuple - et il serait intéressant, sinon aisé, de rechercher dans quelle mesure ils se sont influencés réciproquement - il a été marqué par l'archétype de l'enfant. Et, ce qui est extrêmement curieux, c'est que la catégorie angélique qui s'est le plus radicalement puérilisée est celle qui, a priori, semblait s'y prêter le moins.

Les Hiérarchies célestes du' pseudo-Denys l'Aréopagite (V, 201, a 212 c ; XIII, 304 d; XV, 325 d) répartissent les neuf essences en trois groupes:

Trônes, Chérubins, Séraphins;

Puissances, Vertus, Dominations;

Principautés, Archanges et Anges.

Les cinq termes abstraits n'ont abouti à aucune figuration. Les archanges n'apparaissent guère qu'avec les anges pour composer une gradation. Trois d'entre eux ont reçu un nom et un rôle individuel, et sont figurés comme de beaux jeunes gens: Raphaël, Gabriel et Michel. Cette humanisation les a fait honorer comme des saints ; les deux derniers figurent comme tels dans la Chanson de Roland (CLXXVI). Le mot séraphique, appliqué à saint Bonaventure, à la vision extatique de saint François d'Assise, a désigné une spiritualité éminente. Les Chérubins semblaient protégés contre toute évolution par la terreur qui entoure leur nom dans l'Ancien Testament. Philon a consacré tout un traité aux chérubins qui, assistés d'une tournoyante épée de feu, gardent après la faute l'entrée du paradis | terrestre. Iaveh traverse l'orage porté sur leurs ailes. Ezéchiel les voit emportant son char: des êtres quadruples, ayant une tête humaine, une de lion, une de taureau, une d'aigle, quatre ailes, un corps couvert d'yeux et les pieds semblables à ceux d'un veau, ce que Denys interprète symboliquement. L'Apocalypse décrit quatre

(1) Einfülunang in das Wesen der Mythologie (trad. franç. 1953). Le chapitre sur laarchétype est de Juvg, voir $\S 3$ sur l'hermaphrodisme de l'enfant; le chapitre sur l'Enfant divin est de KerénYi. 
chérubins tout couverts d'yeux, avec six ailes et les quatre visages qui devaient devenir ceux des évangélistes. Ces représentations ont certainement été influencées par des monuments babyloniens (1). Encore faut-il faire remarquer que le chérubin aux membres multiples n'est pas sans ressemblance avec Phanès qui tient dans la cosmogonie orphique une place parfois occupée par Éros. Comment cette figure redoutable, inhumaine, a-t-elle pu aboutir aux définitions que Littré aligne sans s'étonner de leur hétérogénéité : «Dans le christianisme, anges de la première hiérarchie; familièrement "une face de chérubin, mon petit chérubin"; en peinture et en sculpture, tête d'enfant avec des ailes. «On aimerait pouvoir marquer les étapes avec quelque précision. Anatole France introduit parmi ses anges révoltés un être de la première hiérarchie, colossal en toutes choses, qu'il nomme un kéroub: le seul prononcé du mot chérubin aurait annihilé les images de lourdeur, de puissance, qu'il voulait suggérer. Tous les anges ont été affectés d'une beauté qui est l'attribut de la transcendance ; c'est ainsi qu'il faut imaginer, emportant l'âme de Roland, saint Gabriel, saint Michel del Peril et «l'ange Cherubin » envoyés par Dieu. Mais peu à peu le chérubin, résorbé tout entier par l'archétype de l'enfant, est tombé à l'état de joli bébé, aussi bien en français qu'en anglais.

Figures juvéniles ou enfantines, les anges n'ont aucun sexe, alors qu'Éros les a tous les deux. Dès que la représentation cesse d'être liée à l'idée de fertilité et soutenue par elle, l'utrumque glisse au neutrum. Le vertu profonde de l'archétype de l'enfant, concrètement sentie par les anciens, n'est plus qu'inconsciente dans le christianisme.

(1) Il ne s'agit ici que des représentations, non des définitions théologiques concernant les pouvoirs des anges. - Sur les origines babyloniennes du type du chérubin hébraĩque, voir P. Dhorme et H.-L. Vincent, Retue Biblique, t. 55, 1926. - Sur la transformation des Amoretti en angelots, Pierre Gruarr, Mellanges Smets, 1952, p. 287-293. Ce fut d'abord, je crois, pour entourer Jésus enfant que l'ange adolescent se transforma en angelot dans la peinture religieuse. 
Cette vertu explique la présence du petit garçon nu dans la décoration des sarcophages, des stèles funéraires, dans les peintures des caveaux. Cette décoration est attestée par des monuments romains, qui utilisent une symbolique qui vient principalement de la Grèce. Elle comporte du reste beaucoup de problèmes qui sont loin d'être résolus et qui ne sauraient être abordés ici. Plus d'un monument est d'une interprétation aussi difficile que ces premières stèles attiques pour lesquelles plusieurs explications ont été proposées $\left.{ }^{1}\right)$.

On peut admettre toutefois qu'en général la décoration funéraire est une promesse de bonheur. Celle-ci s'exprime à travers des figures divines et des épisodes légendaires interpréttés symboliquement, leur signification primitive ayant été pliée à l'aspiration majeure d'un temps qui voulait lire une espérance de résurrection personnelle dans les histoires d'Alceste et d'Iphigénie, dans les aventures d'Osiris, d'Attis et, surtout, de Dionysos : non seulement Zagreus est ressuscité, mais rien mieux que la végétation ne prouve que ce qui a verdi reprend vie après avoir eu quelque temps l'apparence de la mort. Beaucoup de motifs relèvent de sa légende et de ses attributs. Les jeux fort libres de Satyres, de Ménades, de Priapes, tels qu'on les voit sur les sarcophages, ne pourraient guère s'expliquer, selon notre sentiment, que si les morts attendaient dans l'audelà la plénitude de tous les plaisirs physiques, ce qui ne correspond à aucune croyance grecque connue. Ce déchaînement sexuel n'est nullement propre à l'époque tardive. Pour en découvrir les origines, il faudrait probablement quitter le domaine de la tradition hellénique, auquel on s'est trop longtemps confiné, et interroger l'art funéraire étrusque, sculpture et peinture, où se trouvent, associées à la mort, des scènes d'une incroyable audace. Ces monuments, que les musées n'exposent pas, qui sont rarement reproduits, ne sont pas d'un accès aisé. Nous ne pouvons ici qu'indiquer le problème, en nous bornant provisoirement à ce qui concerne les repré-

(1) Friis Jorunsza, The attic grave reliefs of the classical period, Copenhague, 1951, p. 51 sqq. - Franz Cusoont, Recherches sur la symbolique funéraire des Romains et Lux perpetua (2949) notamment p. $250-1,373,407$ à 420. 
sentations funéraires de l'enfant, qui ne laissent pas d'être énigmatiques. Des Amoretti hilares et mêmes ivres expriment à première lecture un bonheur assez vulgaire. Il faut probablement voir en eux, non seulement la figure, mais les valeurs incluses dans l'archétype de l'enfant, symbole de naissance et de renaissance.

Ainsi s'explique également la présence, sur les sarcophages, de l' ros androgyne et de l'être double. Des artistes du Nord voyageant en Italie au $\mathrm{xvI}^{\mathrm{e}} \mathrm{s}$. en ont vu et les ont dessinés avant qu'ils aient disparu ou qu'ils aient été intentionnellement mutilés, car on fit souvent disparaître une ambiguité dont on était choqué faute d'en comprendre la signification. Zoëga au début du siècle dernier en a publié plusieurs, un notamment où un jeune garçon androgyne tient la place d'Ariane ( ${ }^{1}$ ). Le mariage de celle-ci avec Dionysos est un des thèmes de la sculpture funéraire. Ailleurs, c'est Dionysos qui est androgyne. Un sarcophage du musée des Thermes ( $\mathrm{n}^{\circ}$ 124682) montre une Ariane strictement voilée vers laquelle se retourne un Dionysos presque nu; la draperie, disposée de façon à mettre le sexe en évidence, révèle un corps féminin contrastant avec l'Hermès tout viril qui est à sa droite (fig. VIII). D'autres monuments devraient être soumis à un examen attentif, libre des préjugés qui ont trop longtemps gêné les recherches sur les affleurements du rêve de la bisexualité dans la religion et l'art des Grecs.

Ce n'est certainement pas un hasard si une collection particulièrement riche d'Éros androgynes ou non et d'androgynes non ailés a été découverte dans une nécropole. Ils représentent à eux seuls la moitié des effigies exhumées à Myrina. Parmi eux figurent de curieuses statuettes que Pottier et Reinach désignent comme des Eros funéraires (nos 123-147), type particulier, disent-ils, aux terres cuites asiatiques; le vêtement enveloppe le corps, la tête et couvre parfois la bouche; l'attitude est raide; les jambes nues sont jointes. Certains tombeaux en contenaient jusqu'à trente ou quarante, identiques, brisés $\left(^{2}\right)$.

(1) Micrualt.ts, ROmische Skizzenbücher nôrdischer Künstler dans Arch. Jahrb., t. 7, 1892, p. 84. - ZoẼaA, Bassirilievi antichi di Roma, Rome, 1808, t. II, p. 77 (voir aussi pl. LXXII) cités et reproduits par Römer, pp. 859 et 860 fig. 50 et 51 . - Jones, Museo Capitolino, p. 29, mentionne, sur un sarcophage, (Atrio, 10a) « a nude male(?) figure... much damaged, in part intentionnaly». Nul doute qu'il n'y en ait d'autres.

(2) Myrina, n* 70, pl. XII, 5, ailé, couronné de feuillage, la tête baissée, les seins apparents sous le vêtement; n 131, 139, 144, 145, pl. XII, 12, 34; XVII, 1, 34. Plu- 
I Le plus curieux est un androgyne ailé (n० 86 , p. 331, pl. XV, Louvre 219, reproduit dans Jung et Kerényi, Introduction à l'essence de la mythologie) de $36 \mathrm{~cm}$. de haut, d'un bon style, vêtu d'une tunique sans manches, serrée à la taille et formant une sorte de jupe flottante. Un ample himation monte derrière la tête en une coiffure féminine, s'enroule autour du cou et retombe sur l'épaule et le bras gauche. La main droite passe sous la tunique et la retrousse pour dévoiler le sexe; la gauche tient un vase. Les seins et les jambes sont féminins.

Pottier a été frappé de voir cet être ailé faire le geste de l'anasyrma, caractéristique des statues d'Hermaphrodite que nous avons appelées démétriennes et de leurs dérivés. La position de la tête, toutefois, est différente. La figure démétrienne regarde de face, avec la raideur de l'hermès dont elle dérive. L'Êros tourne la tête vers la droite, esquissant le mouvement de torsion qui se trouve suggéré ailleurs, et qui est nettement accusé sur le petit monument funéraire de Sens (supra, p. 26). Le Bacchus androgyne du sarcophage des Thermes est entièrement tourné en arrière. Il y a là une signification qui provisoirement nous échappe.

Quant au geste de l'anasyrma, on le retrouve, moins net, chez d'autres Éros funéraires de Myrina: la tunique relevée jusqu'en haut des jambes. Très semblable aux Éros funéraires est un Attis androgyne retrouvé avec eux à Myrina $\left.{ }^{(1}\right)$. Éros toutefois n'a jamais les pantalons qui caractérisent Attis, dont le vêtement s'ouvre pour révéler le ventre, tandis qu'Éros relève sa tunique.

\section{D'ÉROS À GANYMEDE}

Représenté surtout par de petites statues destinées d'être placées en plein air, dans les jardins, à l'intérieur des maisons, dans les tombeaux, l'Éros androgyne ou non - est-il Amour? est-il Hermaphrodite? - figure également sur des objets et sur des bijoux

sieurs exemplaires fort petits sont peu lisibles. - WnTter, Terrakotten, p. 346, 7 et 8 ; deux exemplaires sont au British Museum, Synopsis, II, p. 86, 27 et 30 .

(1) Voir Myrina, n॰ 71, pl. XVII, 7; n॰ 137, pl. XXXIV; n॰ 143, 144, 145, pl. XXVII, 4, 3 et 1 ; n 309, pl. XLI, cf. p. 448. Les pièces sont souvent trop petites et trop grossières pour étre interprétées avec certitude. - Voir aussi la curieuse terre cuite de Berlin représentant un Éros faisant l'anasyma (Gerhard, pl. I, 7). 
auxquels son image conférait, dans une mesure difficile à préciser, une valeur de talisman.

Ad. Greifenwalden, dans ses Griechische Eroten (Berlin, 1959), a publié une trentaine de vases, tous fort beaux, représentant plusieurs types différents; on n'y trouve aucune indication de bisexualité. Mais il n'en est pas de même du seul objet dont il donne la photographie, un miroir de bronze du début du ve siècle avant J.C. (fig. 28, British Museum), soutenu par deux personnages ailés : un Éros nu, nettement androgyne; une femme vêtue, Niké, dit dubitativement l'auteur, hypothèse confirmée par la présence de plusieurs Victoires parmi les Iros de Myrina. Le miroir, symbole du Soleil, figure, on l'a vu, parmi les rares attributs du dieu double. Il faudrait pouvoir comparer cette pièce à d'autres semblables afin d'en éclairer la signification.

Des boucles d'oreilles en or, de la seconde moitié du rve siècle avant J.-C., représentent Ganymède enlevé par un aigle qui est Zeus lui-même (fig. IX) $\left.{ }^{(1}\right)$. La destination du bijou permettait à l'artiste de suspendre réellement le personnage, alors qu'une statue posée devait lui donner un point d'appui à terre. Le Ganymède de Léocharès était célèbre. On ne sait s'il faut le reconnaître dans le marbre du Vatican (Reinach, Stat., I, 192, 2) ou dans celui de Venise $(191,3)$. Ils sont d'inspiration assez différente. Dans le premier, où l'aigle et l'enfant sont adossés à un tronc d'arbre, l'aigle est simplement le messager de Zeus; dans le second, Zeus lui-même, sous la forme de l'aigle, baise du bec la bouche de Ganymède, dont les bras lui entourent le cou. Les boucles de New-York, qui semblent être à peu près contemporaines de Léocharès, s'inspirent nettement du type de Venise, où le dieu lui-même enlève l'enfant aimé, lequel, dans la statue, n'est nullement androgyne, alors qu'il l'est nettement dans l'interprétation de l'orfèvre.

Il y a des contiguités entre hermaphrodisme et pédérastie. On connaît des figurines d'hermaphrodites viriloĩdes tenant un coq, présent rituel, pourrait-on dire, de l'éraste à l'éromène $\left(^{2}\right)$. Cette

(4) New-York, Metropolitan Museum of Art, Dick Fund, 1937. Elles semblent avoir été découvertes dans un tombeau à Salonique. Dans un art plus ancien, un Zeus tout humain emporte l'enfant : voir J. Bonrdmas, Greck Art, fig. 97, vase attique à figures rouges, vers 490 (Louvre) et fig. 111, terre cuite peinte, vers 470 (Olympie).

(5) Wrinter, I, p. 181, 5 et 182, 3. D'autres oiseaux avaient la meme valeur, la caille, le porphyrion, l'oie, Arist, Oiseaux, 705-7. - Les fouilles du Cabireion prés de Thespies 
intention existe-t-elle, à côté d'autres, dans le terme de Londres (supra, p. 17) où un être double présente des raisins à un oiseau difficile à identifier? D'autre part, Apollonius de Rhodes (III, 111 sqq.) montre, dans le jardin de Zeus, Éros et Ganymède jouant avec des osselets d'or. Un passage curieux de Tatien (Ado. Nat., 56) en dit davantage, mais l'interprétation n'en est pas aisée:

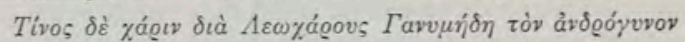

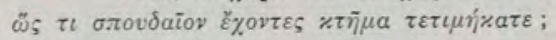

A la fin de l'antiquité, androgyne, avec le nuance méprisante qu'avait toujours eue gynandre, désigne souvent, soit un eunuque, soit un efféminé. Tatien l'applique ici à celui que la légende considérait comme le plus illustre des éromènes. Condamnant en bloc tous les états intersexuels, il avait peut-être à ce sujet des idées analogues à celles des philologues de la première moitié du XIx siècle, qui expliquaient le dieu double par les conceptions des Grecs sur l'amour des jeunes gens. Mais on ne voit pas bien quelle responsabilité il attribue à Léocharès. On pourrait entendre:

«Pour quelle raison avez-vous révéré Ganymède l'androgyne en le considérant, grâce à Léocharès, comme une chose digne d'être recherchée "?

Mais l'ensemble du discours dément cette interprétation. C'est un réquisitoire contre l'immoralité des artistes, et dans la suite, qui est altérée, Praxitèle est également mis en accusation. Il faut donc entendre. "Pour quelle raison, à travers l'œuvre de Léocharès, avez-vous honoré Ganymède? " Tatien a vu celui-ci plus «androgyne" que les répliques connues ne le donnent à penser; le marbre de Venise, comme celui de Rome, offrent un garçon dans la fleur de l'adolescence, nullement efféminé. Le mot de Tatien serait justifié pour les boucles de New-York. Celles-ci ont peut-être accusé une indication qui était déjà dans la statue et que les répliques en marbre ont atténuée.

Elle se trouve en revanche accentuée sur une peinture de Stabies où, en présence d'un androgyne coiffé d'un bonnet phrygien, Reinach (Peint., 98, 8) s'est demandé s'il s'agit d'un Hermaphrodite ou d'un Ganymède. En le qualifiant d'un mot qui, de son temps,

ont révélé beaucoup de figurines tenant un coq, des adolescents aux énormes coiffures, peut-être une stylisation des couronnes de feuillages que portent tant d'Éros. P. WoLtzRs, Kabirenheiligtum bei Theben, dans Ath. Mitt., t. 15, 1890. 
avait pris un sens privatif, Tatien aurait-il retrouvé à son insu une valeur plus ancienne, nettement positive? Le nom est grec, et

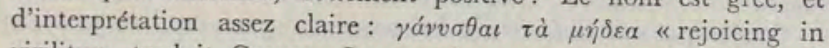
virility ", traduit Graves. Le premier texte qui parle de lui, le chant XX de l'Iliade (232-5) révèle le sens premier de la légende. Ce n'est pas Zeus qui l'enlève, mais les dieux, à cause de sa beauté, afin qu'il soit leur échanson, office qu'Hermès avait d'abord accompli (Lucien, Dial. dieux, 24), et qui consiste à leur verser ce que les Grecs appelaient le nectar et l'ambroisie et qui figure dans les contes de tous les pays sous le nom d'Eau de la Vie. Ils enlèvent [Ganymède, dont la mère s'appelle Callirrhoé, pour s'assurer contre ha mort ( $\left.{ }^{1}\right)$. Ganymède alterne dans cet office avec Hébé dont le nom est peut-être synonyme du sien (Arist., Nuées, 976) et qui, à l'époque de Pausanias (II, 13,3), était encore honorée à Phlious sous le nom de Ganyméda. Nous avons là, semble-t-il, un de ces couples dont la mythologie germanique offre un exemple et qui sont nombreux à Rome. Hébé a été attirée dans la légende d'Héraclès. ILes deux pouvoirs furent-ils parfois attribués à Ganymède? On ne peut dépasser l'hypothèse.

- Son rôle funéraire semble clair. Des tombeaux de Thespies sont sorties quantité de figurines le représentant, la chlamyde sur les épaules, sur sa tête frisée une couronne semblable à celle des Éros de Myrina, des adolescents du Cabireion tout proche. Elles sont trop grossières pour qu'on puisse rien conclure de leur anatomie $\left({ }^{2}\right)$.

Que signifie, dans la phrase de Tatien, le mot $\tau \varepsilon \tau \iota \mu \dot{\eta} r \alpha \tau \varepsilon$, qui marque sûrement plus qu'une simple admiration? Une réponse plausible est donnée par l'art romain, qui a conféré un sens eschatologique à l'échanson des dieux. Il apparaît sur des sarcophages et des peintures funéraires qui toutes parlent d'espérance, pour des raisons du reste différentes. Iphigénie a été sauvée de la mort, Alceste, Hippolyte, Dionysos Zagreus ont été ressuscités; Priape désigne l'annuelle floraison végétale, l'annuelle fécondité animale;

(1) Transporté dans le ciel, Ganymède y devient l'Aquarius. Roland Cruruy, L'ecu de la Vie, dans Mém. soc. se. du Hainaut, t. 77, 1963, p. 111-149, analyse sous cet aspect la légende des Argonautes. - J. Husaux et M. Leroy, La légende du Phénix, 1939, p. 128 sqq., 200,226 , ont bien montré l'équivalence de l'aigle et du phénix, mais on hésite à alléguer ici la symbolique de ce dernier, qui n'est bien connue que pour la fin de l'antiquité.

(2) Lenorarant, Gazette arch, t. 1, 1875, pl. XXIV, en publie une, qui passa ensuite dans la collection Oppermann. 
Hermaphrodite rassure l'homme sur sa pérennité par l'ostension de sa double nature; Ganymède fut enlevé au ciel.

Quelle que soit la secte qui fit construire la basilique de la Porte Majeure, celle-ci est pleine de symboles de régénération et d'espoir. Sapho dans l'abside demande une vie nouvelle au plongeon de Leucade; les stucages de l'atrium et des nefs portent des motifs dionysiaques, des bacchantes, un Priape ithyphallique. Au centre de la voûte, un triomphant Ganymède est enlevé, non point par un aigle, mais par un génie ailé, entouré de deux Éros, de quatre Attis, des Leucippides enlevées par les Dioscures. L'état des stucages ne permet de distinguer aucune indication de bisexualité $\left(^{1}\right)$. Là se trouvent réunis, au centre du monument, des figures auxquelles des traditions nombreuses attribuèrent les deux pouvoirs, autour d'un être qui, au moins à la fin de l'antiquité, fut considéré comme androgyne. Ce qui donne un intérêt particulier à la rencontre, c'est qu'elle a lieu dans un monument destiné à inspirer foi et confiance dans une prolongation heureuse de l'existence terrestre : la fonction de l'être double apparaît ici spiritualisée.

\section{LA DYADE DIVISÉE}

J'ai supposé ci-dessus que l'archétype du dieu double avait pu /aboutir sporadiquement à des représentations où la bisexualité, au lieu d'affecter un être unique, est supportée par deux êtres jumeaux létroitement unis. Des monuments dont Déonna a été le premier à voir l'intérêt, on pourrait rapprocher un curieux bronze de Berlin,

(1) Descriptions et photographies dans J. Carcoproo, La basilique pythagoriciome de la Porte Majaure, 1924, p. 49. L'ensemble de la décoration rend difficile l'interprétation proposée par P. Boyascé, Funus acerbum, dans R.E.A., t. 54,1952, p. 287, qui voit simplement dans Ganymède et Attis de jeunes morts appelés à pleurer un autre enfant disparu prématurément. Tout dans le monument parle d'espérance. Et pourquoi, si c'était une simple chapelle commémorative, serait-elle souterraine, ce qui implique certainement un symbole de renaissance dans une matrice tellurique? Sur Ganymède dans Tart funéraire, voir Espérandieu, V. 3699 et VII. 5632, 4965. On retrouve sur le monument funéraire d'Igel (rve s.) une symbolique presque semblable à celle de la basilique: $\mathrm{H}$. Dragendorfy et E. Krǘerr, Das Grabmal von Igel, 1924, p. 71, 81. - Sur Attis, voir P. Lumbrechr, Attis, van herdersknaop tot God, Bruxelles, 1962, ainsi que les judicieuses remarques de M. R. Cruhay, Ant. Class. t. 33, 1964, p. 257-9. 
trouvé en Épire et datant, semble-t-il, du début du $\mathrm{III}^{\mathrm{e}}$ siècle avant J.-C. Deux personnages ailés sont debout côte à côte. Leurs ailes, identiques, leur font une sorte d'auréole. L'homme, nu, porte la main au menton de la femme qui, sans le regarder, pose la sienne sur l'épaule de son compagnon. Elle est vêtue, mais le nombril est découvert $\left.{ }^{1}\right)$. Le personnage masculin est certainement un Éros, mais Psyché est rarement représentée ailée, sauf dans les peintures de Pompéi, et ses ailes sont alors celles du papillon, non de l'oiseau. Son histoire, qu'Ovide n'a pas racontée, n'est connue qu'à partir d'Apulée et sous une forme romancée. Aurions-nous ici une sorte de dédoublement de l'Éros bisexué, et ce dédoublement serait-il à l'origine du très énigmatique mythe de Psyché? On peut se faire la même question devant un charmant groupe en terre cuite de Boston (fig. $\mathrm{X}$ ) : à gauche une jeune femme vêtue, diadémée; à droite un jeune homme exactement de la même taille, couronné d'un bourrelet de feuillage; il est à demi-nu, le vêtement, artificiellement retenu entre les jambes au mépris de la pesanteur, dévoile le sexe. Une seule paire d'ailes, qui sont plutôt d'insecte que d'oiseau: l'une part de l'épaule droite du garçon, l'autre de l'épaule gauche de la fille.

Remarquons au surplus que faire Éros objet ou sujet d'amour est une erreur mythologique analogue à celle du sculpteur qui a figuré un Hermaphrodite tourné vers la terre sur laquelle il vient, semble-t-il, de laisser couler sa semence. C'est attribuer un état d'activité à des êtres destinés à rester de pures puissances. Ils donnent l'impulsion, sans plus.

Certains rites, parallèlement aux figurations, attestent la vertu de la superposition des deux pouvoirs.

Le flamine Dialis doit être marié ; il ne peut pas divorcer; il doit se démettre s'il devient veuf. Son mariage, comme celui des autres flamines majeurs et du rex sacrorum, doit avoir été célébré par confarreatio, c'est-à-dire avec les cérémonies qui donnaient à l'union le caractère le plus sacré. Tous devaient être issus d'une union analogue. L'importance de la flaminica est énigmatique. Bachofen y voyait une sublimation romaine d'un « het rischer Amazonentum» archaĩque ; Frazer et d'autres pensent que la prêtresse était plus ancienne que le prêtre.

(1) Publié par P. Woltzers, Arch. Zitung, t. 42, 1884, p. 1 = Rennıch, Stat., II, 460, 5. 
Si celui-ci doit être doublé d'un être féminin dont la présence, et même la seule existence, est nécessaire à son efficacité, serait-ce parce que leur jumelage avait une vertu analogue à celle d'un être unique revêtu des deux puissances? Hypothèse assez vraisemblable dans le milieu romain où apparaissent des dyades divines, simples divisions d'une figure unique, presque toutes considérées comme promotrices de la fertilité et de la fécondité. Nés de parents étroitement unis, ils sont assistés dans certaines cérémonies, si eux-mêmes n'ont pas d'enfants pour accomplir l'office, le flamine par un garçon, sa femme par une fille dont les parents étaient encore vivants, comme si chacun des enfants devait être porteur de la puissance des deux sexes, et l'actualiser en quelque sorte. Le prestige des patrimi matrimi existait en Grèce aussi bien qu'à Rome, attesté surtout dans des fêtes relatives à la fécondité de la terre, et dans des rites comportant une couronne, une guirlande, un feuillage sacré $\left(^{1}\right)$ : seuls des amphithaleis pouvaient prendre part aux courses des Scirophories, pouvaient porter l'eiresionê.

\section{PROLONGEMENTS}

Le syncrétisme de l'époque tardive ne pouvait qu'accuser la ressemblance entre l'être double et plus d'une figure primitivement masculine. Attis est souvent un Éros en vêtements asiatiques; il se confond ailleurs avec Ganymède. Un petit lécythe attique du ve siècle, du musée de Cassel, montre un personnage ailé qui fuit devant un sanglier: est-ce un Éros ou un Adonis? Sur une peinture de Pompéi, un petit Éros nu admire un Narcisse dont le vêtement tombant révèle la double nature, comme il arrive souvent dans les figurations d'Hermaphrodite $\left({ }^{2}\right)$. Cette œuvre médiocre est reproduite dans le répertoire de Reinach (p. 196, 3) ; tous les personnages

(1) Liste dans l'appendice II de l'Adonis de FrAzer, lequel a bien vu qu'il y a un lien entre le mariage du flamine, l'existence des couples divins à Rome et le privilège des patrimi-matrimi.

(2) J. Bozнunu, Ein neuer Erosmythos, Philol., t. 60 (1901) p. 321 . Etude récente de W. Atallah, Adonis dans la litt. et lart grees, 1966, p. 166. - Mau (Röm. Mitt., t. 5, 1890) avait publié ce Narcisse. - Pour la confusion des types, cf. P. Perdrizet, Voyage dans la Macidoine, B.C.H., t. 21, 1897, p. 514-528. 
de cette page et de la suivante sont androgynes, même s'ils ne sont pas désignés comme tels. On pourrait signaler plus d'un glissement analogue.

Il en est de plus intéressants, et qui donnent davantage à réfléchir. On connaît les interprétations grecques et romaines de Horus-Harpocrate et les méprises auxquelles le transfert donna lieu : le doigt posé sur la bouche transforma le dieu-enfant en un dieu du silence; la petite mitre fut prise pour une flamme. Harpocrate est généralement représenté nu. Sir Mortimer Wheeler (Roman art and archeology, 1964, p. 223) a publié un petit bronze trouvé à Taxila en Pakistan, ville rebâtie autour de l'ère chrétienne par des Parthes hellénisés ou romanisés. Cette statuette, qui doit venir d'Alexandrie, montre Harpocrate dans la longue robe des petites filles. Y eut-il dans le monde classique une variante féminine du petit dieu égyptien? Ou, plutôt, par ce vêtement ambigu, Harpocrate fut-il explicitement ramené à l'archétype de l'enfant, sexuellement indéterminé ?

Ici se pose une question difficile, celle des transferts. Les présentes recherches l'ont rencontrée plus d'une fois, à des niveaux différents. On recourt uniquement à la tradition grecque pour expliquer le symbolisme funćraire de l'antiquité: cette tradition, n'aurait-elle pas subi, dès ses origines, des influences orientales? La théorie qui, sommairement, fait d'Hermaphrodite un immigré d'Asie, n'est guère soutenable. Mais la figure n'a-t-elle pu être influencée par celle d'Isis, de Hapi? Des versions orientales de l'archétype ont pu revenir vers l'ouest et être soumises à l'esthétique classique. De curieux amalgames de techniques et de traditions hétérogènes, résultant de cheminements compliqués, requerraient des discriminations difficiles. On n'a pu ici qu'indiquer, au passage, quelques problèmes. 



\section{OUVRAGES CITÉS EN ABRÉGÉ}

L'article Eros dans Roscher est de A. Furtwangler (1890). Celui du P.-W. est de O. WASER (1909).

L'article Hermaphroditos dans Roscher est de P. Herrmann (1890). Celui du P.-W. est de J. Jessen (1912).

BABELON et BLANCHET.

H. Baumann.

M. Delcourt.

Ém. EsPÉrandieU.

Ed. Gerhard.

J. Grmas.

H. St. JoNEs.

M. P. Ninsson.

ID.

E. Pottier et S. ReINAch.

S. ReINACH,

ID.

ID.

ID.
- Catalogue des bronzes de la Bibliotheque Nationale, 1895.

- Das doppelte Geschlecht, ethnologische Studien zur Bisexualität in Ritus und Mythos, 1956.

- Hermaphrodite, mythes et rites de la bisexualite dans l'antiquité classique, 1958, cité Herm. L'édition anglaise (Londres, 1961) contient en appendice une étude sur les légendes des saintes déguisées en hommes, remaniement d'un article de la R.H. R., 1958, t. 153, Le complexe de Diane dans l'hagiographie chrétienne.

- Recueil des bas-reliefs de la Gaule romaine, 1907.

- Ueber den Gott Eros, Abh. d. Akad. Wiss. Berlin, 1848, repris dans Kleine Schriften, II, pp. 58-93. Excellent résumé, auquel on prêta trop peu d'attention, dans l'arrangement par J. D. Guignaut des Religions de l'antiquité(1851), traduction de la Symbolik und Mythologie der alten Völker de Creuzer (1810).

- Ueber den Liebesgott, Abh. d. Ak. Berlin, 1851, repris dans Kleine Schriflen, II.

- A catalogue of the ancient sculptures preserved in the municipal collections of Rome, Museo Capitolino, 1912, 2 e éd., 1926.

- Geschichte der griechischen Religion, 2e éd., 1951.

- Griechische Feste von religiöser Bedeutung, mit Ausschluss der attischen, 1906.

- La nécropole de Myrina, 2 vol., 1887.

- Cultes, mythies et religions, 5 vol., 1905-1923, cité C.M.R.

- Répertoire de la statuaire grecque et romaine, $3^{\text {e éd., }}$ 6 vol., 1913, 1930.

- Répertoire des reliefs grecs et romains, 3 vol., 1909.

- Répertoire des peinlures grecques el romaines, 1 vol., 1922 
L. S. A. M. von Römer. - Ueber die andrognnische Idee des Lebens, pp. 711941 du Jahrbuch für sexuelle Zwischenstufen, t. V, 2, 1903.

Fr. WINTER

- Die Typen der figürlichen Terrakotten, t. II et III des Antike Terrakotten de Reinhard Kekulé von Stradewitz. Les indications I et II renvoient à Iter et $2^{\text {er }}$ Teil. 


\section{TABLE DES ILLUSTRATIONS}

I. Hermaphrodite Chablais, Rome, Museo del Capitolino (p. 21).

II. Bronze, Rome, Museo dei Conservatori (p. 28).

III. Fontaine de fertilité, Rome, Museo delle Terme (p. 31).

IV. Vase Gnathia, Vienne, Kunsthistorisches Museum (p. 56).

V. Éros androgyne, Vienne, Kunsthistorisches Museum (p. 58).

VI. Éros androgyne, Boston, Museum of fine Arts (p. 59).

VII. Éros androgyne, Boston, Museum of fine Arts (p. 59).

VIII. Sarcophage, Rome, Museo delle Terme (p. 63).

IX. Pendants d'oreille, New-York, Museum of fine Arts (p. 65).

X. Dyade divisée, Boston, Museum of fine Arts (p. 69). 


\section{TABLE DES MATIÈRES}

Introduction $\quad . \quad . \quad . \quad . \quad+7$

Essai de typologie . . . . . . . . . 13

I. Monuments du culte . . . . . . . 15

II. Type démétrien . . . . . . . 18

L'Hermaphrodite Chablais . . . . . . 21

III. Type aphroditéen . . . . . . . 23

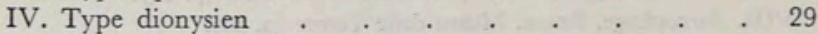

V. Type priapique . . . . . . . . . . 32

VI. L'Hermaphrodite couché . . . . . . 33 Attributs . . . . . . . 35

Le culte d'Hermaphrodite . . . . . . . 40

Son propre jumeau . . . . . . . . . 45

Éros et Hermaphrodite . . . . . . . 48

L'œuf primordial . . . . . . . . . 51

Éros androgyne . . . . . . . . . 54

L'archétype de l'enfant . . . . . . . . 59

Rôle funéraire . . . . . . . . . 62

D'Éros à Ganymède . . . . . . . . . . 64

La dyade divisée . . . . . . . . . . 68

Prolongements . . . . . . . . . 70

Ouvrages cités en abrégé . . . . . . . . . 73

Table des illustrations . . . . . . . . . . 76 
PLANCHE I

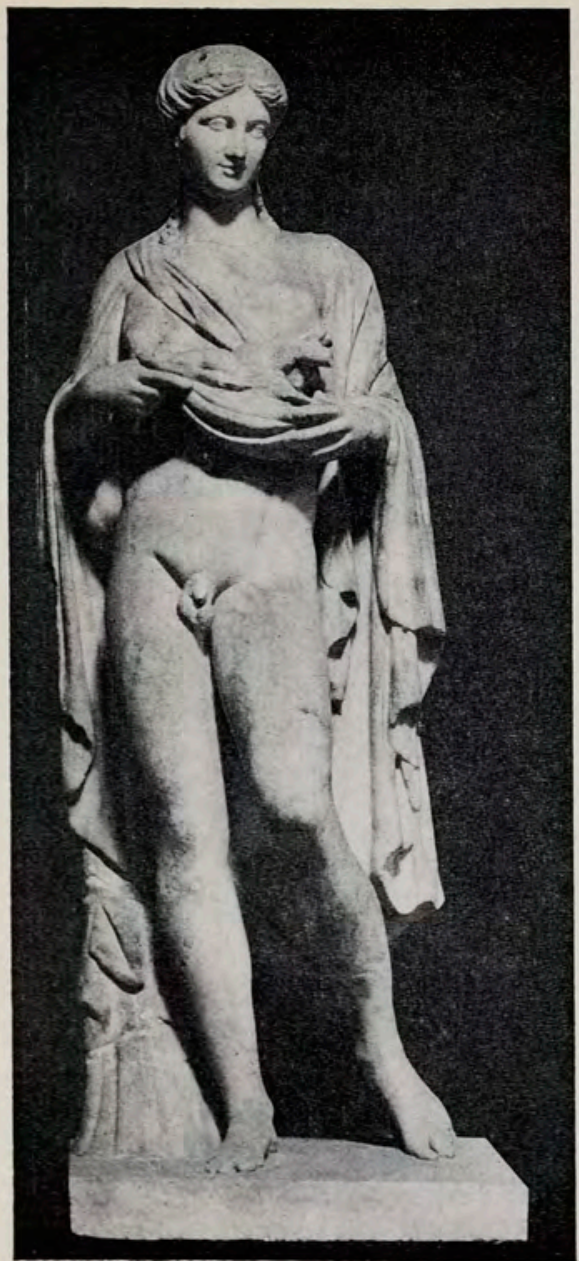

Hermaphrodite Chablais, Rome, Museo Capitolino (p. 21). 
PLANCHE II

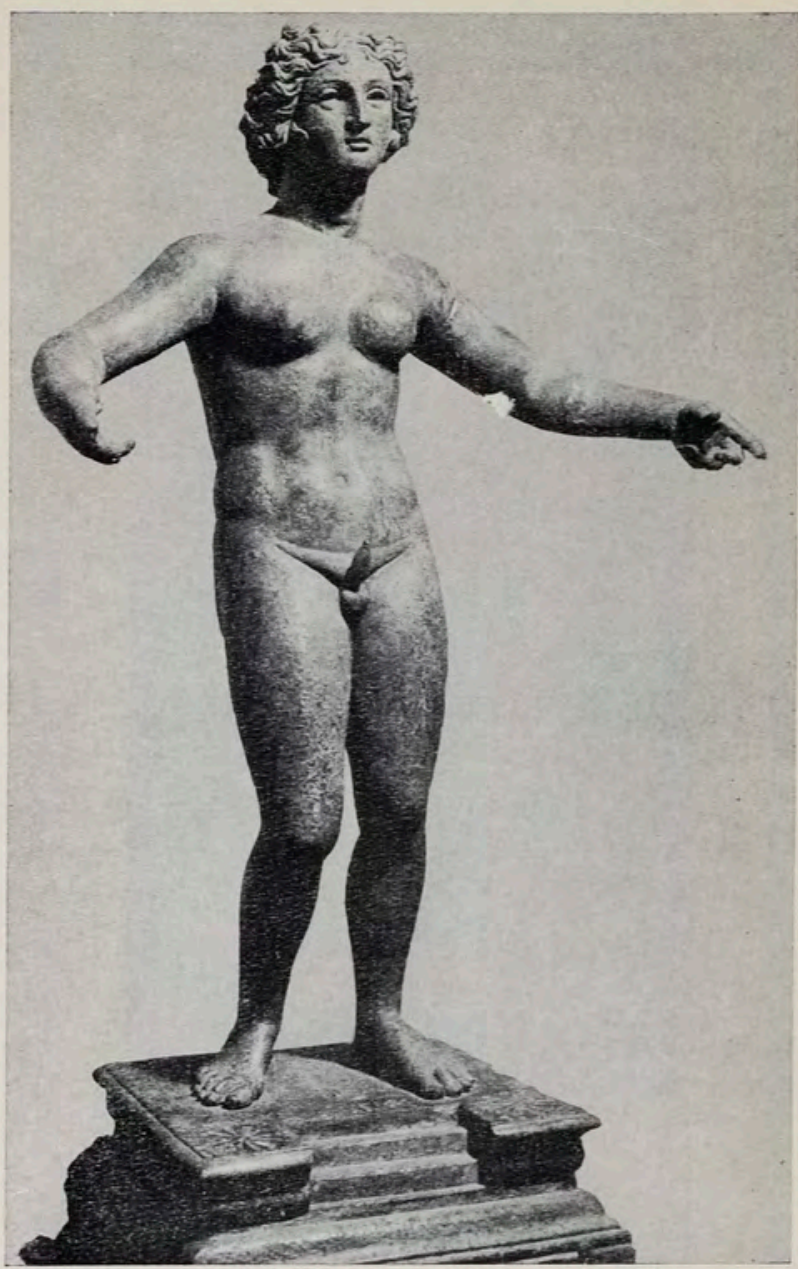

Bronze, Rome, Museo dei Conservatori (p. 28). 
PLANCHE III

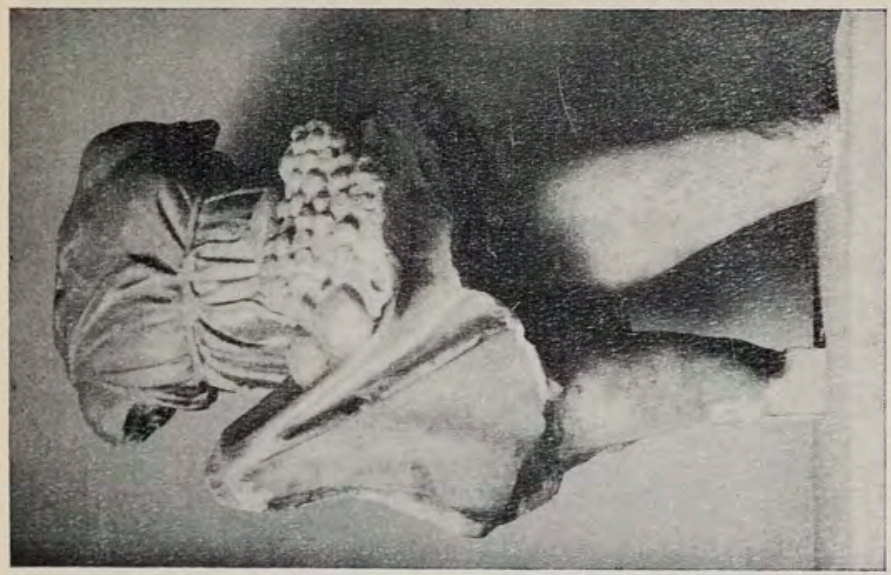

ले
डे
है
है

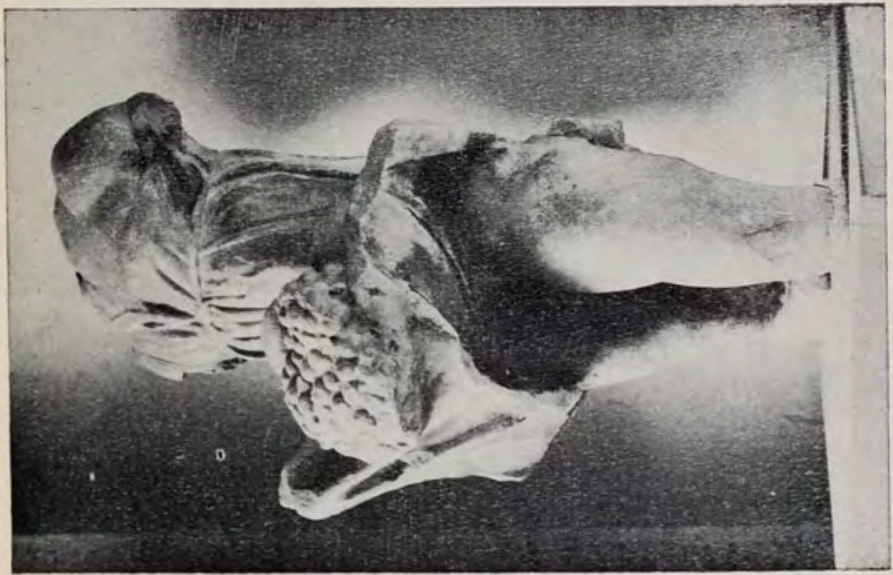

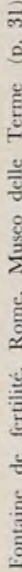

气ี

荁 
PLANCHE IV

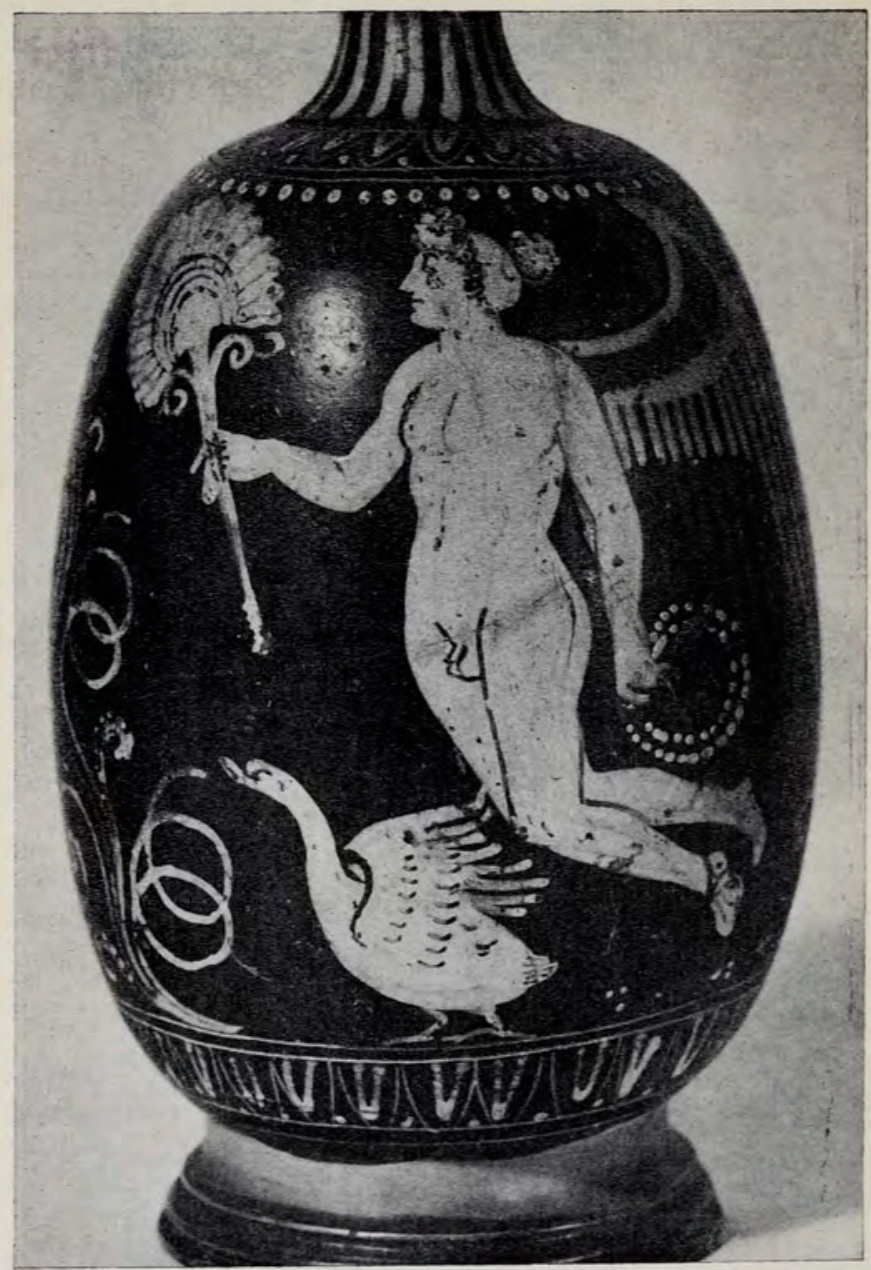

Vase Gnathia, Vienne, Kunsthistorisches Museum, Antikensammlung (p. 56). 
PLANCHE V

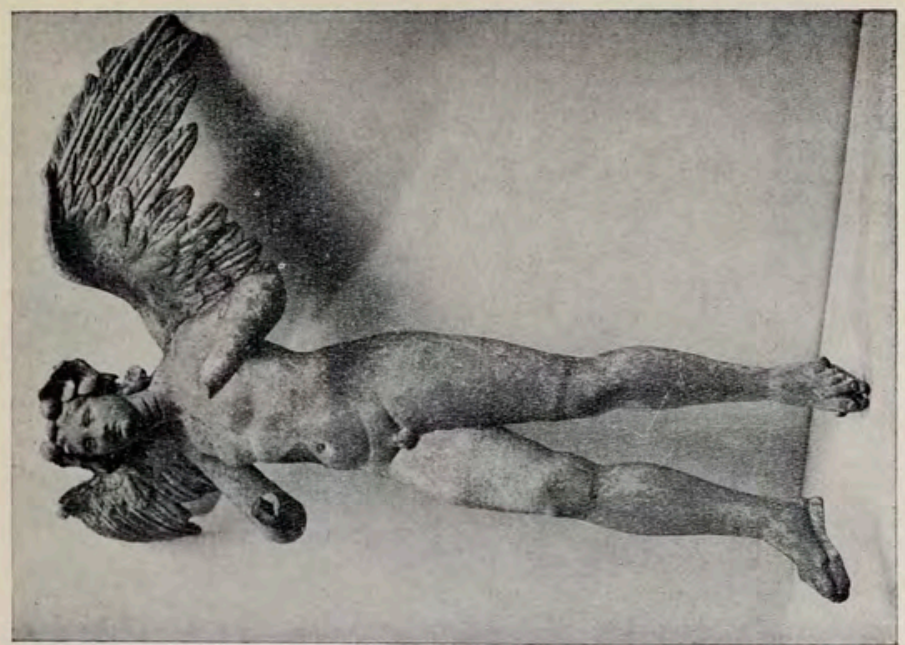

要

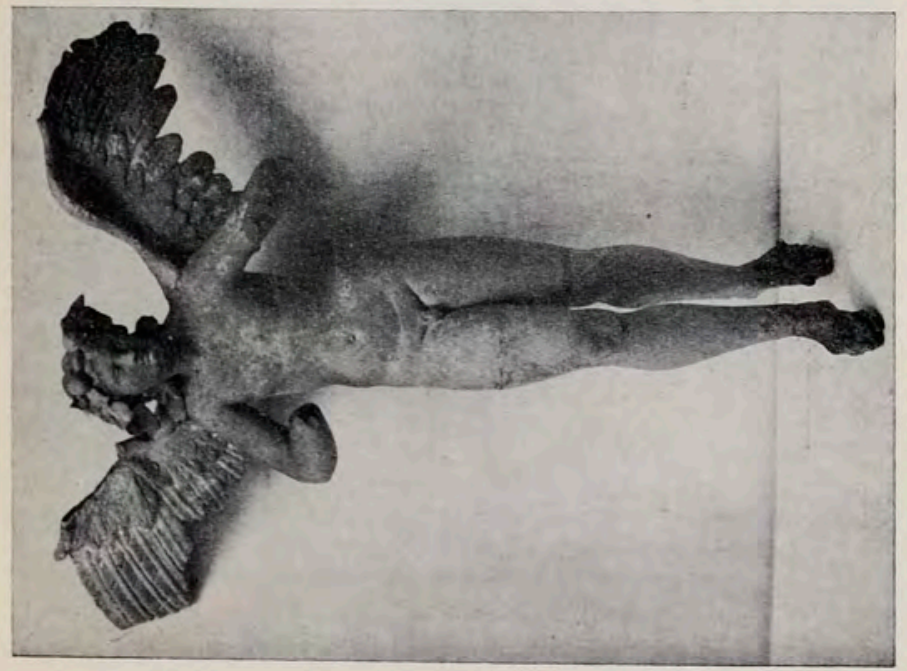

 
PLANCHE VI

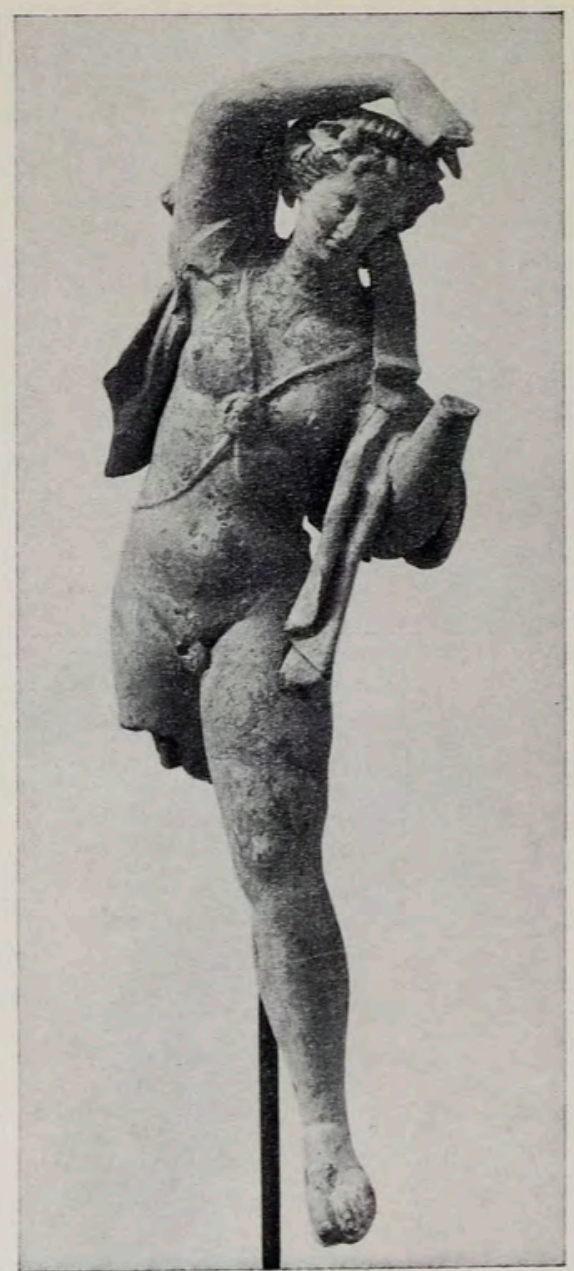

Eros androgyne, Boston, Museum of fine Arts (p. 59). 
PLANCHE VII

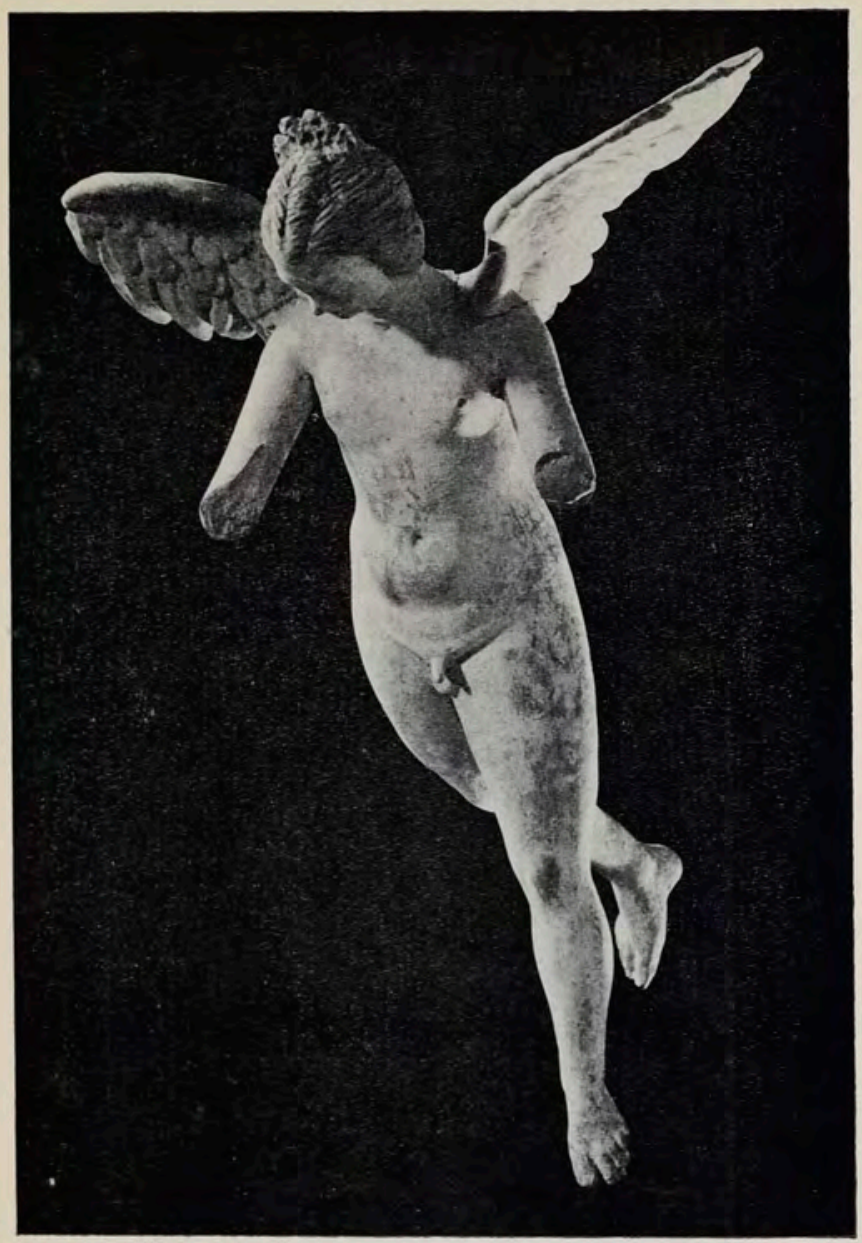

Éros androgyne, Boston, Museum of fine Arts (p. 59). 


\section{PLANCHE VIII}
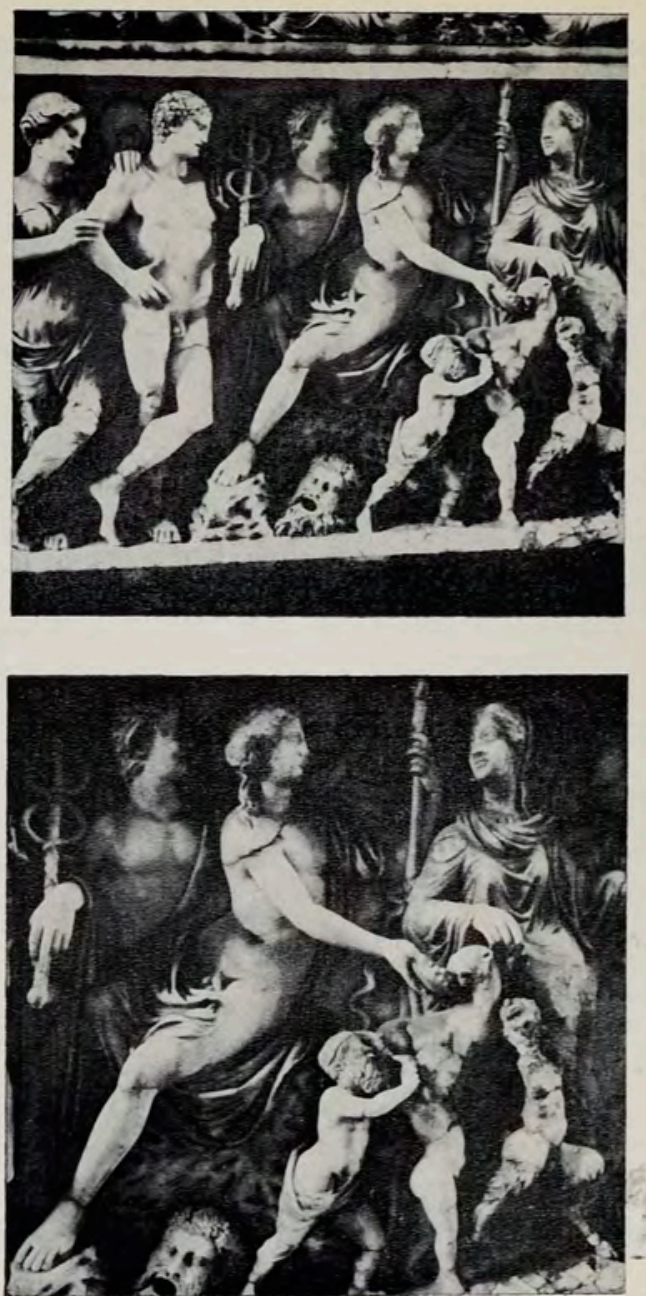

Sarcophage, Rome, Museo delle Terme (p. 63). 
PLANCHE IX

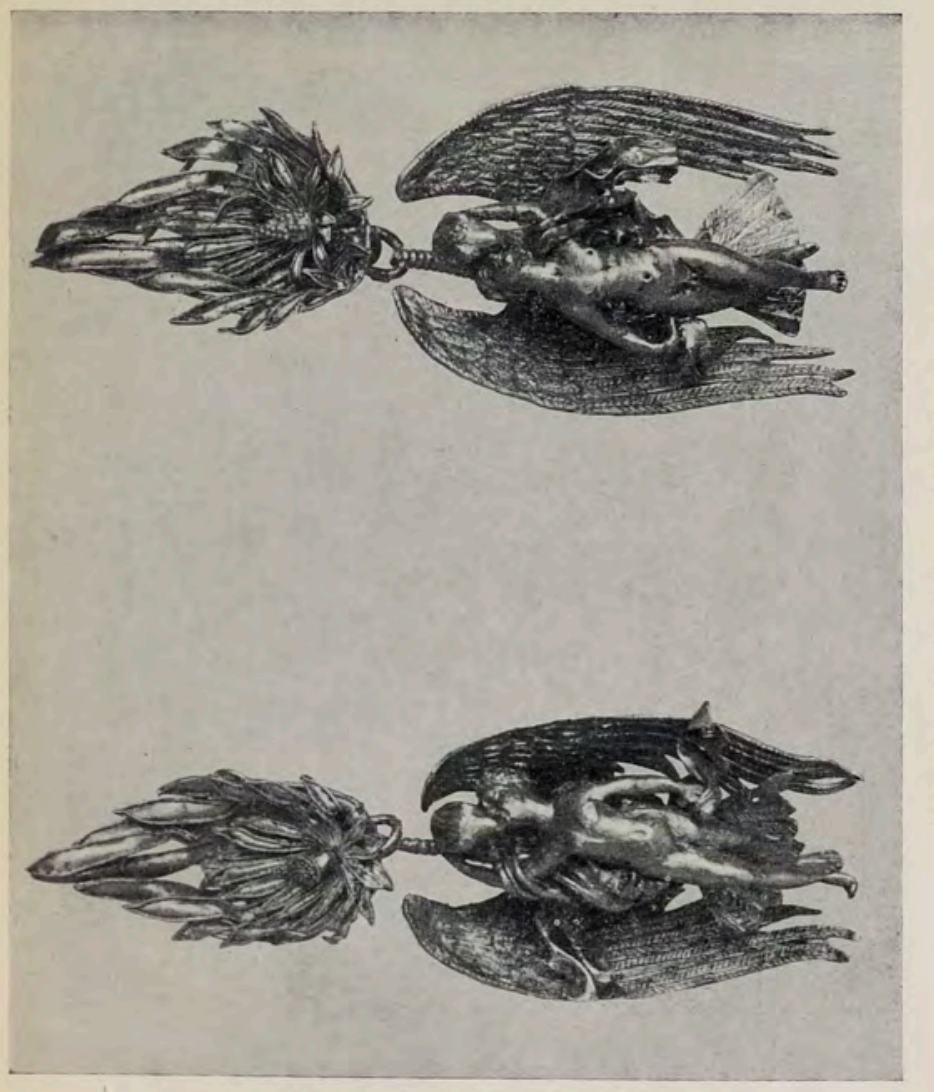


PLANCHE X

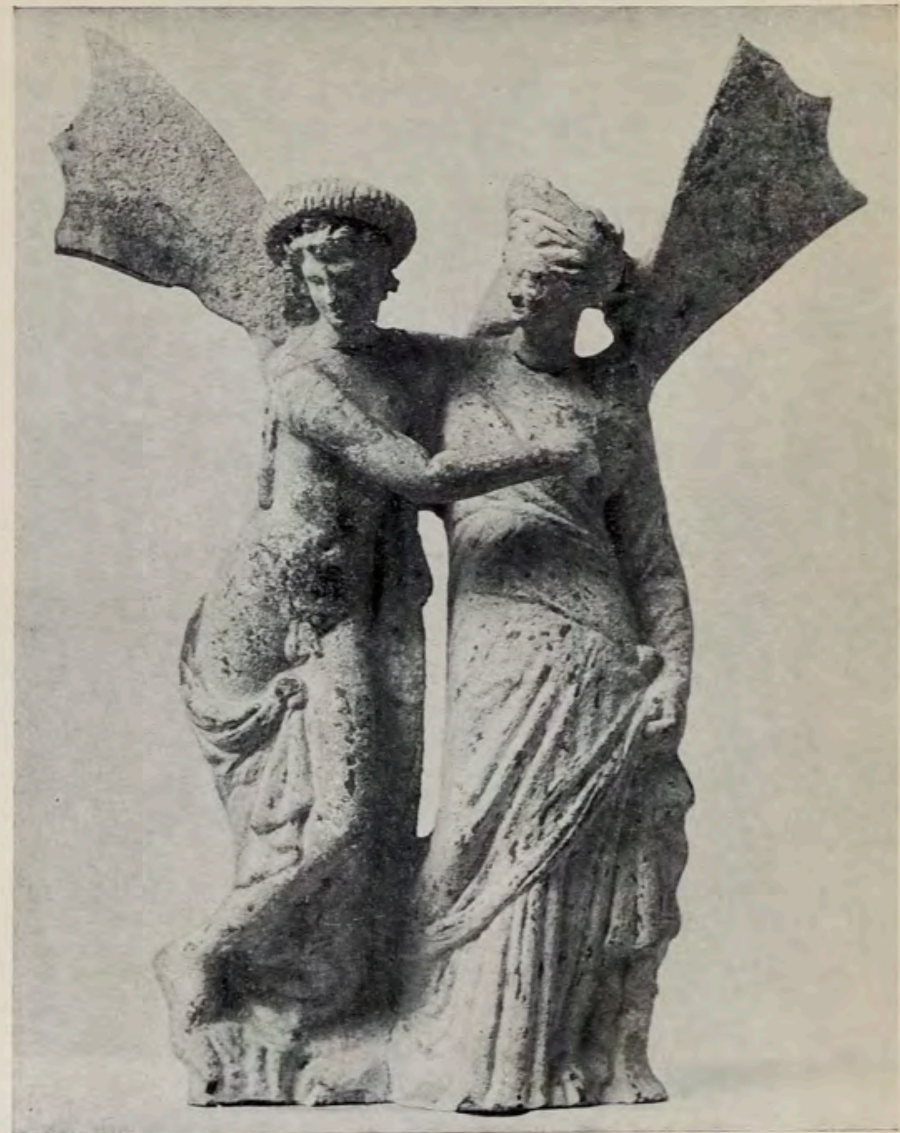

Dyade divisće, Boston, Museum of fine arts (p. 69).

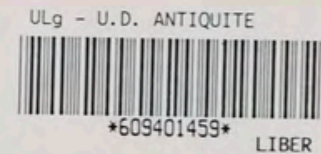




\section{COLLECTION LATOMUS}

\section{0, rue Colonel Chaltin, Bruxelles 18}

Compte de chèques postaux 7526.46 de la Société d'Études Latines de Bruxelles

II. - Hommage à Joseph Bidez et à Franz Cumont (1949), x-392 p. in- $8^{\circ}, 1$ frontispice et $26 \mathrm{pl}$

Exemplaire de luxe sur featherweight

III. - F. BENorr, Les mythes de l'outre-tombe. Le cavalier à l'anguipède et l'écuyère Epona (1950), $100 \mathrm{p}$. in $-8^{\circ}, 23$ fig. et $10 \mathrm{pl}$.

v. - Latomus, Deux discours inauguraux, avec intr., trad. et notes par L. BAkfLints (1951), $64 \mathrm{p}$. in $-8^{\circ}$.

IX. - W. Deonsu, Le symbolisme de l'acrobatie antique (1953), 148 p. in $-8^{\circ}, 127 \mathrm{fig}$.

XVIL. - Conrad de Hirsau, Dialogus super auctores, éd. orit. pan R. B. C. HuYGENs (1955), 72 p. in $-8^{\circ}$

XVIII. - W. Deonva, Deux études de symbolisme religieux. La légende de Pero et de Mimon et lallaitement symbolique. L'aigle et le: bijou, à propos du oollier d'Harmonie décrit par Nonnos (1955), $124 \mathrm{p}$. in $-8^{\circ}, 10 \mathrm{pl} ., 25 \mathrm{fig}$.

XX. - G. M. A. Richter. Greek Portraits. I. A Study of their Development (1955), 52 p. in $-8^{\circ}, 10$ pl., 36 fig.

XXI. - W. DEonsa, De Telesphore au " moine bourru ". Dieux, génies et démon encapuchonnes (1955), $168 \mathrm{p}$. in $-8^{\circ}, 50 \mathrm{fig}$.

XXIII. - Hommages à Max Niedermann (1956), 352 p. in $-8^{\circ}$ Exemplaire de luxe sur featherweight

XXIV. - Ph. DE SCHAETzEN, Index des terminaisons des marques de potiers galloromains sur terra sigillata (1956), $80 \mathrm{p}$. in $-8^{\circ}$.

XXV. - G. DumḱzI, Déesses latines et mythes védiques (1956), 124 p. in-8".

XXVI. - J. Heurcon, Trois études sur le a ver sacrum: (1957), 52 p. in- $8^{\circ}$.

XXVII, - Fauonii Eulogii Disputatio de Somnio Scipionis, éd. et trad. de R..A. VAN WEDDINGEN (1957), $72 \mathrm{p}$. in- $8^{\circ}$

XXVIII. - Hommages à Waldemar Deonna (1957), vmr540 p. in-8*, 69 pl. Exemplaire de luxe sur featherweight

XXIX. - Les deux livres de Catulle, regroupés et traduits par L. HerrannN (1957), xvur-142 p. in $-8^{\circ}$

XXX. - E. BoLAFF, La critica filosofica e letteraria in Quintiliano (1958), 64 p. in -8

XXXI. - G. DumḱzIL, L'idéologie tripartie des Indo-Européens (1958), 124 p in-8

XXXII. - A. E. Astis, The Lex Annalis before Sulla (1958), 48 p. in 8 p

XXXIII. - Ch. Favez, Saint Jérôme peint par lui-même (1958), 56 . p. in-8*

XXXIV, - L. Herranan, Le seoond Lucilius (1958), 248 p. in- $8^{\circ}$.

XXXV. - M. L. PALıdisi, A proposito della tradizione poetica sulla battaglia di Azio (1958), $48 \mathrm{p}$. in $-8^{\circ}$

XXXVL - G. M. A. Ricirer, Greek Portraits. H. To what Extente were they Faithful Likenesses? (1959), 48 p. in- $8^{\circ}, 16$ pl., 57 , fig. . . . $120 \mathrm{~F}$

XXXVII. - W. DeONsA, Mercure et le scorpion (1959), 52 p. in. $8^{\circ}$. 75 F.

XXXVHi. - M. Ranard, Technique et. agriculture en pays trévire et rémoisi (1959). 72 p. in $-8^{\circ}, 7$ pl., 9 fig.

XXXiX. - D. Tsontchev, Mtonuments de la sculpture romaine en Bulgarie méridionale (1959), 44 p. in $8^{\circ}, 24$ pl., 67 fig.

XL. - W. Deosisa, Un divertissement de table. A clochepied $(1959)$ i 40 p. in- $8^{\circ}$, 17 fig.

XL.L - J. StEngers, La formation de la frontière linguistique en Belgique ou de la legitimité de l'hypothèse historique (1959), $56 \mathrm{p}$. in- $8^{\circ}$.

XIII. - Ch. CL. vaN Essen,. Précis d'histoire de Part antique en thalie (1960), 152 p. in $-8^{\circ}, 71 \mathrm{pl}, 26$ fig.

XLIII. - E. W. Bodsar, Cyriaciss of Ancona and Achens (1960), $256 \mathrm{p}$. in $-8^{\circ}$

XLIV. - Hommages à Léon Herrmann (1960), xI-804 p. in -8\%, is fig., $52 \mathrm{pl}$.

XLV. - Hommages à Georges Dumézil $(1960)$, xxiv-240 p. in-8\%, 3 pl. Exemplaire de luxe sur featherweight

XLVI. - W. DEONSA et M. RENARD, Croyances et superstitions de table dans la Rome antique (1961), 154 ppi in-8\%, $26 \mathrm{pl}$.

XLVII. - J. BALTY, Etudes sur la Maison Carrée de Nimes (1960), 204 p. in- 8 : 5 fig., $27 \mathrm{pl}$.

XLVIII. - G. M. A. Richrier, Greek Portraits, III. How were Likenesses transmitted in Ancient Times : Small Portraits and Near-Portraits in Terracotta Greek and Roman (1960), 60 p. in $-8^{\circ}, 50$ pl., 230 fig.

XLIX. - J. Beaujeu, L'muendie de Rome en 64 et les Chrétiens (1960), 48 p. in- $8^{\circ}$.

L. - E. TheVenot, Les Eduens n'ont pas trahi. Essai sur les relations entre les Eduens et César (1960), 194 p. in-8\%, 6 pl.

LI. - J. HArsund, Les origines des recherches françaises sur Phabitat rural galloromain (1961), 52 p. in- $8^{\circ}, 6$ pl.

$600 \mathrm{~F}$. $750 \mathrm{~F}$

$150 \mathrm{~F}$

$90 \mathrm{~F}$.

$200 \mathrm{~F}$

$100 \mathrm{~F}$.

$250 \mathrm{~F}$

$525 \mathrm{~F}$.

$750 \mathrm{~F}$

$120 \mathrm{~F}$

$200 \mathrm{~F}$

$80 \mathrm{~F}$.

$120 \mathrm{~F}$.

LOG0) $\mathrm{F}$

$1.500 \mathrm{~F}$.

$250 \mathrm{~F}$

90: $\mathbf{F}$.

$200 \mathrm{~F}$

$80 \mathrm{~F}$.

$80 \mathrm{~F}$.

$375 \mathrm{~F}$

$70 \mathrm{~F}$

$100 \mathrm{~F}$

$100 \mathrm{~F}$.

60. F.

60 $\mathrm{F}$.

$300 \mathrm{~F}$.

$375 \mathrm{~F}$.

$1200 \mathrm{~F}$.

$450 \mathrm{~F}$.

$700 \mathrm{~F}$.

275: F.

$350 \mathrm{~F}$

$180 \mathrm{~F}$.

$75 \mathrm{~F}$.

$300 \mathrm{~F}$.

$85 \mathrm{~F}$. 


\title{
COLLECTION LATOMUS
}

\author{
60, rue Colonel Chaltin, Bruxelles 18 \\ (Voir la page prectente)
}

LII. - Embricon de Mavence, La vie de Mahomet, éd. G. Cambrer (1961), 94 p. in-8. LIII. - R. ChevaluifR, Rome et la Germanie au $1^{\text {et }}$ s. de notre ère (1961), $49 \mathrm{p}$. in-8 ${ }^{\circ}$.

LIV. - G. M. A. Richter. Greeks Portraits. IV. Iconographical Studies: A Few Suggestions (1962), 52 p. in $8^{\circ}, 26 \mathrm{pl} . .61$ fig.

LV. - Cl. VANDERSL.Even, Chronologie des préiets d'Égypte de 284 à 394 (1962), 202 p. in $-8^{\circ}$

LVI. - M. LeGLuY, Les Gaulois en Afrique (1962), 44 p. in $8^{\circ}, 1$ pl.

LVII. - M. Detifnese, Homère, Hésiode et Pythagore. Poésie et philosophie dañs le pythagorisme ancien (1962), $116 \mathrm{p}$. in $8^{\circ}$

LVIII. - Hommages à Albert Grenier (1962), xrv.-1665 p. in-80, 338 pl: Exemplaire de luxe sur featherweight

LIX. - Perse, Satires, ed et tr. de L. Herrmusx (1962), XIV-41 P. in-80

LX. - J. GaGÉ, = Matronalia s. Essai sur les dérotions et les organisations cultuelles des femmes dans lancienne Rome (1963), 290 p. in-80

LXI. - R. JoLY, Le Tableau de Cébès et la philosophie religieuse (1963), 92 p. in $8^{\circ}$

LXIII. - E. L. Brown, Numeri Vergiliani. Studies in = Eclogues = and = Georgics * (1963), 146 p. in $8^{\circ}$

LXIV. - A. P. Detsicas, The Anonymous Central Gaulish Potter known as X-3 and his Connections (1963), $73 \mathrm{p}$. in- $8^{\circ}, 9$ fig., $16 \mathrm{pl}$.

LXV. - H. BrrdoN, Le génie latin (1963), 264 p. in-8

LXVI. - D. C. EArL, Tiberius Gracchus. A Study in Politics (1963), 120 p. in-8*, 1 dépliant

LXVII. - Cl. Herrans, Le rôle judiciaire et politique des femmes sous la République romaine $(1964), 128 \mathrm{p}$. in $8^{\circ}$

LXVIII. - M. Detuenne, Crise agraire et attitude religieuse chez Hésiode (1964), 64 p. in $-8^{\circ}$,

LXIX. - L. Herrmans, Les fables antiques de la broderie de Bayeux (1964), 62 p. $21 \times 28$, in $-80,42 \mathrm{pl}$

LXX. - Hommages à Jean Bayet (1964), xv1-752 p. in $-8^{\circ}, 44$ pl. $1.000 \mathrm{~F}$. Exemplaire de luxe sur featherweight $.1500 \mathrm{~F}$.

LXXI. - G. B. FLetCHER, Annotations on Tacitus (1964), 108 p. in-8o . . 160 F.

LXXII. - P. Decourlé, La notion d'ex-voto anatomique chez les Etrusco-Romains (1964), 44 p. in $-8^{\circ}, 19 \mathrm{pl}$.

LXXIII. - B. FExIK, = Miad X, and the : Rhesus s. The Myth (1964), 64 p. in $8^{\circ}$

LXXIV. - M AMrr, Athens and the Sea. A Study in Athenian Sea-Power (1965),

- in B Puscal The Cults of Cisalpine Gaul (1964)

L. - J.M. CrolsiL. Les Latures mortes campaniennes. Répertoire descriprif r es peintures de nature morte du Musée National de Naples, de Pompéi, Hercuanuni ct Stabies (1965) 134 p. $21 \times 28$, in $-8^{\circ}, 127$ pl. .

LXXVII. - H. ZEHXACKER, Les statues du sanctuaire de Kamart (Tunisie) (1965), $86 \mathrm{p}$, in $-8^{\circ}, 17 \mathrm{pl}$.

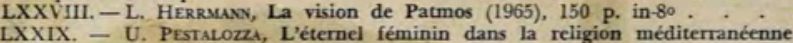

LXXIX, - U. PestaLozza, L'éternel féminin dans la religion méditerranéenne

LXXX. - D. TUdor, Sucidava, une cité daco-romaine en Dacie (1965), 140 p. in-8, 35 fig., $30 \mathrm{pl}$.

LXXXI. - J. Frrz, Ingenuus et Régalien (1966), 72 p. in $-8^{\circ}$

LXXXII. - J. Cotrs, Les villes libres de rOrient gréco-romain et Penvoi au supplice par acclamations populaires (1965), $176 \mathrm{p}$, in-8\%, $5 \mathrm{pl}$. . . . . .

LXXXIII. - J. SCHWArTZ, Biographie de Lucien de Samosate (1965), 168 p. in-80

LXXXIV. - VIRGIE, Les Bucoliques. Traductiog en yers de H. DEs ABBAYES. Avant-propos de E. DE SANT-DENIS (1966), 92 p. in $8^{\circ}$.

LXXXV. - J. BALTY, Essai d'iconographie de Pempereur Clodius Albinus (1966), 70 p. in $-80,10 \mathrm{pl}$.

LXXXVI - M. DELCoUrT, Hermaphroditea (1966), 76 p. in $-80,10 \mathrm{pl}$.

$80 \mathrm{~F}$.

$100 \mathrm{~F}$.

$225 \mathrm{~F}$.

$350 \mathrm{~F}$.

$600 \mathrm{~F}$.

$150 \mathrm{~F}$. $300 \mathrm{~F}$.

$125 \mathrm{~F}$.

$280 \mathrm{~F}$. $150 \mathrm{~F}$.

$280 \mathrm{~F}$.

$250 \mathrm{~F}$.

$180 \mathrm{~F}$.

$150 \mathrm{~F}$.

\section{LATOMUS}

Tables générales des tomes $\mathrm{I}$ (1937) à XX (1 761$)$

Frais de port et d'expédition en plus. 